\title{
REVIEW
}

\section{Global report on preterm birth and stillbirth (3 of 7): evidence for effectiveness of interventions}

\author{
Fernando C Barros ${ }^{\dagger 1}$, Zulfiqar Ahmed Bhutta ${ }^{\dagger * 2}$, Maneesh Batra ${ }^{\dagger 3}$, Thomas N Hansen ${ }^{4}$, Cesar G Victora ${ }^{5}$, Craig E Rubens ${ }^{6,7}$ \\ and the GAPPS Review Group
}

\begin{abstract}
Introduction: Interventions directed toward mothers before and during pregnancy and childbirth may help reduce preterm births and stillbirths. Survival of preterm newborns may also be improved with interventions given during these times or soon after birth. This comprehensive review assesses existing interventions for low- and middleincome countries (LMICS).

Methods: Approximately 2,000 intervention studies were systematically evaluated through December 31, 2008. They addressed preterm birth or low birth weight; stillbirth or perinatal mortality; and management of preterm newborns. Out of 82 identified interventions, 49 were relevant to LMICs and had reasonable amounts of evidence, and therefore selected for in-depth reviews. Each was classified and assessed by the quality of available evidence and its potential to treat or prevent preterm birth and stillbirth. Impacts on other maternal, fetal, newborn or child health outcomes were also considered. Assessments were based on an adaptation of the Grades of Recommendation Assessment, Development and Evaluation criteria.
\end{abstract}

Results: Most interventions require additional research to improve the quality of evidence. Others had little evidence of benefit and should be discontinued. The following are supported by moderate- to high-quality evidence and strongly recommended for LMICs:

- Two interventions prevent preterm births_-smoking cessation and progesterone

- Eight interventions prevent stillbirths - balanced protein energy supplementation, screening and treatment of syphilis, intermittant presumptive treatment for malaria during pregnancy, insecticide-treated mosquito nets, birth preparedness, emergency obstetric care, cesarean section for breech presentation, and elective induction for postterm delivery

- Eleven interventions improve survival of preterm newborns - prophylactic steroids in preterm labor, antibiotics for PROM, vitamin K supplementation at delivery, case management of neonatal sepsis and pneumonia, delayed cord clamping, room air (vs. 100\% oxygen) for resuscitation, hospital-based kangaroo mother care, early breastfeeding, thermal care, and surfactant therapy and application of continued distending pressure to the lungs for respiratory distress syndrome

Conclusion: The research paradigm for discovery science and intervention development must be balanced to address prevention as well as improve morbidity and mortality in all settings. This review also reveals significant gaps in current knowledge of interventions spanning the continuum of maternal and fetal outcomes, and the critical need to generate further high-quality evidence for promising interventions.

\section{Introduction}

Global preterm birth and stillbirth rates may be improved with interventions directed toward women before and

\section{${ }^{+}$Co-first authors}

*Correspondence: zulfiqar.bhutta@aku.edu

2Division of Women \& Child Health, Aga Khan University, Karachi 74800, Pakistan Full list of author information is available at the end of the article during pregnancy, labor and birth. Such interventions, along with those given to preterm newborns, may also improve preterm survival and other maternal, newborn and child health $(\mathrm{MNCH})$ outcomes. Nearly 50 existing interventions are discussed in this article, and were selected on the basis of available evidence of impact, ability to be used in low- and middle-income countries (LMICs), and other factors discussed below. They are organized by stage and recipient: 
Interventions directed toward the mother to prevent preterm birth or stillbirth

- Before pregnancy

- During pregnancy

- Pregnancy infections

- High-risk pregnancies

- Intrapartum interventions to prevent stillbirth

Interventions to improve preterm survival

- Intrapartum interventions given to the mother

- Postpartum interventions directed toward the preterm newborn

This article discusses the evidence base for these interventions, and gives special reference to LMICs. A recommendation is provided for each intervention. When available, the evidence is assessed for preterm birth, stillbirth, preterm survival and other $\mathrm{MNCH}$ outcomes.

This is the third article in a global report on preterm birth and stillbirth. The first two articles describe the definitions, data and known causes $[1,2]$. The next few articles discuss scaling up proven interventions, advocacy barriers and opportunities, and ethical considerations relating to these issues [3-5]. The concluding article presents recommendations for a Global Action Agenda [6].

\section{Methods}

This review systematically evaluates interventions to prevent preterm birth and stillbirth, and to improve survival among preterm newborns. More than 80 biologically plausible interventions were initially selected (Table 1). Figure 1 illustrates the final selection process for the 49 interventions included in this review.

Approximately 2,000 studies were reviewed on interventions addressing preterm birth (or low birth weight), stillbirth (or perinatal mortality), and preterm survival. This number includes systematic reviews and metaanalyses, along with stand-alone papers from observational or experimental studies. Interventions with a beneficial impact on other maternal, newborn and child health outcomes, but that did not influence preterm birth or stillbirth outcomes, were not considered.

The search engines used were PubMed and The Cochrane Library. Search terms included "stillbirth"," "perinatal mortality," "fetal death"," "preterm"," "low birth weight"and "low birthweight." Targeted search terms were also used for each intervention (e.g., "iron" AND "supplementation" AND "pregnancy"; and "cervical cerclage" AND "pregnancy"), with humans as limits. These terms are defined in article 1 of this global report [1].

The last search date was December 31, 2008. (Note that papers published after this date may influence key findings in this article.) The emphasis was to identify randomized and quasi-randomized study designs. Where such trials were not available, observational studies were included. When a high-quality meta-analysis was available, it served as the basis for the review, and was updated with results of more recent studies when available.

Perinatal mortality studies are also considered, as some did not separate stillbirths from overall perinatal mortality. Few studies distinguished between antepartum and intrapartum stillbirths. Studies reporting on overall low birth weight rates, or mean birth weights, are also included when preterm birth was not reported as a separate outcome.

For each intervention, an adaptation of the Grades of Recommendation Assessment, Development and Evaluation (GRADE) criteria $[7,8]$ was used to rate the level of available evidence into either high, moderate, low or very low (see Table 2).

The GRADE system starts from a pre-established quality of evidence rating for each type of study design, but allows flexibility for lowering or increasing this rating. For example, results from randomized controlled trials (RCTs) may be downgraded from "high" to "moderate" quality if there are methodological shortcomings such as lack of precision, the possibility of reporting bias or other limitations to study quality. On the other hand, results from observational studies may be upgraded from "low" to "moderate" if the studies are particularly strong (e.g., when confounding variables are unlikely or when there is a dose-response gradient).

The original GRADE system requires individual ratings for each study included in the review. The overall rating provided in this review is based on the collective appraisal of all publications on each intervention, since it was largely based on existing meta-analyses or on fresh pooled analyses carried out for stillbirth interventions and some preterm postnatal interventions.

A major advantage of the GRADE system, compared to other classifications, is it provides a practical recommendation regarding each intervention, assessing the extent to which one can be confident adherence to a recommendation will do more good than harm. The recommendation is based on the quality of evidence, how the evidence may be translated to practice in a specific setting such as LMICs, the level of baseline risk, and on potential tradeoffs between expected benefits, harms and costs.

The recommendation for each intervention was then placed in one of the following categories:

- Strong in favor

- Weak in favor

- Weak against

- Strong against

Recommendations against the intervention does not necessarily indicate there is evidence the intervention does harm; such recommendations most often reflect no evidence of benefit, and due to the costs incurred there are no reasons for further implementation. 
Table 1. List of interventions

\begin{tabular}{|c|c|c|c|}
\hline Selected & Interventions & Selected & Interventions \\
\hline \multicolumn{2}{|c|}{ Group 1: Interventions given before pregnancy } & \multicolumn{2}{|c|}{ Group 5: Intrapartum interventions to prevent stillbirth } \\
\hline$x$ & Birth spacing & $x$ & Birth preparedness \\
\hline \multirow[t]{3}{*}{$x$} & Indoor air pollution control & $x$ & Fetal movement monitoring \\
\hline & Prevention of female genital mutilation & $x$ & Emergency obstetric care \\
\hline & & $x$ & Cesarean section for breech presentation \\
\hline \multicolumn{2}{|c|}{ Group 2: Interventions given during pregnancy } & $x$ & Elective induction of labor for post-term delivery \\
\hline$X$ & Smoking cessation programs & $x$ & Elective induction of term PROM \\
\hline$x$ & Balanced protein energy supplementation & $x$ & Home delivery vs. facility delivery \\
\hline$x$ & Multiple micronutrient supplementation & & Instrumental deliveries (forceps versus vacuum) \\
\hline$x$ & Iron and folate supplementation & & Amnioinfusion \\
\hline$x$ & Zinc supplementation & & Cervical ripening and induction of labor with different \\
\hline$x$ & Magnesium sulfate supplementation & & prostaglandins \\
\hline$x$ & Supplementation with long-chain polyunsaturated fatty acids & & Magnesium sulphate for treatment of preeclampsia/eclampsia or \\
\hline$x$ & Cardiotocographic monitoring & & preterm labor \\
\hline$x$ & Doppler and late ultrasound monitoring & & Maternal hyperoxygenation \\
\hline
\end{tabular}

Anti-platelet agents in pregnancy, including aspirin

Anti-malarials

Anti-oxidants

Vitamin A/Beta-Carotene supplementation

Group 3: Interventions for pregnancy infections

$X \quad$ Screening and treatment of syphilis

X Intermittent presumptive treatment during pregnancy (IPTp) for malaria

X Insecticide-treated mosquito nets (ITNs)

$X \quad$ Screening and treatment of asymptomatic bacteriuria

$X \quad$ Screening and treatment of bacterial vaginosis

$X \quad$ Prevention of mother-to-child transmission of HIV

$X \quad$ Anti-helminthic treatment

$X \quad$ Screening and treatment of periodontal disease

\section{Group 4: Interventions for pregnancies with high-risks of PTB or SB}

$X \quad$ Progesterone

$X \quad$ Cervical cerclage

X Multivitamins for HIV+ women

Amniotic fluid volume assessment

Antepartum fetal heart rate monitoring with cardiotocography

Cervical pessaries to prevent preterm birth

Fetal biophysical test scoring

Home versus hospital monitoring for high-risk pregnancies

In-hospital fetal surveillance unit

Intrapartum cardiotocography and pulse oximetry

Management of gestational diabetes mellitus

Non stress testing or vibroacoustic stimulation

Use of the partograph

Fetal movement monitoring

Heparin in pregnancy

Management of intrahepatic cholestasis

Pelvimetry

Plasma exchange

Pregnancy risk screening

Ultrasound scanning
Group 6: Antepartum and intrapartum interventions to improve preterm survival

X Prophylactic corticosteroid therapy in preterm labor

$X \quad$ Antibiotics for PROM/PPROM

$X \quad$ Antibiotics for preterm labor with intact membranes

$X \quad$ Delayed cord clamping

Vitamin A to the mother

Group 7: Postnatal interventions to improve preterm survival

$X \quad$ Neonatal resuscitation

$X \quad$ Vitamin A supplementation

$X \quad$ Vitamin K supplementation

$X \quad$ Zinc supplementation

$X \quad$ Selenium supplementation

$X \quad$ Chlorhexidine treatment on the cord

$X \quad$ Case management of neonatal sepsis and pneumonia

X Early breastfeeding

$X \quad$ Thermal care

$X \quad$ Application of continued distending pressure or CPAP to the lungs for RDS

X Intravenous immune globulin (IVIG)

X Surfactant therapy for RDS

Emollient therapy

Hand washing

Prophylaxis of eye infection

Use of Appropriate Low-cost Technology (incubators, techniques for minimally invasive intravenous access, protection against the excessive use of oxygen)
X Kangaroo mother care (KMC)

$\mathrm{X}$ indicates interventions described in the text. Interventions without the $\mathrm{X}$ were reviewed but not included due to one or more of the following reasons: (a) the available evidence was very limited; (b) there was no evidence of an impact; (c) the intervention requires high technology; (d) the intervention is seldom used; (e) the intervention was applicable to a small subgroup of pregnant women. 


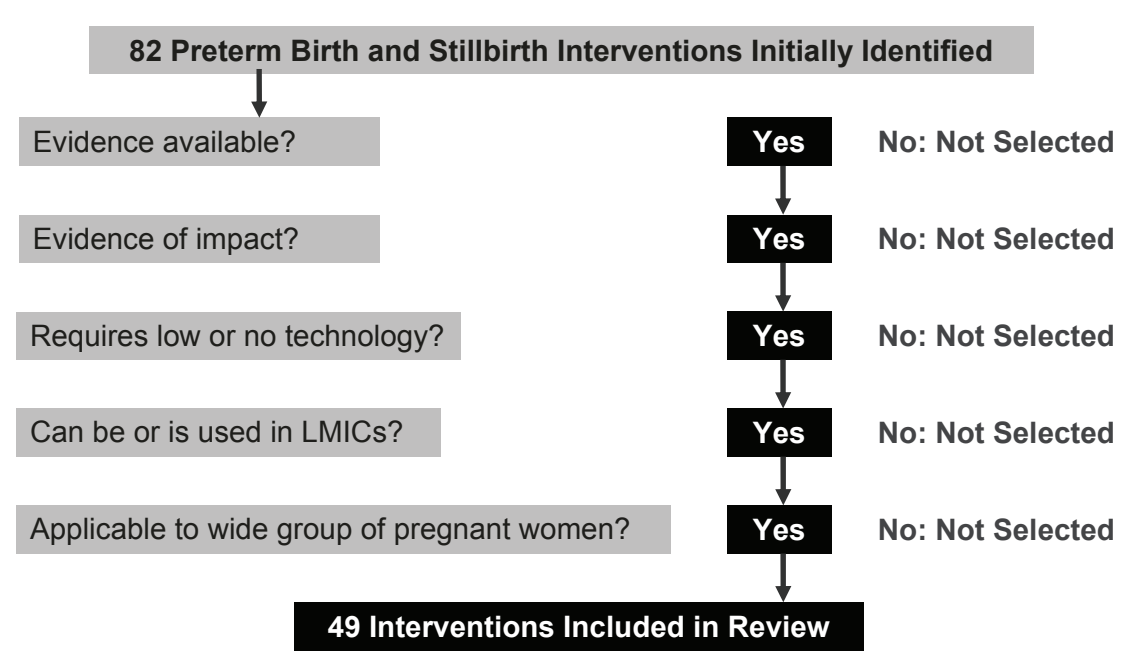

Figure 1. Intervention selection process.

Table 2. GRADE Criteria for Quality of Evidence

\begin{tabular}{|c|c|c|}
\hline Quality of Evidence & Study Design & Interpretation \\
\hline High & Randomized Controlled Trials (RCTs) & Further research is very unlikely to change our confidence in the estimate of effect. \\
\hline Moderate & $\begin{array}{l}\text { Low-Quality Randomized Trials or } \\
\text { High-Quality Observational Studies }\end{array}$ & $\begin{array}{l}\text { Further research is likely to have an important impact on our confidence in the } \\
\text { estimate of effect and may change the estimate. }\end{array}$ \\
\hline Low & Observational Studies & $\begin{array}{l}\text { Further research is very likely to have an important impact on our confidence in the } \\
\text { estimate of effect and is likely to change the estimate. }\end{array}$ \\
\hline Very Low & Any Other Evidence & Any estimate of effect is very uncertain. \\
\hline
\end{tabular}

In these assessments, recommendations are provided not only for the main outcomes in this review, but also for the intervention's impact on other $\mathrm{MNCH}$ outcomes when relevant. For many interventions, the recommendations for preventing stillbirth or preterm birth conflict with the recommendation for overall $\mathrm{MNCH}$ outcomes. This will be further discussed in the next article on the delivery of interventions.

\section{Results}

The 49 interventions reviewed below are classified according to service delivery strategies across the continuum of care. Table 1 shows all interventions considered in this review. The narrative below is restricted to interventions for which a reasonable amount of evidence is present, and, or, those relevant to low- and middle-income countries. This review of the evidence indicates a remarkable paucity of data on preterm birth and stillbirth for many potentially relevant interventions.

Table 3 summarizes the assessment of the quality of evidence and level of recommendation for each intervention using the GRADE system. These recommendations consider the preterm birth and stillbirth outcomes, as well as other important maternal and neonatal outcomes. It is important to note that most studies reviewed lacked statistical power to pick up as statistically significant an effect on stillbirth, as their main outcomes were more frequently pregnancy and childbirth-related conditions. In addition, many studies-particularly from LMICs-did not report on preterm birth as an outcome.

\section{Interventions given before pregnancy Birth spacing}

A number of hypotheses explain why short or long birth intervals could affect perinatal health. For short intervals, maternal nutrition depletion is the most often proposed; women do not have time to recover from the expenses related to pregnancy and lactation before getting pregnant again. For long intervals, the reasons are less clear, but it appears reproductive capacity declines after delivery, and that diseases affecting the mother could have an effect on both fertility and the health of the baby [9]. Optimally-spaced births can potentially reduce fetal and maternal morbidity and mortality.

Access to modern family planning methods is still problematic in many low-income countries [10]. It is 
Table 3. Summary of assessments for preterm birth and stillbirth interventions (based on GRADE system)

\begin{tabular}{|c|c|c|c|c|c|c|c|c|c|}
\hline \multirow[b]{2}{*}{$\begin{array}{l}\text { Intervention } \\
\text { (by stage or recipient) }\end{array}$} & \multicolumn{5}{|c|}{ Quality of evidence } & \multicolumn{4}{|c|}{ Recommendation for implementation } \\
\hline & SB & PMR & PTB & LBW & $\begin{array}{l}\text { Other MNCH } \\
\text { Outcomes }\end{array}$ & SB/PMR & PTB & LBW & $\begin{array}{l}\text { Other MNCH } \\
\text { Outcomes }\end{array}$ \\
\hline \multicolumn{10}{|c|}{ Interventions given before pregnancy } \\
\hline Birth Spacing & Low & Mod & Mod* & Mod* & Mod* & Weak & Weak & Weak & $\begin{array}{l}\text { Strong: } \\
\text { Maternal and } \\
\text { Child Mortality }\end{array}$ \\
\hline Periconceptional Folate & Mod & Mod & Low & Low & High & $\begin{array}{c}\text { Weak } \\
\text { Against }\end{array}$ & Weak & Weak & $\begin{array}{l}\text { Strong: Neural } \\
\text { Tube Defects }\end{array}$ \\
\hline Indoor Air Pollution Control & Low & - & $\begin{array}{l}\text { Very } \\
\text { Low }^{* *}\end{array}$ & Low & High & Weak & $\begin{array}{l}\text { Weak } \\
\text { Against }\end{array}$ & Weak & $\begin{array}{l}\text { Strong: } \\
\text { Respiratory } \\
\text { Infections }\end{array}$ \\
\hline \multicolumn{10}{|c|}{ Interventions given during pregnancy } \\
\hline Smoking Cessation Programs & s Low & Low & High & High & High & Weak & Strong & Strong & $\begin{array}{l}\text { Strong: } \\
\text { Smoking-Related } \\
\text { Diseases }\end{array}$ \\
\hline $\begin{array}{l}\text { Balanced Protein Energy } \\
\text { Supplementation }\end{array}$ & High & - & $\begin{array}{l}\text { High } \\
\text { No Effect }\end{array}$ & High & - & Strong & $\begin{array}{l}\text { Strong } \\
\text { Against }\end{array}$ & Strong & $\begin{array}{l}\text { Strong: Infant } \\
\text { Mortality }\end{array}$ \\
\hline $\begin{array}{l}\text { Multiple Micronutrient } \\
\text { Supplementation }\end{array}$ & $\begin{array}{l}\text { High } \\
\text { No Effect }\end{array}$ & Mod & $\begin{array}{l}\text { High } \\
\text { No Effect }\end{array}$ & High & $\begin{array}{c}\text { High } \\
\text { (Maternal } \\
\text { Anemia, IMR) }\end{array}$ & $\begin{array}{l}\text { Weak } \\
\text { Against }\end{array}$ & $\begin{array}{l}\text { Strong } \\
\text { Against }\end{array}$ & Strong & $\begin{array}{c}\text { Weak Against: } \\
\text { Neonatal } \\
\text { Mortality }\end{array}$ \\
\hline $\begin{array}{l}\text { Iron and Folate } \\
\text { Supplementation }\end{array}$ & $\begin{array}{c}\text { Mod } \\
\text { No Effect** }\end{array}$ & $\begin{array}{l}\text { Mod } \\
\text { No Effect** }\end{array}$ & $\begin{array}{l}\text { Mod } \\
\text { No Effect** }\end{array}$ & $\begin{array}{l}\text { Mod } \\
\text { No Effect** }\end{array}$ & $\begin{array}{c}\text { High } \\
\text { (Maternal } \\
\text { Anemia) }\end{array}$ & $\begin{array}{l}\text { Weak } \\
\text { Against }\end{array}$ & $\begin{array}{l}\text { Weak } \\
\text { Against }\end{array}$ & $\begin{array}{l}\text { Weak } \\
\text { Against }\end{array}$ & Strong: Anemia \\
\hline Zinc Supplementation & $\begin{array}{l}\text { High } \\
\text { No Effect }\end{array}$ & $\begin{array}{l}\text { High } \\
\text { No Effect }\end{array}$ & $\begin{array}{l}\text { High } \\
\text { High }\end{array}$ & $\begin{array}{l}\text { High } \\
\text { No Effect }\end{array}$ & $\begin{array}{c}\text { Mod } \\
\text { (Reduced } \\
\text { C-Sections) }\end{array}$ & $\begin{array}{l}\text { Strong } \\
\text { Against }\end{array}$ & Weak & $\begin{array}{l}\text { Strong } \\
\text { Against }\end{array}$ & Weak \\
\hline $\begin{array}{l}\text { Magnesium Sulfate } \\
\text { Supplementation }\end{array}$ & High & High & $\operatorname{Mod}^{* *}$ & $\operatorname{Mod}^{* *}$ & $\begin{array}{c}\text { High } \\
\text { (Cerebral Palsy) }\end{array}$ & $\begin{array}{l}\text { Strong } \\
\text { Against }\end{array}$ & $\begin{array}{l}\text { Weak } \\
\text { Against }\end{array}$ & $\begin{array}{l}\text { Weak } \\
\text { Against }\end{array}$ & $\begin{array}{c}\text { Weak: } \\
\text { Supplementation } \\
\text { Strong: Treatment } \\
\text { of Eclampsia and } \\
\text { Prevention of } \\
\text { Cerebral Palsy }\end{array}$ \\
\hline Calcium Supplementation & $\begin{array}{l}\text { High } \\
\text { No Effect }\end{array}$ & - & Mod & Mod & $\begin{array}{c}\text { High } \\
\text { (Preeclampsia) }\end{array}$ & $\begin{array}{l}\text { Strong } \\
\text { Against }\end{array}$ & Weak & Weak & $\begin{array}{l}\text { Strong: } \\
\text { Preeclampsia }\end{array}$ \\
\hline $\begin{array}{l}\text { Supplementation with } \\
\text { Fatty Acids }\end{array}$ & - & - & $\begin{array}{l}\text { High } \\
\text { No Effect }\end{array}$ & $\begin{array}{l}\text { High } \\
\text { No Effect }\end{array}$ & - & - & $\begin{array}{l}\text { Strong } \\
\text { Against }\end{array}$ & $\begin{array}{l}\text { Strong } \\
\text { Against }\end{array}$ & \\
\hline $\begin{array}{l}\text { Cardiotocographic } \\
\text { Monitoring }\end{array}$ & Low & Mod & - & & & Weak & & & \\
\hline $\begin{array}{l}\text { Doppler and Late } \\
\text { Ultrasound Monitoring }\end{array}$ & $\begin{array}{l}\text { High } \\
\text { No Effect }\end{array}$ & & - & - & & $\begin{array}{l}\text { Strong } \\
\text { Against }\end{array}$ & - & - & \\
\hline \multicolumn{10}{|l|}{ Pregnancy infections } \\
\hline $\begin{array}{l}\text { Screening and Treatment } \\
\text { of Syphilis }\end{array}$ & Mod* & $\begin{array}{l}\text { Very } \\
\text { Low }^{* *}\end{array}$ & Mod* & Mod* & Mod* & Strong & Weak & Weak & $\begin{array}{l}\text { Strong: Congenital } \\
\text { Syphilis }\end{array}$ \\
\hline $\begin{array}{l}\text { Intermittent Presumptive } \\
\text { Treatment During Pregnancy } \\
\text { (IPTp) for malaria }\end{array}$ & Mod & High & Low* & High & High & Strong & Weak & Strong & $\begin{array}{l}\text { Strong: Maternal } \\
\text { Malaria }\end{array}$ \\
\hline $\begin{array}{l}\text { Insecticide-Treated } \\
\text { Mosquito Nets (ITNs) }\end{array}$ & High & - & Low $^{* *}$ & High & High & Strong & $\begin{array}{l}\text { Weak } \\
\text { Against }\end{array}$ & Strong & $\begin{array}{l}\text { Strong: Maternal } \\
\text { Malaria }\end{array}$ \\
\hline $\begin{array}{l}\text { Screening and Treatment } \\
\text { of Asymptomatic Bacteriuria }\end{array}$ & $* *$ & $* *$ & LoW $^{* *}$ & High & $\begin{array}{c}\text { High } \\
\text { (Maternal } \\
\text { Morbidity) }\end{array}$ & - & Weak & Strong & $\begin{array}{c}\text { Strong: } \\
\text { Pyelonephritis, } \\
\text { Maternal Morbidity }\end{array}$ \\
\hline $\begin{array}{l}\text { Screening and Treatment } \\
\text { of Bacterial Vaginosis }\end{array}$ & - & - & $\begin{array}{l}\text { High } \\
\text { No Effect }\end{array}$ & $\begin{array}{l}\text { High } \\
\text { No Effect }\end{array}$ & - & - & $\begin{array}{l}\text { Strong } \\
\text { Against }\end{array}$ & $\begin{array}{l}\text { Strong } \\
\text { Against }\end{array}$ & - \\
\hline $\begin{array}{l}\text { Prevention of Mother-to- } \\
\text { Child Transmission of HIV }\end{array}$ & Low & Low & Low & - & $\begin{array}{l}\text { High } \\
\text { (PMTCT) }\end{array}$ & $* *$ & $* *$ & $* *$ & Strong: PMTCT \\
\hline & & & & & & & & & Continued overlea \\
\hline
\end{tabular}


Table 3. Continued

\begin{tabular}{|c|c|c|c|c|c|c|c|c|c|}
\hline \multirow[b]{2}{*}{$\begin{array}{l}\text { Intervention } \\
\text { (by stage or recipient) }\end{array}$} & \multicolumn{5}{|c|}{ Quality of evidence } & \multicolumn{4}{|c|}{ Recommendation for implementation } \\
\hline & SB & PMR & PTB & LBW & $\begin{array}{l}\text { Other MNCH } \\
\text { Outcomes }\end{array}$ & SB/PMR & PTB & LBW & $\begin{array}{l}\text { Other MNCH } \\
\text { Outcomes }\end{array}$ \\
\hline \multicolumn{10}{|c|}{ Pregnancy infections (continued) } \\
\hline Anti-Helminthic Treatment & Low & Low & Low & Low & $\begin{array}{l}\text { High } \\
\text { (Maternal } \\
\text { Hookworm) }\end{array}$ & $\begin{array}{l}\text { Weak } \\
\text { Against }\end{array}$ & $\begin{array}{l}\text { Weak } \\
\text { Against }\end{array}$ & $\begin{array}{l}\text { Weak } \\
\text { Against }\end{array}$ & $\begin{array}{l}\text { Strong: Maternal } \\
\text { Anemia }\end{array}$ \\
\hline $\begin{array}{l}\text { Screening and Treatment of } \\
\text { Periodontal Disease }\end{array}$ & - & - & Mod $^{* *}$ & $\operatorname{Mod}^{* *}$ & $\begin{array}{l}\text { Low } \\
\text { (Maternal } \\
\text { Oral Health) }\end{array}$ & & $\begin{array}{l}\text { Weak } \\
\text { Against }\end{array}$ & $\begin{array}{l}\text { Weak } \\
\text { Against }\end{array}$ & $\begin{array}{l}\text { Weak: Maternal } \\
\text { Oral Health }\end{array}$ \\
\hline \multicolumn{10}{|c|}{ Interventions for pregnancies with high-risks of preterm birth or stillbirth } \\
\hline Progesterone & Mod & & High & High & - & $\begin{array}{l}\text { Weak } \\
\text { Against }\end{array}$ & Strong & Strong & - \\
\hline Cervical Cerclage & $\begin{array}{c}\text { High } \\
\text { No Effect }\end{array}$ & & $\begin{array}{l}\text { High } \\
\text { No Effect }\end{array}$ & & - & $\begin{array}{l}\text { Weak } \\
\text { Against }\end{array}$ & $\begin{array}{l}\text { Strong } \\
\text { Against }\end{array}$ & - & - \\
\hline $\begin{array}{l}\text { Multivitamins for } \\
\text { HIV+ Women }\end{array}$ & Low & Low & $\begin{array}{l}\text { Mod } \\
\text { No Effect }\end{array}$ & $\begin{array}{l}\text { Mod } \\
\text { No Effect }\end{array}$ & - & $\begin{array}{l}\text { Weak } \\
\text { Against }\end{array}$ & $\begin{array}{l}\text { Weak } \\
\text { Against }\end{array}$ & $\begin{array}{l}\text { Weak } \\
\text { Against }\end{array}$ & - \\
\hline \multicolumn{10}{|c|}{ Intrapartum interventions to prevent stillbirths } \\
\hline Birth Preparedness & High & Mod & - & - & & Strong & - & - & \\
\hline Use of Partogram & Low & Low & - & - & & Weak & - & - & \\
\hline Fetal Movement Monitoring & Low & - & - & - & & trong Against & - & - & \\
\hline Emergency Obstetric Care & Mod* & Mod* $^{*}$ & - & - & $\begin{array}{c}\text { Mod } \\
\text { (Maternal } \\
\text { Outcomes) }\end{array}$ & Strong & - & - & $\begin{array}{l}\text { Strong: Maternal } \\
\text { Mortality }\end{array}$ \\
\hline $\begin{array}{l}\text { Cesarean Section for } \\
\text { Breech Presentation }\end{array}$ & - & High & - & - & & Strong & - & - & \\
\hline $\begin{array}{l}\text { Elective Induction for } \\
\text { Post-Term Delivery }\end{array}$ & Mod & High & - & - & & Strong & - & - & \\
\hline $\begin{array}{l}\text { Elective Induction } \\
\text { for Term PROM }\end{array}$ & & Mod & & । & $\begin{array}{c}\text { High } \\
\text { (Maternal and } \\
\text { Infant Outcomes) }\end{array}$ & Weak & & & $\begin{array}{l}\text { Strong: Maternal } \\
\text { and Infant } \\
\text { Outcomes }\end{array}$ \\
\hline Home Delivery & & Mod & - & - & & $\begin{array}{l}\text { Weak } \\
\text { Against }\end{array}$ & & & \\
\hline \multicolumn{10}{|c|}{ Intrapartum interventions to improve preterm survival } \\
\hline $\begin{array}{l}\text { Prophylactic Steroids in } \\
\text { Preterm Labor }\end{array}$ & - & - & High & - & $\begin{array}{l}\text { High } \\
\text { (Neonatal } \\
\text { Morbidity) }\end{array}$ & - & Strong & - & $\begin{array}{l}\text { Strong: Neonatal } \\
\text { Morbidity }\end{array}$ \\
\hline Antibiotics for PROM & - & - & High & - & $\begin{array}{l}\text { High } \\
\text { (Neonatal } \\
\text { Morbidity) }\end{array}$ & & Strong & & $\begin{array}{l}\text { Strong: Neonatal } \\
\text { Morbidity }\end{array}$ \\
\hline $\begin{array}{l}\text { Antibiotics for Preterm } \\
\text { Labor with Intact Membranes }\end{array}$ & - & - & High & - & & & $\begin{array}{l}\text { Strong } \\
\text { Against }\end{array}$ & & \\
\hline Delayed cord clamping & & & High & & & & Strong & & \\
\hline \multicolumn{10}{|c|}{ Postnatal interventions to improve preterm survival } \\
\hline \multicolumn{10}{|l|}{ Neonatal Resuscitation } \\
\hline $\begin{array}{l}\text { - Modes of oxygen delivery } \\
\text { and resuscitation } \\
\text { techniques: CPR }\end{array}$ & & & Low & & - & & - & & - \\
\hline $\begin{array}{l}\text { - Modes of delivery and } \\
\text { techniques: bag and mask }\end{array}$ & & & Mod & & - & & - & & - \\
\hline $\begin{array}{l}\text { - CPR techniques: long- \& } \\
\text { short-term outcomes }\end{array}$ & & & Low & & - & & - & & - \\
\hline $\begin{array}{l}\text { - Room air (vs. 100\% oxygen) } \\
\text { for resuscitation }\end{array}$ & & & High & & - & & Strong & & - \\
\hline
\end{tabular}


Table 3. Continued

\begin{tabular}{|c|c|c|c|c|c|c|c|c|}
\hline \multirow[b]{2}{*}{$\begin{array}{l}\text { Intervention } \\
\text { (by stage or recipient) }\end{array}$} & \multicolumn{4}{|c|}{ Quality of evidence } & \multicolumn{4}{|c|}{ Recommendation for implementation } \\
\hline & PMR & PTB & LBW & $\begin{array}{l}\text { Other MNCH } \\
\text { Outcomes }\end{array}$ & SB/PMR & PTB & LBW & $\begin{array}{l}\text { Other MNCH } \\
\text { Outcomes }\end{array}$ \\
\hline \multicolumn{9}{|c|}{ Postnatal interventions to improve preterm survival (continued) } \\
\hline $\begin{array}{l}\text { Training programs for } \\
\text { health facilities }\end{array}$ & & Mod & & - & & Weak & & - \\
\hline Vitamin A supplementation & & Mod & & - & & $\begin{array}{l}\text { Weak } \\
\text { Against }\end{array}$ & & - \\
\hline Vitamin K supplementation & & Mod & & $\begin{array}{c}\text { Mod } \\
\text { (antenatal) }\end{array}$ & & Strong & & $\begin{array}{l}\text { Weak: } \\
\text { antenatal }\end{array}$ \\
\hline Zinc supplementation & & Low & & - & & $\begin{array}{l}\text { Weak } \\
\text { Against }\end{array}$ & & - \\
\hline Selenium supplementation & & Mod & & - & & Weak & & - \\
\hline $\begin{array}{l}\text { Chlorhexidine treatment } \\
\text { on the cord }\end{array}$ & & Mod & & - & & - & & - \\
\hline $\begin{array}{l}\text { Case management of } \\
\text { neonatal sepsis and pneumonia }\end{array}$ & & Mod & & - & & Strong & & - \\
\hline \multicolumn{9}{|l|}{ Kangaroo mother care (KMC) } \\
\hline Hospital-based KMC & & High & & - & & Strong & & - \\
\hline Community-based KMC & & Low & & - & & - & & - \\
\hline Early breastfeeding & & High & & $\begin{array}{c}\text { Mod } \\
\text { (neonatal } \\
\text { mortality) }\end{array}$ & & Strong & & - \\
\hline $\begin{array}{l}\text { Thermal care (skin to skin; } \\
\text { plastic wraps) }\end{array}$ & & Mod & & - & & Strong & & - \\
\hline $\begin{array}{l}\text { Application of continued } \\
\text { distending pressure to the } \\
\text { lungs for RDS }\end{array}$ & & High & & $\begin{array}{l}\text { High } \\
\text { (reducing chronic } \\
\text { lung disease, and } \\
\text { as alternative to } \\
\text { intubation) } \\
\text { Low pneumothorax }\end{array}$ & & Strong & & $\begin{array}{c}\text { Strong: } \\
\text { bronchopulmonary } \\
\text { dysplasia }\end{array}$ \\
\hline $\begin{array}{l}\text { Intravenous immune } \\
\text { globulin (IVIG) }\end{array}$ & & High & & & & Weak & & \\
\hline $\begin{array}{l}\text { Surfactant therapy } \\
\text { for RDS }\end{array}$ & & High & & $\begin{array}{c}\text { High } \\
\text { (reducing chronic } \\
\text { lung disease) }\end{array}$ & & Strong & & Strong \\
\hline
\end{tabular}

(*) Due to ethical issues, RCTs are not possible.

(**) Limited evidence, or outcomes not reported.

(-) Not applicable or no evidence

calculated that birth spacing promotion in countries with high birth rates could reduce one third of maternal deaths and $10 \%$ of childhood mortality [11]. After a birth, the interval before attempting a new pregnancy should be at least 24 months to reduce the risk of adverse maternal and infant outcomes [12].

Preterm birth

A meta-analysis of observational studies [9] showed a $40 \%$ increase in preterm births when the birth interval was shorter than 6 months, relative to babies born after a birth interval of 18-23 months (RR 1.40; CI 1.24-1.58). The corresponding odds ratios were 1.61 (95\% CI 1.391.86) for low birth weight and 1.26 (95\% CI 1.18-1.33) for
IUGR. A 20\% increase in preterm births was also found when the birth interval was 60 months or longer (OR $1.20 ; 95 \%$ CI 1.17-1.24). There are no intervention studies, however, showing that promoting birth spacing will reduce either preterm births or low birth weight.

\section{Stillbirth}

Stephansson et al. [13], using a logistic regression analysis on the Swedish registry data, showed that compared with interpregnancy intervals (IPIs) $12-25$ months, very short IPIs (0-3 months) were linked to an increased risk of stillbirth, though nonsignificant (adjusted OR $=1.3$; 95\% CI: 0.8-2.1). IPIs greater than 72 months also increased women's risk of stillbirth in this study (adjusted OR $=1.5$; 
95\% CI: 1.1-2.1). Other studies have also shown a link between increased risk of fetal loss and short or long IPIs $[14,15]$.

\section{Assessment}

The quality of evidence relating birth spacing to preterm birth and low birth weight is moderate, as it is based on a large number of carefully conducted observational studies. While it is not expected that randomized trials will be conducted on the value of birth spacing in the future, there is a critical need for evaluating the effectiveness of various strategies to promote birth spacing, induced terminations and prevention of unwanted pregnancies [16]. The level of recommendation is, therefore, weak in favor of this intervention to prevent preterm birth and low birth weight.

The overall quality of evidence of the impact of birth spacing on perinatal mortality is moderate, but data on stillbirths are sparse. Therefore, this intervention has low evidence of benefit for preventing stillbirth and the recommendation is weak in favor of its use for this outcome. Further evaluation of interventions promoting birth spacing is needed with reference to stillbirth outcomes. However, birth spacing is strongly recommended due to its important effects on both maternal and child health outcomes [12].

\section{Periconceptional folate}

Folic acid is a key element involved in DNA metabolism and necessary for red cell formation and correct closure of the neural tube. Almost all people who do not consume supplemental folic acid are folate deficient, and periconceptional folate supplementation reduces neural tube defects by $50-70 \%$ [17]. It is calculated that a $90 \%$ coverage of folate use in low- and middle-income countries would reduce nearly $80 \%$ of such defects [18].

\section{Preterm birth}

No intervention studies show an effect of periconceptional folate supplementation on preterm birth or low birth weight. Three observational studies conducted in the United States were identified in this review. The first found a two-fold increased risk of preterm birth and low birth weight in women with low daily folate intake and low serum folate levels at 28 weeks of gestation [19]. Another observational study, conducted before and after folate fortification programs in California, found small reductions in adjusted risks after the fortification for low birth weight (RR 0.94; 0.93-0.96) and preterm birth (RR 0.96; 0.94-0.97) [20]. A third observational study [21] showed that preconceptional folate supplementation for longer than one year was associated with a reduced incidence of spontaneous preterm birth between 28 and 32 weeks (hazard ratio $0.45,0.23-0.85$ ), but no significant effect was noted between 32-36 weeks of gestation.

\section{Stillbirth}

A Cochrane review, including three trials that reported perinatal outcomes, concluded that periconceptional folic acid supplementation is of proven benefit in reducing neural tube defects, reflected by a statistically significant reduction in its rate (RR 0.28; 95\% CI 0.13-0.58), but impact on stillbirths is that of a $22 \%$, nonsignificant reduction (RR 0.78; 95\% CI 0.34-1.78) [22].

\section{Assessment}

The quality of evidence is low for preterm birth, but because the three observational studies point in the same direction, the recommendation is weak in favor of the intervention. The quality of evidence is moderate for stillbirths given the wide uncertainty in the results; the intervention cannot be recommended exclusively for preventing stillbirth and thus received a weak recommendation against the intervention for this outcome. Nevertheless, periconceptional folate is strongly recommended for other MNCH outcomes due to its protective effect on neural tube defects. Further studies are needed to assess potential long-term benefits of folic acid supplementation during pregnancy.

\section{Indoor air pollution}

The daily energy needs of around 50\% of the world's population are met by the burning of solid fuels [23]. Cooking is usually the domain of women, especially in developing countries even during pregnancy. Their homes are usually crowded and poorly ventilated, leading to intense smoke exposure that could harm the growing fetus as smoke metabolites cross the placental barrier.

\section{Preterm birth}

Observational studies in Guatemala, Pakistan and Zimbabwe show an association between this practice and decreased birth weight, but no information is available on preterm births $[24,25]$. In addition, no intervention studies are available on the impact of reduced indoor air pollution on either low birth weight or preterm birth.

\section{Stillbirth}

Studies on the impact of indoor air pollution on stillbirths are restricted to South Asian countries. Mavalankar, in India, found a nonsignificant increase in stillbirth risk in a case control study among women exposed to smoke (OR 1.5; 95\% CI 1.0-2.1)[26]. Another population-based Indian study showed that women using biomass fuels had a significantly higher risk of stillbirth than those utilizing cleaner fuels (OR 1.44; 95\% CI 1.04-1.97)[27]. Siddiqui et 
al. from Pakistan reported nearly a two-fold greater risk of stillbirths in pregnant women exposed to biomass fuel (OR 1.90; 95\% CI 1.10-3.20) [28].

\section{Assessment}

There is a lack of studies relating indoor air pollution to preterm birth, especially randomized controlled trials $[29,30]$. Therefore the quality of evidence is very low and the recommendation is weak against the intervention for this particular outcome. For low birth weight and stillbirths, the quality of the evidence is low, as it is largely based on observational studies. However, the intervention is strongly recommended for the prevention of respiratory infections [31, 32]. Future studies of measures to reduce indoor air pollution must also measure pregnancy and neonatal outcomes.

\section{Interventions given during pregnancy Smoking cessation programs}

More than $80 \%$ of all smokers now reside in low- and middle-income countries, with an estimated prevalence of $49 \%$ among men and $8 \%$ among women [33, 34]. Recent prevalence studies of smoking during pregnancy also show wide variability, [35] with rates above $25 \%$ in South America [36], 8\% in urban Africa [37] and 18\% in the Pacific Islands [38].

Mechanisms that increase the risks of preterm birth and stillbirth among smokers are not clear. It is known, however, that both nicotine and carbon monoxide are potent vasoconstrictors, produce placental damage, and decrease the uteroplacental blood flow [39].

\section{Preterm birth}

Cigarette smoking is a well-known cause of preterm birth and intrauterine growth restriction [40]. In a Cochrane review published in 2004, smoking cessation interventions significantly reduced low birth weight (RR 0.81;0.70-0.94) and preterm birth (RR 0.84; 0.72-0.98), as well as smoking during pregnancy [41]. It should be noted, however, that the experience of smoking cessation programs is predominantly from high-income countries [42].

\section{Stillbirth}

Notwithstanding the established benefits to mother and fetus, there are few studies that have reported the effect of smoking cessation on perinatal outcomes and stillbirths. One cohort study from Sweden shows increased risk of stillbirths among smokers [43].

\section{Assessment}

The quality of evidence is high for both preterm birth and low birth weight, and the intervention has a strong recommendation, especially in countries where smoking has a high prevalence during pregnancy. The strong recommendation is reinforced by other well-known effects of smoking on health. The lack of studies on smoking cessation and stillbirth outcomes points to a data gap that should be filled. Maternal exposure to second-hand smoke is an additional research gap. It should also be noted that all studies reviewed originate from high-income settings, and therefore intervention studies in low- and middle-income settings are needed.

\section{Balanced protein energy supplementation}

Maternal undernutrition is still a major problem in the world's poor countries [44]. Energy intake in pregnancy is positively associated with fetal growth [40]. In populations with food insecurity and high rates of maternal undernutrition, balanced energy protein supplementation-including up to $25 \%$ of the total energy content in the form of protein-may improve fetal growth and reduce the risk of fetal and neonatal death.

\section{Preterm birth}

A Cochrane review of seven trials of balanced protein energy supplementation for pregnant women did not show a significant effect on preterm births (RR 0.83; 0.65-1.06), but intrauterine growth restriction was reduced by $32 \%$ (RR $0.68 ; 0.54-0.86$ ) [45]. Five of the seven trials were carried out in LMICs.

\section{Stillbirth}

The same review showed a significant reduction in the risks of stillbirth (RR 0.55; 95\% CI 0.31-0.97) and a nearsignificant reduction in neonatal deaths (RR 0.62; 95\% CI $0.37-1.05)[45]$.

\section{Assessment}

The quality of evidence is high and the intervention is not recommended for preventing preterm birth. However, this intervention is strongly recommended in appropriate populations (food insecure households and mothers with low body mass index) due to its affect on fetal growth and on preventing stillbirth.

\section{Multiple micronutrient supplementation}

Low serum levels of micronutrients such as iron, folate and zinc, are highly prevalent among pregnant women in low-income settings, and are associated with preterm birth and stillbirth [44, 46-48]. Undernourished pregnant women consume less vitamins and minerals in their diets and have reduced blood volume and decreased uterine blood flow [49]. As a consequence, different nutritional interventions have been tried for women at high risk of nutritional deficiencies, including supplements of specific micronutrients, such as zinc, iron and folate, magnesium and calcium, given either singly or in combination. 
Preterm birth

A review of nine RCTs comparing multiple micronutrient supplementation during pregnancy with either no supplements, two or fewer micronutrients, or placebo, showed a reduction in low birth weight (RR 0.84; 95\% CI 0.74-0.95), IUGR (RR 0.92; 95\% CI 0.86-0.99) and maternal anemia (RR $0.61 ; 0.52-0.71)$, but no effect on preterm birth [50]. A more recent trial in Tanzania compared multivitamins with placebo; the intervention group showed a reduction in low birth weight (RR 0.82; 95\% CI 0.70-0.95) and in the frequency of small for gestational age newborns (RR 0.77; 95\% CI 0.68-0.87), but no effect on preterm births or fetal mortality [51].

A 2006 meta-analyses of multiple micronutrient supplementation compared with iron and folic acid found no differences in maternal or neonatal outcomes [50]. However, when a 2008 RCT from Indonesia [52] was added to this meta-analysis, a significant reduction in low birth weight was observed (OR 0.84; 95\% CI 0.74-0.95) [53].

\section{Stillbirth}

A reasonably large number of studies have recently evaluated the impact of multiple micronutrients on perinatal mortality and stillbirth outcomes. A recent meta-analysis was conducted, including trials published since the most recent Cochrane reviews, of the impact of multiple micronutrient supplementation in pregnancy [54]. The meta-analysis (nine RCTs, $\mathrm{N}=40,222$ women, $\mathrm{N}=20,277$ intervention group, $\mathrm{N}=19,945$ controls) compared the impact on stillbirths of multiple micronutrient supplementation during pregnancy (intervention) with either iron or iron and folate (controls) and found a nonsignificant trend toward reduced stillbirths among the intervention group versus the control group (RR 0.91, 95\% CI: 0.80-1.03).

One note of caution was provided by the report of increased birth asphyxia among babies in the intervention group in two micronutrient supplementation RCTs carried out in Nepal [55-57]. Their pooled analysis showed increased rates of perinatal and neonatal mortality (RR 1.52; 95\% CI 1.03-2.25) in the intervention group. However, such an effect was not found in the Indonesia randomized trial, where infant mortality was $18 \%$ lower among infants whose mothers were supplemented with micronutrients [52]. In sites where these RCTs were carried out, most births took place either at home or in health posts, with limited access to emergency obstetric care. In Indonesia however, the study area had trained midwives and a signifcnatly greater proportion of births were assisted by skilled birth attendants. Thus this intervention must be viewed in the context of health system functionality and might provide benefits in circumstances where skilled care and facility births are available [58].
Assessment

There is high quality evidence the intervention has a significant impact on low birth weight but no effect on preterm births or stillbirths. However, due to moderatequality evidence of increased neonatal mortality in South Asia, more information is necessary from effectiveness trials in different health systems settings before the intervention can be recommended for scaling up.

\section{Iron and folate supplementation}

Iron and folate are key elements for red cell production and iron-deficiency anemia, the most common nutrient deficiency among pregnant women. Routine iron or ironfolate supplementation is recommended for correcting anemia during pregnancy [59].

\section{Preterm birth}

A meta-analysis of four trials of iron supplementation during pregnancy, with and without folic acid, [60] showed a reduction in anemia but no significant effect on preterm birth (RR 0.76 ; 95\% CI $0.47-1.24$ ) or low birth weight (RR 0.59; 95\% CI 0.23-1.49).

\section{Stillbirth}

The impact of iron or iron-folate supplementation on the prevention of stillbirth is mixed, [54] partly because most studies are underpowered to detect differences. The Cochrane review by Pena-Rosas et al. on antenatal iron supplementation found a nonsignificant risk of increased perinatal mortality with iron supplementation compared to placebo (RR 2.50, 95\% CI 0.10-59.88)[60]. Another study from The Gambia, reported stillbirth rates of $2.9 \%$ vs. $4.3 \%$ in intervention (200 $\mathrm{mg}$ oral ferrous sulphate) and control groups, respectively [61].

Assessment

There is moderate evidence of a lack of effect for ironfolate supplementation on preterm birth, low birthweight and stillbirth. Although this is based on randomized trials, the quality of the evidence is moderate, because the confidence intervals are very wide. The recommendation-based exclusively on these outcomes-is weak against supplementation. Nevertheless, the well known impact of iron and folate in the prevention of maternal anemia result in a strong recommendation in favor of supplementation.

\section{Zinc supplementation}

Zinc plays an important role in many biological functions, including protein synthesis and nucleic acid metabolism [62]. Mild to moderate zinc deficiency is common in low-income settings, where pregnant women tend to consume less than the recommended daily intake of $15 \mathrm{mg}$ [63]. 


\section{Preterm birth}

In a Cochrane review of 13 trials, seven of which were from low-middle income countries, zinc supplementation during pregnancy led to a modest reduction of $14 \%$ (95\% CI 0.76-0.98) in preterm birth, but had no effect on low birth weight (RR 1.05, 95\% CI 0.94-1.17), suggesting this effect may be restricted to large preterm babies [64] .

\section{Stillbirth}

The recent Cochrane review of 9000 pregnancies mentioned above had 7 studies that reported no effects on stillbirth and perinatal mortality outcomes. The single study [55] undertaken in Nepal, a population with low maternal zinc status, reported no effect on stillbirths or other perinatal deaths ( $R R$ 1.03, 95\% CI 0.71-1.51). A recent review of the subject [65] also did not report any stillbirth or other perinatal outcomes [55].

\section{Assessment}

The quality of evidence for zinc supplementation on stillbirth, preterm birth and low birth weight is high. The intervention is not recommended for the prevention of low birth weight or stillbirths, and has a weak recommendation for preventing preterm births, given its small effect size. No firm conclusion was reached on the effect of maternal zinc supplementation on stillbirth.

\section{Magnesium sulfate supplementation}

Magnesium sulfate reduces uterine contractility both in vivo and in vitro, indicating this intervention may prevent preterm birth and stillbirth [66].

\section{Preterm birth}

A meta-analysis of seven intervention trials with oral magnesium treatment starting before the 25th week of gestation showed a lower frequency of preterm birth (RR 0.73, 95\% CI $0.57-0.94)$, as well as a reduction in low birth weight (RR $0.67,95 \%$ CI 0.46 to 0.96 ) and improved maternal outcomes (hemorrhage and hospital admissions). However, authors of the Cochrane review noted that the studies included in the review had important shortcomings [67].

\section{Stillbirth}

The Cochrane review [67] included three RCTs with 1954 recipients that reported stillbirth outcomes and showed no impact (RR 1.0, 95\% CI 0.29-3.44).

\section{Assessment}

The quality of evidence is moderate for both preterm birth and low birth weight, and there is a weak recommendation against the intervention until better studies become available. There is fairly consistent evidence that magnesium has no impact on stillbirth, and the recommendation is strong against the intervention for this outcome. A recent Cochrane review shows a reduced risk of cerebral palsy in the offspring of high-risk women who received magnesium sulfate [68] and thus this intervention should be evaluated further with a range of alternative outcomes.

\section{Calcium supplementation}

It is estimated that hypertension complicates $5 \%$ of all pregnancies and $11 \%$ of first pregnancies, accounting for nearly 40,000 maternal deaths annually [69]. Due to the known inverse association between calcium intake during pregnancy and hypertension, [70], supplementation has been tried in a number of studies.

\section{Preterm birth}

Calcium supplementation trials in low-risk women in populations with low-calcium diets reduced the risk of preeclampsia (RR 0.48; 95\% CI 0.33-0.69) but its impact on preterm birth (10 trials, RR 0.81 ; $95 \%$ CI $0.64-1.03$ ) and low birth weight ( 8 trials, RR $0.84,95 \%$ CI 0.68-1.03) was not quite significant [71]. However, when the analysis was restricted to the four small studies including 568 women at high risk of preeclampsia, there was a significant decrease in preterm birth (RR 0.45, 95\% CI 0.24 to 0.83 ).

In a recent small placebo-controlled RCT in low-risk Indian primigravidae with low dietary calcium, calcium supplementation led to less preeclampsia (OR 0.31; 95\% CI 0.15-0.63) and significantly fewer preterm births (OR 0.51; 95\% CI 0.28-0.93)[72].

\section{Stillbirth}

The Cochrane review [71] reported stillbirth and neonatal death before discharge in 10 trials with 15,141 participants, but showed no impact (RR 0.89, 95\% CI 0.79-1.09).

\section{Assessment}

The quality of evidence for preterm birth and low birth weight is moderate, and the intervention has a weak recommendation for preventing preterm birth. For stillbirth, the quality of evidence is high suggesting a lack of effect. Therefore, the intervention is not recommended for these particular outcomes. However, it is strongly recommended for preventing preeclampsia in populations with low levels of dietary intake of calcium.

\section{Supplementation with long-chain polyunsaturated fatty acids} Long-chain polyunsaturated fatty acids (LCPUFA) are precursors to the 3-series prostaglandins, which modulate inflammatory and vascular effects [73]. Because hypertension during pregnancy and preeclampsia are associated with vasoconstriction and endothelial damage, it is postulated these fatty acids play a beneficial role. 
Preterm birth

Five randomized trials found that marine oil supplementation to low-risk women did not show any effect on preterm births (RR 0.92, 95\% CI 0.79, 1.07), low birth weight, or the risk of preeclampsia [74]. Two RCTs showed LCPUFA supplementation was associated with a significantly lower rate of early preterm birth $(<34$ weeks of gestation) (RR 0.39, $95 \%$ CI 0.18, 0.84)[75].

Stillbirth

No reported outcomes.

\section{Assessment}

The quality of evidence is high showing no effect of the intervention to prevent preterm birth and low birth weight. The recommendation against the intervention is strong for these outcomes given the current state of evidence. Further studies are needed on a possible effect on early preterm birth.

\section{Cardiotocographic monitoring}

One Cochrane review and two observational studies testing the impact of antepartum cardiotocography (including both NST and CST) on perinatal outcomes were identified [76-78]. The Cochrane review by Pattison \& McCowan [76] included four studies $(\mathrm{N}=1,588$ pregnancies) of the impact of cardiotocography use on perinatal mortality in high- or intermediate-risk pregnancies. The trial reported a trend toward increased perinatal mortality in the cardiotocography group versus controls receiving no monitoring or whose cardiotocography results were concealed from the clinician; ( 3 trials, $\mathrm{N}=1279$ pregnancies, OR 2.85, 95\% CI: 0.99-7.12). However, the studies were underpowered to assess such an impact. The observational studies do indicate a correlation between non-reassuring cardiotocographic traces and adverse perinatal outcomes, including stillbirth. While there are few RCTs evaluating the impact of cardiotocographic monitoring on reducing stillbirth, apparent reductions in stillbirth rates have followed the incorporation of the stress testing and cardiotocographic monitoring into protocols for management of high-risk pregnancy in the United States. Fetal arousal tests such as vibroacoustic stimulation have largely been evaluated in high-income countries. There is a need for further studies in LMICs with limited CTG facilities [79].

\section{Assessment}

There are surprisingly few studies evaluating the relationship of cardiotocographic monitoring with stillbirth and the overall quality of available evidence is low. In light of the probable link with improved outcomes in developed countries, and the widespread use of low-cost CTG monitoring equipment in clinical practice, the current recommendation is weak. Further studies must be conducted with appropriate design and power to assess this intervention in health systems in developing countries.

\section{Doppler and late ultrasound monitoring}

Doppler ultrasound is a technique to study the fetoplacental and/or uteroplacental circulatory dynamics. A Cochrane review included $11 \mathrm{RCTs}$ comparing umbilical artery Doppler ultrasound in complicated pregnancies with no Doppler, and found a nonsignificant $21 \%$ reduction in the stillbirth rate (OR 0.79, 95\% CI 0.461.34) [80]. A similar review of late ultrasound examination for all pregnancies - whether or not these were complicated - showed no effect [81].

\section{Assessment}

There is high-quality evidence suggesting a lack of effect on stillbirth, and the recommendation against this intervention is strong.

\section{Interventions for pregnancy infections Screening and treatment of syphilis}

Syphilis during pregnancy is common in many LMICs, with prevalence in local studies varying widely from less than $1 \%$ to $10 \%$ or higher [82]. African studies show prevalence during pregnancy of $3.4 \%$ in Uganda, [83] $7.7 \%$ in Tanzania,[84] $12 \%$ in Malawi, and $17.4 \%$ in Cameroon [85]; [86]. Syphilis produces villitis and obliterative arteritis, which are severe lesions in the placenta associated with fetal and newborn mortality [87].

\section{Preterm birth}

During pregnancy, observational studies show associations between syphilis and both preterm birth and low birth weight. In Tanzania, women with high-titer active syphilis had a six-fold greater risk of preterm birth and a three-fold increase in low birth weight compared with seronegative women. It was estimated that syphilis accounts for one fourth of the preterm births in this population [88]. An earlier study from Malawi also found an increase of preterm and low birth weight babies among women with syphilis (OR 3.6; 95\% CI 1.6-7.9) [89]. All studies reviewed are from LMICs.

Penicillin effectively reduces the risk of congenital syphilis $[84,90]$, but there are no intervention studies showing an effect of syphilis screening and treatment on preterm birth.

Stillbirth

The effectiveness of antibiotics in curing gestational syphilis and preventing congenital infection was established in the 1940s, before RCTs had been adopted [90]. Observational studies in Swaziland, and Kenya suggest syphilis screening and treatment is associated with reduced perinatal mortality [91] and reduced 
stillbirths [84, 92]. In the Tanzanian study [84], the proportion of stillbirths was higher among women treated for low-titer active syphilis $(4.8 \%)$ vs. seronegative women $(2.5 \%)$ (crude OR = 1.95, 95\% CI: $0.96-4.0$ ); being similar for women treated for high-titer active syphilis (2.3\%) versus seronegative ones (2.5\%). For ethical reasons it was not possible to have an untreated group with syphilis, but these results suggest that treatment of high-titer women can reduce the risk. The results for low-titer women are difficult to interpret in the absence of an untreated comparison group.

\section{Assessment}

The quality of evidence for preventing preterm birth, low birth weight and stillbirth is moderate, being based on observational studies and accumulated knowledge. Given the current level of knowledge, it is not expected that RCTs will be conducted as these would be unethical. The recommendation is weak in favor of the intervention for preventing preterm birth or low birth weight. The recommendation is strong in favor of recognizing and treating maternal syphilis to reduce stillbirth and congenital syphilis.

\section{Intermittent presumptive treatment during pregnancy (IPTp) (for malaria)}

Malaria is a key cause of maternal illness and anemia in pregnancy, especially among primiparae in areas where malaria is endemic such as sub-Saharan Africa and parts of Latin America and Asia. Malaria prevention includes the use of antimalarial drugs administered presumptively through strategies such as intermittent preventive treatment during pregnancy (IPTp) and the use of insecticide-treated bed nets (ITNs).

\section{Preterm birth}

Malaria infection may affect fetal growth and gestational duration through maternal anemia and placental infection [93]. A systematic review of interventions with antimalarials during pregnancy showed that - among women in their first or second pregnancies - treatment reduced anemia, parasitaemia, placental malaria, perinatal deaths and low birth weight (six trials, RR 0.57; 95\% CI 0.46-0.72). No effect on preterm births was observed in the only trial assessing this outcome [94].

\section{Stillbirth}

A Cochrane review on prophylactic antimalarials or IPTp showed no overall effect, but when the analyses were restricted to women in their first or second pregnancy, antimalarials significantly reduced perinatal mortality (RR 0.73 ; 95\% CI 0.53-0.99) and were associated with a smaller, nonsignificant reduction in stillbirths (RR 0.87; 95\% CI 0.62-1.21) [94].
Assessment

Although there is little evidence for preterm birth or stillbirth, the quality of evidence is high for using IPTp to reduce low birth weight and perinatal mortality in malariaendemic areas. IPTp is thus strongly recommended for women in their first or second pregnancy.

\section{Insecticide-treated mosquito nets (ITNs)}

ITNs are known to decrease malaria transmission and reduce mortality [95]. Nevertheless, it is estimated that only a small fraction of women and children living in malarious areas are currently protected [96].

\section{Preterm birth}

A review of five randomized clinical trials of ITNs during pregnancy-four in Africa and one in Thailand-showed a $33 \%$ reduction in low birth weight in the African trials, but no effect in Thailand [97]. In the only trial with information on preterm births, conducted in Kenya [98], no effect was demonstrated.

\section{Stillbirth}

The same Cochrane review showed a 33\% reduction in fetal losses (abortions and stillbirths) in the first to fourth pregnancy (RR 0.67; 95\% CI 0.47-0.97), but not in fifth and higher-order pregnancies $[97,99]$.

\section{Assessment}

The quality of evidence is high for low birth weight and stillbirth, and the intervention is strongly recommended for these outcomes. There is very limited evidence-a single RCT-for preventing preterm birth, and the recommendation is weak (against), given that this trial found no effect. Overall, ITNs are strongly recommended due to their effect on maternal and child mortality and morbidity. There are few studies employing a combination of IPTp and ITN on pregnancy outcomes, including preterm birth and stillbirth.

\section{Screening and treatment of asymptomatic bacteriuria}

Genital and urinary infections, including asymptomatic bacteriuria, may affect preterm birth. One possible pathway could be a direct intrauterine infection, but it is also possible that the infection produces an inflammatory reaction that leads to preterm birth, even after the infection has been treated [39].

\section{Preterm birth}

Observational studies show an association between maternal urinary tract infections and both preterm birth and low birth weight. A meta-analysis of four observational studies indicated a decreased risk of preterm birth (RR 0.51, 95\% CI 0.36-0.69) in nonbacteriuric pregnant women in comparison to those with bacteriuria [100]. 
A 2007 meta-analysis evaluated 14 RCTs comparing the effect of antibiotics versus placebo [101] on different outcomes. Treatment reduced maternal pyelonephritis (RR 0.23; 95\% CI 0.13-0.41) and low birth weight (7 studies; RR 0.66; 95\% CI 0.49-0.89), but did not significantly reduce preterm birth (3 studies; OR $0.37 ; 95 \%$ CI 0.10-1.36). The three studies addressing preterm birth, however, had a number of methodological problems, such as using different cutoff points $(<38$ weeks in two studies and $<37$ weeks in one), having small sample sizes, and different diagnostic and treatment criteria.

Stillbirth

No reported outcomes.

\section{Assessment}

The quality of evidence for preterm birth is low, but it is high for low birth weight. The intervention is strongly recommended for preventing low birth weight and reducing maternal morbidity, but has a weak recommendation for preventing preterm births. Further studies are required on preterm birth and stillbirth.

\section{Screening and treatment of bacterial vaginosis}

As is the case for bacteriuria, bacterial vaginosis might contribute to preterm labor through infectious or inflammatory mechanisms [39]. Pregnant women with bacterial vaginosis are two to three times more likely to have a preterm birth than women without vaginosis [39]. It is not clear, however, whether this is a causal association [102].

\section{Preterm birth}

Several systematic reviews of screening and treatment for bacterial vaginosis found no impact on preterm births or low birth weight [103-108]. Because of this, routine pregnancy screening and treatment of bacterial vaginosis is not recommended [109-111].

However, RCTs in which antibiotics were given before 20 weeks found a significant reduction in preterm births (RR 0.72; 95\% CI 0.55-0.95) [107]-but further trials are needed before a recommendation for early treatment can be issued. It is possible the bacteria that cause the infection may ascend into the uterus before or during early pregnancy, starting an inflammatory response that would not be affected by late treatment [39].

Stillbirth

No reported outcomes.

\section{Assessment}

There is high quality evidence the treatment of bacterial vaginosis has a lack of effect for preventing preterm birth or low birth weight. A strong recommendation is made against the use of the intervention. The effect of early treatment of bacterial vaginosis on preterm birth and stillbirth is a research gap that needs to be addressed.

\section{Prevention of mother-to-child transmission of HIV}

In high-income countries, highly active antiretroviral therapy (HAART) has markedly reduced vertical transmission rates of HIV. However, there is concern that preterm rates may have increased among treated women. Analyses have yielded inconsistent results with respect to pregnancy outcomes. In particular, it is uncertain whether or not combination ART-most specifically that which includes protease inhibitors (PI's) - is associated with an increase in preterm births.

\section{Preterm birth}

Observational studies, particularly those from Europe, report increased rates of preterm birth in women receiving HAART during pregnancy. This risk was particularly pronounced for PI use that started early in pregnancy or before conception. For example, a multicenter European collaborative study including nearly four thousand mothers reported relative risks of preterm birth of 2.60 (95\% CI 1.43-4.75) and 1.82 (95\% CI 1.13-2.92), for those exposed to combination therapy with and without a protease inhibitors, respectively, compared to no treatment [112]. An observational study in the USA also showed increased rates of preterm birth among women receiving HAART with protease inhibitors, compared with any other treatment option (OR 1.8; 95\% CI 1.1-3.0)[113]. However, a 2007 meta-analysis of 1 retrospective and 13 prospective studies, including the aforementioned, showed that antiretroviral therapy during pregnancy is not associated with an overall increased risk of preterm birth [114]. The use of combination regimens before or early in pregnancy may slightly increase the risk of preterm birth, although confounders such as maternal HIV-stage may contribute to this observation. Observational studies suggest an association between preterm birth and use of HAART in pregnancy, in particular initiating PI-based HAART early in gestation, but inadequately control for stage of maternal HIV disease and other potential confounding variables [115-118].

\section{Stillbirth}

Fewer studies report on stillbirth outcomes and antiretroviral therapy during pregnancy. A report combining two completed clinical trials and five ongoing, prospective observational studies from the United States found similar rates of stillbirths between women who did and did not receive antiretroviral therapy during 
pregnancy [119]. Follow-up analysis from 2 of the included observational studies continued to show either no association between ART and stillbirth [113] or a decreased risk for stillbirth (OR 0.06, 95\% CI 0.02-0.18) [120]. Townsend et al., 2007 compared women on HAART with women on mono/dual therapy. In comparison with exposure to mono/dual therapy, exposure to HAART was associated with a nonsignificant increased risk of stillbirth (adj. OR=2.27, 95\% CI: 0.965.41; $\mathrm{p}=0.063)[121]$.

Finally, there was no significant difference in stillbirth rates between groups of women treated with HAART throughout pregnancy and short-course therapy in the two studies originating from low-income countries [122, 123].

\section{Assessment}

The use of combination antiretroviral therapy has dramatically decreased the rate of maternal-to-child HIV transmission. However, observational data suggest a possible association between ART therapy and increased risk of preterm birth. This may be particularly burdensome in low-income countries, particularly those with less access to neonatal care. Large-scale, randomized, controlled trials are needed to define the risk of HAART therapy and adverse pregnancy outcomes.

\section{Anti-helminthic treatment}

Hookworm infestation is associated with anemia in women and children in endemic areas. In such areas, routine antenatal mebendazole therapy could greatly reduce the prevalence of anemia in pregnancy.

\section{Preterm birth}

One RCT in Peru found no difference in low birth weight between women receiving anti-helminthitic therapy (mebendazole) compared to placebo $(8.1 \%$ and $8.7 \%$, respectively; $\mathrm{p}=0.7)$. Both groups received iron supplements. No information on gestational age was available [124]. A recent Cochrane review of the treatment of soil-related helminths in pregnancy shows no statistically significant impact on preterm birth (RR $0.85,95 \%$ CI $0.38-1.87$ ) or low birth weight (RR 0.94, 95\% CI 0.61-1.42) [125].

\section{Stillbirth}

An observational study from Sri Lanka on the effect of mebendazole therapy during pregnancy on birth outcomes showed that stillbirths and perinatal deaths combined were significantly less common among women who received mebendazole as part of antenatal care (RR 0.55; 95\% CI 0.4-0.77) [126]. However, the Peruvian RCT did not show statistically significant differences in rates of miscarriage, stillbirth $(8 / 522$ in the mebendazole plus iron group vs. 4/520 in placebo plus iron) or early neonatal death [127], but was underpowered for these outcomes.

\section{Assessment}

The quality of evidence is low, and there is a weak recommendation against using anti-helminthics to prevent stillbirth. Very little information is available on preterm birth. Hookworm treatment, however, is recommended for pregnant women to reduce anemia in high-prevalence populations.

\section{Screening and treatment for periodontal disease}

Periodontal disease has been associated with preterm birth, but the biological pathway for this association is not known. One possible explanation may be gingival infection resulting in intrauterine infection, via maternal bacteraemia and transplacental passage. This relationship is not proven [39].

\section{Preterm birth}

A meta-analysis of observational studies indicate associations between periodontal disease and preterm birth [128], but clinical trials show conflicting results [129]. From the four available RCTs, two showed no effect of treatment on preterm birth or low birth weight [130]. The other two described reductions in preterm birth, and one RCT showed a reduction in low birth weight $[131,132]$.

\section{Stillbirth}

No reported outcomes.

\section{Assessment}

Although RCTs on the impact of periodontal treatment on preterm birth or low birth weight are available, the quality of the evidence is moderate, because results so far are inconclusive. Currently, the intervention is not recommended for the sole intent of preventing preterm birth or low birth weight. The intervention may be beneficial for improving maternal oral health, but further research on fetal outcomes is needed.

\section{Interventions for pregnancies with high-risks of preterm birth or stillbirth \\ Progesterone}

Progesterone has been proposed for preventing the recurrence of preterm birth. The possible mechanisms supporting its use include: anti-inflammatory action, oxytocin antagonism (producing relaxation of smooth muscle), maintenance of cervical integrity, and reduced gap-junction formation [109]. 
Preterm birth

A meta-analysis of six randomized trials comparing the use of progesterone with placebo in high-risk women, showed a reduction of preterm births in the intervention group (RR 0.65, 95\% CI 0.54-0.79)[133], as well as a decreased prevalence of low birth weight (four studies, RR 0.63, 95\% CI 0.49-0.81). Five of the six trials are from high-income settings.

\section{Stillbirth}

The same meta-analysis failed to show a significant impact on perinatal deaths (five studies, RR 0.66; 95\% CI 0.37-1.19).

\section{Assessment}

The evidence of progesterone use to prevent recurrence of preterm birth is high and the intervention is strongly recommended. For stillbirth, the evidence is moderate due to the wide confidence interval, and the recommendation is weak against this intervention.

\section{Cervical cerclage}

Cervical cerclage is used for the treatment of an incompetent cervix that is associated with previous spontaneous abortion or miscarriage.

\section{Preterm birth}

In four RCTs of cervical cerclage for high-risk women, reviewed in a Cochrane publication [134], there was no difference in the occurrence of preterm births between intervention and control women (RR 1.04, 95\% CI 0.99-1.10).

\section{Stillbirth}

Another Cochrane review showed a nonsignificant 20\% reduction in perinatal loss, death at or after 24 weeks of gestation and up to the first week of neonatal life. (RR 0.80, 95\% CI 0.48-1.36) [135]. A more recent systematic review of seven RCTs also found similar results for pregnancy loss or death before hospital discharge (OR 0.81, 95\% CI 0.60-1.10) [136].

\section{Assessment}

The quality of evidence is high for both preterm birth and pregnancy loss. The recommendation is strong against the intervention for preventing preterm delivery, and weak against for preventing stillbirth, due to greater uncertainty in the evidence.

\section{Multivitamins for HIV+ women}

Poor maternal micronutrient status has been associated with faster clinical and immunological evolution of HIV disease. This association led to research on vitamin supplementation [137].

\section{Preterm birth}

A systematic review of four RCTs comparing the use of vitamin A with placebo in HIV-positive pregnant women did not show significant effects on maternal-to-child HIV transmission (OR 1.06; 95\% CI 0.89-1.26) or preterm birth (RR 0.88, 95\% CI 0.65-1.19). The intervention significantly increased mean birth weight by $89 \mathrm{~g}$ (95\% CI 85-95) and resulted in a near-significant reduction in low birth weight (RR 0.83, 95\% CI 0.68-1.01) [138].

Stillbirth

Only one study reported fetal loss (miscarriage and stillbirth) and indicated a reduction in stillbirth with multivitamin supplementation among HIV-infected women in pregnancy (30/512 in supplemented groups versus 49/509 in controls (RR 0.61, 95\% CI 0.39-0.94) [137].

\section{Assessment}

The quality of evidence for preterm birth and low birth weight is moderate due to uncertainty in the estimates, whereas the quality is low for stillbirth given that only one study is available. The recommendation is weak against this intervention.

\section{Intrapartum interventions to prevent stillbirth}

Intrapartum deaths account for a third of all stillbirths globally. Interventions to reduce such deaths include acting on the demand side by helping families seek care from skilled attendants, and acting on the supply side by improving access to and the quality of skilled care. These interventions are reviewed in terms of their potential impact on stillbirth and other perinatal outcomes, as intrapartum procedures are not carried out with the objective of affecting preterm birth.

\section{Birth preparedness}

Birth preparedness consists of preparing the mother, family and community for delivery and potential complications. It includes several measures such as seeking appropriate care during pregnancy, identifying the place of delivery, acquisition of sterile materials and planning for skilled birth attendance and referral if needed-including setting aside money and arranging for transportation to a facility [139].

In recent years many community based trials in Asia have employed various cadres of community health workers and support groups to promote birth preparedness and effective newborn care [140-143]. Such community-based interventions can play an important role in promoting birth preparedness, especially in seeking emergency obstetric care. However, existing studies include birth preparedness as part of a package of several other antenatal and delivery interventions, so it is not possible to separate the impact of birth preparedness alone. 


\section{Assessment}

There is high quality evidence that community-based interventions that include birth preparedness can prevent stillbirths. However, the effects of birth preparedness per se cannot be assessed. Community-based interventions are strongly recommended in appropriate settings where the proportion of home deliveries is high.

\section{Use of partogram}

A partogram, also called a partograph, is a simple preprinted paper form on which midwives and obstetricians can record the progress of labor. The tool provides a continuous pictorial overview of the progress of labor, and distinguishes between the latent and active phases of labor. Slower progress identified by the alert line on the partograph can be used as a basis for transfer to a facility for skilled intervention and delivery.

The recent Cochrane review by Lavender et al. 2008 [144] showed no statistically significant effect of partogram use on the Caesarean section rate (RR 0.64, 95\% CI: 0.24-1.70), instrumental vaginal delivery (RR 1.00, 95\% CI: 0.85-1.17) or Apgar score <7 at 5 minutes (RR 0.77, 95\% CI: $0.29-$ 2.06). There was no perinatal mortality in the two groups (partograph with 2-hour action line vs. 4-hour action line) in studies in high-resource settings $[145,146]$ included in this review. A large, multicenter study from Southeast Asia [147] reported a stillbirth rate of $0.3 \%$ among women using the partogram vs. $0.5 \%$ for the control group.

\section{Assessment}

The quality of evidence reviewed for evaluating the partogram for care during delivery is low, given the controlled circumstances in which these studies have been conducted. The recommendation is weak in favor of this intervention. Further RCTs are required in which stillbirth is a primary outcome.

\section{Fetal movement monitoring}

Reduced fetal movements are associated with a higher risk of stillbirth, [148] and fetal movement records or kick charts have been proposed as a screening mechanism. However, a large RCT comparing the impact of the use of kick charts on unexplained stillbirths found no difference in the rate of fetal death between the intervention (2.9/1000) and control group (2.7/1000) [149]. Another study comparing fetal monitoring with hormonal profiling in 1191 pregnant women [150] was inconclusive (RR 3.19, 95\% CI 0.13-78.2).

\section{Assessment}

Only two studies are available on this intervention, both from developed countries, with no significant effects on stillbirth. As a consequence, the quality of the evidence is low and there is a strong recommendation against its adoption.

\section{Emergency obstetric care}

Many intrapartum stillbirths can be prevented with improved obstetric care, including emergency cesarean sections (c-sections). It is estimated that no fewer than $5 \%$ of all deliveries require a c-section due to maternal or fetal indicators $[151,152]$. These operations gained wide acceptance several decades ago, and therefore randomized trials are not available regarding their overall effect on stillbirths. Ecological analyses using countries as the data units show that, in low and middle-income countries, each one percentage point increase in the c-section rate is associated with a reduction of 1.6/1,000 in the intrapartum stillbirth rate; this is observed for c-section rates between 0 and $8 \%$, after which the relationship flattened out [153].

Instrumental deliveries using forceps or vacuum extraction account for $5-20 \%$ of all births in most highincome countries [154]. As is the case for c-sections, there are no RCTs of instrumental versus non-instrumental approaches for complicated deliveries, but trials comparing different types of instruments are available. A Cochrane review of seven RCTs comparing vacuum versus forceps reported a nonsignificant difference in perinatal mortality rate in the two methods (OR 0.80 ; 95\% CI 0.18-3.52), with extremely wide confidence limits [155]. Other studies also reported similar neonatal outcomes in the two groups [156]; [157].

\section{Assessment}

The quality of evidence in favor of c-sections or instrumental deliveries, compared to no such procedures, is moderate for stillbirths. Fifteen of the 40 studies reviewed on this topic were carried out in LMICs. RCTs for testing these approaches would be unethical. The recommendation is strong in favor of the interventions to prevent stillbirths. Excessively high c-section rates, however, should be avoided, as the frequency of preterm delivery and neonatal mortality both rise at rates of caesarean delivery of between $10 \%$ and $20 \%$ [158].

\section{Cesarean section for breech presentation}

Around 3-4\% of term singleton pregnancies are complicated by breech presentation. A total of six studies were identified, three of which were from LMICs. A Cochrane review of three RCTs comparing planned cesarean with planned vaginal delivery for breech infants showed a $71 \%$ reduction in perinatal or neonatal death, excluding fatal malformations (RR 0.29; 95\% CI 0.10-0.86) [159].

Assessment

The quality of evidence for preventing perinatal mortality is high and the recommendation for this intervention is strong. 


\section{Elective induction of labor for post-term delivery}

Induction of labor is advocated when vaginal delivery is the appropriate route of delivery and gestational age is 41 completed weeks or more. The Cochrane review comparing induction with expectant management consisting of twelve trials in low-risk women with intact membranes showed a nonsignificant reduction in stillbirths (RR 0.28; 95\% CI 0.05-1.67) and a significant impact on perinatal mortality (RR 0.30; 95\% CI 0.09-0.99)[160]. Only one of the 15 studies identified, which included controlled trials and observational studies, was from an LMIC.

\section{Assessment}

The quality of evidence for elective induction for postterm pregnancies is high for perinatal mortality, and the recommendation is strong in favor of the intervention in low-risk pregnant women at 41 weeks or more.

\section{Elective induction for women with term premature rupture of} membranes (PROM)

Another Cochrane review summarized the effect of induction in women with term, premature rupture of membranes. The pooled results of five RCTs suggest a reduction in fetal or perinatal mortality (OR 0.46; 95\% CI 0.13-1.66)[161]. No stillbirth outcomes were reported separately. Although this difference is not significant, there were significant improvements in other maternal and infant morbidity indicators.

\section{Assessment}

The quality of evidence for perinatal mortality is moderate given the wide uncertainty of the estimates, and the recommendation is weak in favor of induction. However, the recommendation is strong for improving other maternal and infant outcomes.

\section{Home delivery versus facility births}

Mothers in low- and, to a lesser extent, middle-income countries often do not have a choice about where to deliver their babies due to limited access to hospital care. The evidence from RCTs of home versus institutional birth is therefore derived from high-income countries. A Cochrane review [162] found a near-significant increase in risk of perinatal mortality (five trials; RR 1.83; 95\% CI 0.99-3.38) in home-like settings, compared to hospital deliveries. In Australia, an observational study [163] reported a significant reduction in perinatal mortality in delivering at 'alongside hospital' birth centers compared to hospital deliveries, but these results may have been affected by selection bias.

\section{Assessment}

The quality of evidence for perinatal mortality is moderate, and the recommendation is weak against home delivery.

\section{Intrapartum interventions to improve preterm survival}

This section reviews interventions for the mother when preterm labor has been initiated but the newborn has not yet been delivered. The main objective of these interventions is to improve the survival of preterm newborns.

\section{Prophylactic corticosteroid therapy in preterm labor}

Several agencies recommend that women in preterm labor before 34 weeks and those with preterm rupture of membranes (PROM) under 32 weeks should receive a single dose of either betamethasone or dexamethasone [164-166]. A Cochrane review showed use of corticosteroids in preterm labor reduced respiratory distress syndrome by $36 \%$ (RR $0.64,95 \%$ CI $0.56-0.72$ ), with a maximum effect at 32 weeks of gestation. Steroids also reduced cerebral hemorrhage by $70 \%$ (RR $0.30 ; 95 \%$ CI $0.14-0.66$ ), and neonatal mortality by $37 \%$ (RR $0.63 ; 95 \%$ CI 0.51-0.77) [167]. Four of the 21 studies reviewed are from LMICs.

\section{Assessment}

The quality of evidence for preventing preterm birth, morbidity and mortality is high and the intervention is strongly recommended.

\section{Antibiotics for preterm labor with premature rupture of membranes (PROM)}

Premature rupture of membranes is strongly associated with infection of the amniotic membranes, and this infection is independently related to preterm birth, [168] cerebral palsy and chronic lung disease [169]. A Cochrane review showed antibiotic treatment for PROM led to reductions in the proportion of babies born within 48 hours (RR 0.71; 95\% CI 0.58-0.87), and reduced neonatal infections (RR 0.68; 95\% CI 0.53-0.87), surfactant use (RR 0.83; 95\% CI 0.72-0.96), oxygen therapy (RR 0.88; 95\% CI 0.81-0.96), and abnormal cerebral ultrasound scans prior to hospital discharge (RR 0.82; 95\% CI 0.68-0.98) [170]. No differences in long-term follow-up were observed in the babies of intervention and control groups [171]. Five of the 22 studies reviewed are from LMICs.

\section{Assessment}

The quality of evidence on morbidity and mortality is high and the intervention is strongly recommended to be scaled up to improve preterm survival.

\section{Antibiotics for preterm labor with intact membranes}

Meta-analyses of RCTs of the use of antibiotics for preterm labor with intact membranes did not show improvements in preterm birth or in preterm morbidity (RR 1.03; 95\% CI 0.86-1.24) [172, 173]. In addition, in a seven year follow-up study, increased functional 
impairment was described in children whose mothers received erythromycin during labor [174].

\section{Assessment}

The quality of evidence is high, and there is a strong recommendation against antibiotics for preterm labor with intact membranes.

\section{Early versus delayed cord clamping in preterm newborns}

Immediate umbilical cord clamping, often within 15 seconds after delivery, is the current practice in most settings. A limited number of observational trials, most of which were conducted prior to 1980 [175-180] have given way to this belief. These trials reported higher rates of complications in preterm newborns with delayed cord clamping [181].

Two recent meta-analyses of outcomes among preterm newborns [182, 183] have challenged the benefit of immediate cord clamping. Benefits of delayed cord clamping included higher circulating blood volume during the first 24 hours of life, less need for blood transfusions and lower incidence of intraventricular hemorrhage $(\mathrm{RR}=0.53,95 \% \mathrm{CI}=0.35-0.79)$. There was also no significant increase in the risk of respiratory distress syndrome $(\mathrm{RR}=0.83,95 \% \mathrm{CI}=0.59-1.15)$ or necrotizing enterocolitis $(R R=2.08,95 \% \mathrm{CI}=0.52-8.37)$. Early cord clamping was associated with a nonsignificant increased mortality risk in babies compared to delayed clamping (RR1.40, 95\% CI 0.59-3.32, $\mathrm{p}=0.45$ ).

Four recent additional RCTs [184-187] were identified out of which only one study [186] reported relevant outcomes, showing no differences in mortality rates $(\mathrm{p}=1.00)$, intraventricular hemorrhage $(\mathrm{p}=0.67)$ or necrotizing enterocolitis $(p=1.00)$ between the early and delayed cord clamping groups.

\section{Assessment}

On the basis of available evidence, a 30-second delay in cord clamping is a safe intervention for preterm newborns. The quality of the evidence is high and the recommendation is strong in favor of this intervention. All studies are from high-income countries.

\section{Postnatal interventions to improve preterm survival}

This section reviews interventions aimed at improving the management of preterm newborns to reduce neonatal mortality.

\section{Neonatal resuscitation}

About 5-10\% of newborns require some form of resuscitation ranging from simple maneuvers to assisted ventilatory support [188]. Resuscitation is a difficult intervention to review given the obvious constraints in study design and locations. Given the paucity of data and limited studies in preterm newborns, we have also included relevant summary information from studies undertaken among term newborns and have summarized the information from preterm newborns, where available. The final recommendations are thus based on the biological plausibility and feasibility of the intervention.

The literature reviews four main areas of research regarding resuscitation:

\section{Modes of oxygen delivery and resuscitation techniques}

Different approaches have been used for oxygen delivery to the neonate (face mask, bag mask, nasal cannulae, CPAP) and these may vary in terms of achieving adequate oxygen saturation and hence dictate the need for further management (intubations, CPR etc). Only one study addressed preterm neonates exclusively [189] while others reported outcomes in all newborns.

Capasso et al [190] compared oxygen delivery on intermittent positive pressure with nasal cannulae versus facial mask in primary resuscitation of the newborn with moderate asphyxia, concluding that while resuscitation with nasal cannulae required fewer intubations and chest compressions, it had comparable survival rates and Apgar scores to normal controls. Palme et al [191] compared the efficiency of five widely used face masks on newborns with respect to the rates of leakage and frequency and ease of cleaning. They reported least leakage with circular silicone rubber mask ('Laerdal') and found it easier to clean, boil and autoclave.

Massawe et al [192] found that mouth-to-mask and bag-to-mask ventilation were comparable in terms of Apgar scores, heart rate and time to first breath. The only RCT on preterm newborns [189] evaluated the impact of nasal CPAP on BPD and the need for intubation, reporting a lower number of intubations in neonates given nasal CPAP on admission to the NICU compared to those who were not given nCPAP.

These results suggest that nasal CPAP is preferable to manual inflations in preterm newborns and may lower the need for chest compressions and intubations, whereas mouth-to-mask ventilation is equivalent to bag-to-mask ventilation for neonates. The American Academy of Pediatrics has initiated a Helping Baby's Breathe program (AAP, personal communication 2009) to enable lower level health workers to undertake standardized resuscitation in primary care settings. Validation studies of the protocol are underway.

Assessment

As for CPR, while guidelines for resuscitating preterm newborns exist there are a number of areas of uncertainty which require further research and refinement. On the basis of moderate-quality evidence, it appears that bag and mask resuscitation is adequate in most circumstances. 
However, further research is needed to establish the adequacy of this form of resuscitation in community settings in well designed, large scale studies.

\section{Use of cardio-pulmonary resuscitation (CPR) techniques and its long- and short-term outcomes}

The crucial role of neonatal resuscitation in immediate newborn care is well accepted [193]. On the other hand, its use has also been associated with adverse long- and short-term outcomes possibly due to survival of severely affected newborns [194-196]. Given that RCTs of such interventions are difficult, we reviewed seven observational studies from PubMed and one interventional study from Cochrane clinical trials. Segregated data for term and preterm neonates was available for two studies, whereas other authors did not separate these two groups.

Vakrilova et al [197] discussed the need of delivery room cardio-pulmonary resuscitation (CPR) in VLBW and ELBW neonates and reported that birth weight and gestational age are the most important factors, determining the intensity of delivery room CPR and the prognosis in newborns of $<1500$ g. Multiple studies reported the long-term outcomes including language symmetry, attention shift, visual attention, neuropsychological sequela and social and educational adjustments. While language symmetry and attention shift [196] were impaired in the individuals given CPR at birth, there was no difference between the resuscitated and non resuscitated groups in terms of other parameters for long-term outcomes [195, 196, 198, 199]. Dorfsman et al [200] compared two thumb technique of neonatal CPR versus American Heart Association recommended two finger technique. He reported that TT (two thumb) chest compression produced higher MAP, systolic and diastolic blood pressures when compared with TF (two finger) chest compression technique during a clinically relevant duration of prolonged CPR.

Sanchez-Torres et al [194] evaluated the impact of CPR provided in delivery room on survival and short term neurological outcomes in preterm infants. The infants receiving $\mathrm{CPR}$ and those infants who did not were comparable in terms of mortality, NEC, IVH and BPD. However the infants undergoing CPR needed surfactant and oxygen more frequently. On the other hand Deulofeut et al [201] reported higher rates of mortality, IVH and periventricular leucomalacia in neonates who were provided CPR at birth.

\section{Assessment}

While it is entirely appropriate to resuscitate preterm newborns, there are a number of issues that require further research as the current quality of the evidence is low. These include appropriate techniques and duration for $\mathrm{CPR}$ in preterm newborns and understanding intermediate- and long-term outcomes.

\section{Room air (versus 100\% oxygen) for resuscitation}

The optimum oxygen concentration required for newborn resuscitation has been the subject of investigation [202]. While 100\% oxygen has been traditionally used for all cyanotic infants [203], reports of increasing incidence of hypoxic ischemic encephalopathy (HIE), as well as other secondary outcomes, have made its use debatable. High oxygen levels were also associated with adverse outcomes like high oxidative stress [204] and increased incidence of leukemia [205].

It has been proposed that room air is as effective as $100 \%$ oxygen in overcoming neonatal asphyxia, [188] and several studies and systematic reviews addressed this issue [202, 203, 206]; [188, 204, 207-210].

Three intervention studies on preterm infants [211213], all from high-income settings, reported similar mortality and morbidity rates, including BPD, among those resuscitated with room air or $100 \%$ oxygen $(\mathrm{p}=0.95$ for NMR) [211], $\mathrm{p}=0.71$ for NMR [212].

Studies which did not separate term and preterm newborns compared $100 \%$ oxygen with room air, concluding either that outcomes are similar in both groups, or that the room air group has advantages in terms of morbidity and mortality [202, 203, 206]. Saugstad et al [214] also reported no differences in neurodevelopmental outcomes between neonates resuscitated with room or $100 \%$ oxygen and this finding has been replicated in a recent population based study by Hellstrom-Westas et al. [215].

\section{Assessment}

These studies indicate the use of room air is comparable to $100 \%$ oxygen with respect to primary neonatal outcomes with some ostensible benefits. The overall quality of evidence is high and this intervention can be recommended as a standard approach to resuscitating preterm neonates.

\section{Provision of facilities and training health professionals in neonatal resuscitation}

Many studies confirm that training programs for neonatal resuscitation are vital for survival [193, 216, 217].

Impact on preterm infants was observed in three studies where training programs led to significant reductions in terms of mortality and morbidity [218, 219, 220]. Specialized neonatal resuscitation teams have also played an important role in reducing preterm neonatal morbidity and mortality [221].

Additional studies, mostly observational, document the impact of training programs on all newborns, either term or preterm. There is ample documentation on the impact 
of such programs on improving the performance and technical abilities of health professionals, and on reducing neonatal morbidity and mortality rates [219, 222-239]. Similar outcomes were also observed by the employment of specialized neonatal resuscitation teams [221, 240, 241].

Finally, large-scale studies support the effectiveness of resuscitation programs. Sen et al [217] demonstrated a $21 \%$ reduction in mortality after a sick newborn care unit was set up in Kolkata that included resuscitation facilities. Enweronu-Laryea et al [242] reported similar effect of improved neonatal care facilities on neonatal survival in Ghana which provided improved obstetric services, referral systems, well developed neonatal units and trained staff.

\section{Assessment}

While specific data on the benefit of resuscitation training programs on survival of preterm infants is limited, it is plausible that adequately trained health professionals and neonatal resuscitation programes are also effective in reducing asphyxia-related preterm mortality as well as reducing complications such as neurodevelopmental delay, NEC and BPD. Given the large number of observational studies carried out under diverse settings, the quality of the evidence is judged to be moderate. This intervention is recommended with the provision that these outcomes be evaluated in large-scale effectiveness settings.

\section{Vitamin A supplementation in preterm neonates}

Vitamin A is involved in the growth and differentiation of various body cells including those of the respiratory, gastrointestinal and immune systems. Preterm infants are deficient in vitamin $\mathrm{A}$ due to inadequate hepatic stores and the inability to tolerate routine oral supplementation [243, 244].

A 2007 Cochrane review of very low birth weight infants showed a significant but small reduction in death or oxygen use at one month $[R R=0.93 ; 95 \%$ CI $0.88,0.99]$ in infants receiving intravenous vitamin A compared to placebo [243]. There were also nonsignificant reductions in nosocomial infection and neurodevelopmental delays at 18 to 36 months of age.

The recent Lancet Nutrition series identified neonatal vitamin A supplementation in South Asia were associated with a significant reduction in infant mortality at 6 months [245]. From these recent trials of neonatal vitamin A supplementation, it was possible to obtain separate data for preterm infants from three RCTs [246-248]. and to conduct an additional meta-analysis. Neonatal vitamin A supplementation among preterm infants was associated with a nonsignificant reduction in infant mortality at 6 months of age (RR 0.87 ; 95\% CI 0.65, 1.17).

\section{Assessment}

The quality of evidence is moderate given the small number of studies including preterm infants and the uncertainty in estimates. WHO has recently commissioned three large prospective RCTs in community settings to evaluate the impact of neonatal Vitamin A supplementation. Given current knowledge, there is a weak recommendation against its use in preterm infants, but this may well change as the evidence accumulates.

\section{Antenatal and postnatal vitamin K supplementation in preterm infants}

Vitamin $\mathrm{K}$ is a fat-soluble vitamin crucial to the production of many proteins involved with the coagulation process. Since 1961 the Committee on Nutrition of the American Academy of Pediatrics has recommended that prophylactic vitamin $\mathrm{K}$ be administered parenterally to all newborns, primarily for preventing intracranial hemorrhage [249].

Vitamin $\mathrm{K}$ treatment of pregnant mothers before preterm delivery has also been proposed. A Cochrane review [250] evaluated five randomized or quasi-randomized trials of vitamin $\mathrm{K}$ administered parenterally or orally to women at risk of imminent preterm birth, none of which were from LMICs. The primary outcomes were neonatal mortality, neonatal neurological morbidity, as measured by the presence of periventricular haemorrhage $(\mathrm{PVH})$ on ultrasound during the first week of life, and long-term neurodevelopment. Antenatal vitamin K was associated with a nonsignificant reduction in all grades of PVH (RR 0.82, 95\% confidence interval (CI) 0.67-1.00) and in severe PVH (grades 3 and 4) (RR 0.75, 95\% CI 0.45-1.25) for babies receiving prenatal vitamin $\mathrm{K}$ compared with control babies. In a subsequent RCT by Liu et al [251], 90 pregnant women in preterm labor at less than 35 weeks of gestation received vitamin K1 $10 \mathrm{mg}$ per day injection intramuscularly or intravenously for 2-7 days, or no such treatment. The overall rates of PVH were 32 and $52 \%$, respectively $(\mathrm{p}=0.036)$, and the frequency of severe PVH was 5 and $20 \%$, respectively $(\mathrm{p}=0.038)$. Although the quality of the trials is variable and further studies are needed, these data suggest a possible role for antenatal maternal vitamin $\mathrm{K}$ administration as a means of reducing risks of PVH and mortality in preterm infants.

Evidence supporting the use of injectable vitamin $\mathrm{K}$ (phytomenadione) shortly after birth to prevent hemorrhage-related morbidity and mortality was accumulated before RCTs were widely adopted, being based on observational studies. The strongest evidence from high-income countries comes from periods in which concerns about the safety of vitamin $\mathrm{K}$ led to its reduced use in newborns; these periods were followed by increased incidence of hemorrhagic disorders [252]. 
However, the exact dose requirement and frequency in preterm infants remain uncertain. Due to ethical reasons recent RCTs did not include a placebo group, but compared different treatment modes, using vitamin $\mathrm{K}$ status as the primary outcome. [253, 254].

\section{Assessment}

The quality of the evidence for both antenatal and postnatal vitamin $\mathrm{K}$ use is moderate. There is a strong recommendation for postnatal vitamin $K$, and a weak recommendation in favor of antenatal vitamin $\mathrm{K}$ for women in premature labor.

\section{Postnatal zinc supplementation in preterm infants}

Zinc plays an important role in growth and immune function [255]. Zinc is the second most important micronutrient deficiency in infants after Iron [256]. Zinc deficiency has been reported to affect the growth of infants, especially those born preterm or small for gestational age [257].

Six studies addressed postnatal zinc supplementation in infants who were small at birth, but four of these apparently excluded preterm newborns and were not included in the present review [258-261].

One study [262] looked at postnatal zinc supplementation in very low birth weight infants $(<1500 \mathrm{~g})$, most of whom are likely preterm. There was a positive effect of supplementation on length gain, but not for weight or head circumference. There was also a positive effect on locomotor development.

A second study [263] assessed zinc supplementation in low birth weight infants $(<2500 \mathrm{~g})$ in a community based randomized controlled trial. The authors found that postnatal zinc supplementation is effective in reducing incidence of diarrheal episodes and helps in linear growth and weight gain in infants born with low birth weight.

\section{Assessment}

Notwithstanding the interesting findings in these studies, the overall quality of the evidence is low regarding the benefit of zinc supplementation in preterm infants, and there is a weak recommendation against the intervention until further studies with adequate samples and gestational age assessment are available.

\section{Postnatal selenium supplementation}

Selenium is involved in the human immune system and its deficiency can lead to impaired immunity [264, 265].

A Cochrane review comprising three RCTs, [266] assessed the effect of postnatal selenium supplementation on mortality and morbidity in preterm infants. Selenium was associated with a reduction in one or more episodes of sepsis after seven days $[R R=0.73(0.57,0.93)]$. However, no significant difference was seen in rates of mortality or oxygen use. There was a nonsignificant reduction in retinopathy of prematurity (any grade) among supplemented infants. The review concluded that postnatal selenium supplementation potentially reduced episodes of late onset neonatal sepsis but did not improve survival rates.

\section{Assessment}

While some experts have recommended selenium supplementation of preterm formulas (Klein 2002), the quality of the evidence is moderate due to the small number of studies, and there is a weak recommendation in favor of supplementation. Further studies are urgently needed.

\section{Chlorhexidine treatment on the cord}

Of the 4 million annual neonatal deaths, approximately $36 \%$ are attributable to infections [267] with the cord as a common portal of entry for organisms. The use of topical cord antiseptics has been proposed as a potential preventive measure [268]. Chlorhexidine appears to be particularly useful because of its wide-ranging activity against Gram-positive and Gram-negative bacteria [269], and the fact that it can be applied to the umbilical stump of the newborn as well as used for skin wiping and washing.

We identified two RCTs on the use of chlorhexidine on the umbilical stump. The first was restricted to preterm infants with gestational age $<34$ weeks and birth weight $<2500$ g [270], while the other included both term and preterm infants [271]. The Pezzati trial compared chlorhexidine to salicylic sugar powder for umbilical cord care in preterm infants in neonatal care units, showing that the incidence of bacterial colonization was lower with salicylic group compared to chlorhexidine. There were no deaths in this trial, nor was there a control group with traditional cord care.

In Nepal, a community based trial showed that chlorhexidine use was associated with a $24 \%$ nonsignificant reduction (95\% CI 0.55-1.04) in neonatal mortality compared to dry cord-care; among infants enrolled within the first 24 hours, mortality was significantly lower in the intervention group (RR 0.66; 95\% CI 0.46-0.95) [271].

Chlorhexidine can also be used to cleanse the skin of the newborn. A recent large community-based RCT trial in rural Nepal [272] included 17,000 term and preterm infants. The intervention did not significantly affect mortality rates in term infants. However, a statistically significant reduction (28\%) in mortality rates among low birth weight infants was documented $(\mathrm{RR}=0.72,95 \% \mathrm{CI}=0.55-0.95)$.

\section{Assessment}

Despite the interesting findings from these studies, the overall evidence for the benefits of chlorhexidine use 
among preterm infants is moderate and further trials are needed to validate impact before recommending this intervention for widespread use.

\section{Community case management of sepsis and pneumonia in preterm neonates}

The World Health Organization recommends parenteral antibiotic therapy in a health facility as the standard treatment for serious neonatal infections (i.e., septicemia, pneumonia, and meningitis) in LMICs [273]. However, this may not be the most feasible approach in low-income countries and alternative strategies may be needed [193]. Community case-management with antibiotics of neonatal sepsis and pneumonia has shown promising results [274]. The present review has examined the effect of this approach on the survival of sick preterm neonates.

Early studies of community management of neonatal sepsis did not include a sufficient number of preterm newborns for separate analyses [275]. In a similar study Datta et al [276] undertook a prospective controlled study of the case management of ARI in low birth weight infants, but did not distinguish preterm infants. They found a $64 \%$ reduction in case fatality due to ARI in the intervention area as compared to the control population, as well as declines of $24 \%$ (95\% CI 6\%-35\%) in the infant mortality rates and $58 \%$ in the pneumonia specific mortality rates.

The study of home-based newborn care by Bang et al. [233] conducted in rural India found that case fatality in preterm neonates declined by $69.5 \%$ (from 33.3 to $10.2 \%$, $\mathrm{p}<0.0001)$. Case fatality in preterm low birth weight neonates without sepsis who received only supportive care decreased from 28.2 to $11.5 \%$ ( $\mathrm{p}<0.01)$, and among those with sepsis who received supportive care and antibiotics decreased from $61 \%$ to $13.2 \%(\mathrm{p}<0.005)$.

\section{Assessment}

Available data on community-based case management of neonatal sepsis and pneumonia in LMICs make a compelling case for providing such care in circumstances where referral may not be possible. While the overall evidence is moderate due to the small number of studies reporting on results among preterm infants, additional evidence is provided by studies including newborns in general, whether term or preterm. There is a strong recommendation in favor of this intervention in appropriate settings.

\section{Kangaroo mother care (KMC)}

The kangaroo mother care (KMC) method was developed in the 1970's in Colombia in response to overcrowded neonatal care units [277]. This method includes three main components: 1) skin-to-skin contact-a newborn baby is kept in a prone position between the mother's breasts several hours a day; 2) exclusive on-demand breastfeeding; and 3) early hospital discharge with appropriate follow-up. KMC is aimed at low birth weight babies, usually born preterm. It is applied after these babies are stabilized in terms of temperature, respiratory function and feeding [278]. The method has been recently adapted to non-hospital settings [279].

A systematic review carried out in 2003 [278] was updated to incorporate recent trials [279-281]. Four RCTs associated KMC with a reduction in severe morbidity (pooled RR 0.51; 95\% CI 0.37-0.70). Five hospital-based studies reporting on neonatal mortality of infants under $2000 \mathrm{~g}$, showed a pooled RR of 0.64 (95\% CI 0.43-0.94). A community-based RCT in Bangladesh showed a significant reduction in neonatal mortality (RR 0.37; 95\% CI 0.16-0.86) when analyses were restricted to newborns weighing $2000 \mathrm{~g}$ or less, but the difference in infant mortality was not quite significant (RR 0.56; $95 \%$ CI $0.30-1.05)$. It should be noted that $40 \%$ of the infants in this trial did not have a birth weight measure, so this latter analyses should be interpreted with caution. All studies are from LMICs.

\section{Assessment}

There is a high level of evidence that hospital-based KMC is an effective method of preventing severe morbidity and mortality, especially in low- and middle-income countries. The intervention is inexpensive and feasible, and therefore strongly recommended for hospital settings.

On the other hand, the evidence on community-based KMC is restricted to a single study with less clear results. In addition, that study failed to reach compliance with the recommended practice, which raises issues about its feasibility for widespread implementation [279]. New research is needed on the best ways to scale up the intervention at a community level and for estimating its impact on morbidity and mortality.

\section{Early breastfeeding}

Breastfeeding has many beneficial effects, including protection against neonatal morbidity and mortality, [282-284] and long-term improvements in cognitive function $[285,286]$.

The composition of breast milk changes during the first week of life. Colostrum intake is particularly important due to its many antimicrobial properties [287]. Early breastfeeding ensures the infant's intake of colostrum is maximized, and also promotes the establishment of lactation by stimulating prolactin production.

The timely initiation of breastfeeding in the first hour of life is promoted by international organizations, such as UNICEF and WHO [288]. For preterm newborns, most of whom are unable to suckle until 34 weeks of gestational 
age or later, [284, 289, 290] early breastfeeding entails using a cup and spoon to administer expressed milk.

There is ample evidence from RCTs that early skin-toskin contact, as in kangaroo mother care, increases the duration of total and exclusive breastfeeding [278, 280, 291, 292]. Because early breastfeeding is associated with exclusive and total breastfeeding duration, and the latter with reduced morbidity and mortality, it is reasonable to expect that early breastfeeding will reduce these poor outcomes. However, only two observational studies conducted in Ghana and Nepal evaluated the effect of early breastfeeding on neonatal mortality, both showing that delayed initiation was associated with higher neonatal mortality [293, 294]. A third study from Egypt also reported increased diarrhea incidence in the first six months of life among babies who were put to the breast three or more days after birth [295].

The literature comparing breast milk against formula feeding in early life is more abundant than that comparing early versus late breastfeeding initiation. A recent systematic review [284] found two RCTs and three cohort studies, all showing significant protective effects of human milk on systemic infections and necrotizing enterocolitis. A separate 2003 meta-analysis of four RCTs showed preterm babies receiving human milk were less likely to develop necrotizing enterocolitis (RR 0.34; 95\% CI 0.12-0.99) than infants who received formula milk [283]. When a more recent study was added to this metaanalysis, [296] the pooled RR was equal to 0.28 (95\% CI 0.11-0.69).

\section{Assessment}

There is a high quality of evidence that breast milk has beneficial effects in the prevention of necrotizing enterocolitis and severe infections in preterm babies. On the other hand, the level of evidence of an association between early breastfeeding and neonatal mortality is only moderate. The intervention is strongly recommended to be scaled-up due to its multiple benefits.

\section{Thermal care immediately after birth}

The normal body temperature of a newborn baby is between 36.5 and $37.5^{\circ} \mathrm{C}$, and hypothermia refers to body temperature below $36.5^{\circ} \mathrm{C}$ [297]. Hypothermia is a danger sign in preterm babies, [298] and it has long been known that preventing heat losses in these babies improves survival [299]. Preterm babies are highly susceptible to hypothermia due to their low body fat, and this condition is highly prevalent in low- income countries [300-302].

A "warm chain" to prevent hypothermia in the newborn child includes 10 steps: 1 ) warm delivery room; 2) immediate drying; 3) skin-to-skin contact; 4) breastfeeding; 5) bathing and weighing postponed; 6) appropriate clothing/bedding; 7) mother and baby together; 8) warm transportation; 9) warm resuscitation; and 10) training and awareness raising [297]. Other methods to keep the baby's temperature include radiant heaters, polyurethane bags, cling films, thermal mattresses, incubators, and topical application of oil or paraffin-based ointments $[303,304]$.

Because RCTs of thermal care versus no thermal care would not be ethical, available studies compare different methods. A Cochrane review [305] concluded use of plastic wraps or bags, transwarmer mattresses, and early skin-to-skin contact, all kept preterm and/or low birth weight babies warmer compared to routine thermal care. Another Cochrane review compared incubators with radiant heaters in preterm babies [306], showing no differences in severe infections or deaths, although radiant heaters were associated with greater water loss.

Two of these interventions-use of plastic wraps and early skin-to-skin contact-are particularly relevant for LMICs, and were subjected to new meta-analyses. Three studies of skin-to-skin contact $[280,307,308]$ in low birth weight children were located, and the pooled RR of hypothermia was significantly lower in infants in the skin-to-skin group compared to those receiving routine care $(0.13 ; 0.07-0.24)$. Three trials [309-311] and one observational study [312] assessed mortality impact in preterm babies, all with small sample sizes. The overall RR was 0.62 (95\% CI 0.35-1.10). These four studies showed significant improvements in thermal control, as did another Indian trial for which mortality was not reported [313].

In addition, two recent community trials of essential newborn care packages showed hypothermia control can be feasibly scaled-up for home deliveries [314]; [315]. One of these compared a package including traditional skin-to-skin thermal care with a package including ThermoSpot, which is a liquid crystal sticker that indicates hypothermia by changing color. Hypothermia recognition and thermal care increased in both groups, but the ThermoSpot package did not show an advantage over the package of essential newborn care.

Three of the seven studies included in the two metaanalyses were from LMICs.

\section{Assessment}

The quality of the evidence supporting thermal control relative to absence of control is based on observational studies carried out in the distant past, and according to the GRADE guidelines is judged as moderate - even though RCTs would be unethical. Several different approaches were shown to provide adequate thermal control in RCTs. Of particular relevance to LMICs are skin-to-skin contact and plastic wraps, both of which are superior to routine thermal care in terms of keeping 
neonates warm. These provide high quality evidence. Comparisons of skin-to-skin contact relative to routine care suggest a possible impact on mortality, but the confidence interval is wide. The overall recommendation for skin-to-skin contact and plastic wraps is strong.

\section{Application of continuous distending pressure to the lung for respiratory distress syndrome (RDS)}

Continuous distending pressure (CDP) to the lung includes applying positive pressure via the nose or trachea or negative pressure around the chest, and is used to treat respiratory distress syndrome (RDS). In the absence of surfactant replacement therapy, CDP to the lung reduces the need for intubation and mechanical ventilation (pooled RR 0.72; 95\% CI 0.56-0.91) and decreases the composite outcome of death or respiratory failure (pooled RR 0.65; 95\% CI 0.52-0.81) [316]. However, CDP may increase the risk of pneumothorax (pooled RR 2.64; 95\% CI 1.39-5.04). Compared to late administration, early CDP results in a lower use of intubation and mechanical ventilation (RR 0.55; 95\% CI 0.32-0.96) [317].

Nasal CPAP refers to the application of CDP to the lungs via prongs placed in the nose and is a valid alternative to routine intubation and mechanical ventilation in treating RDS [318-324]. In a systematic review comparing prophylactic nCPAP to standard therapy among very preterm infants ( $<32$ weeks or $<1500 \mathrm{~g}$ ) that included two studies, no significant differences in rates of intubation, bronchopulmonary dysplasia, mortality, pneumothoraces or other morbidities were noted [325].

Nasal CPAP may be particularly useful in low-resource settings. In Fiji, a pre-evaluation and post-evaluation showed a $50 \%$ reduction in the need for mechanical ventilation among newborns with RDS after introduction of nCPAP [326]. A small non-randomized study in South Africa found nCPAP reduced mortality by $50 \%$ compared with oxygen alone for preterm newborns between 26 to 28 weeks gestation with RDS [327].

Even in the surfactant era, a multicenter trial of 610 infants between 25 and 28 weeks gestation randomized to either nCPAP or intubation and mechanical ventilation within 5 minutes of birth found no differences in the primary outcome of BPD or death [328], but fewer infants who received CPAP required oxygen at 28 days after birth. Pneumothorax was more frequent in the nCPAP group perhaps because they did not receive early surfactant.

Nasal CPAP is best delivered using bi-nasal prongs while the end expiratory pressure is generated by placing the expiratory limb of a constant flow circuit into water at a depth sufficient to generate the required pressure (bubble CPAP) [329-331]. Other methods are more expensive and may not be more effective [331-333].
Assessment

The quality of evidence of nCPAP for treatment of respiratory failure among preterm newborns to prevent death, bronchopulmonary dysplasia, or both is high and this modality is used routinely in developed countries. In addition, the quality of evidence for the use of nCPAP as an alternative to mechanical ventilation is high, making it particularly appealing in LMIC settings even though only two of the 29 studies reviewed are from such settings. The intervention is strongly recommended, however optimal delivery systems, interfaces and optimal pressures must be elucidated. Further, ensuring adequate support services such as managing airleak syndrome will be important prior to widespread implementation.

\section{Intravenous immune globulin (IVIG)}

Preterm neonates are deficient in immunoglobulins, particularly IgG, [334] and the use of non-specific, polyclonal intravenous immune globulin (IVIG) (normal human IgG immunoglobulin) has been advocated to prevent or treat neonatal infections.

A Cochrane meta-analysis reviewed 19 studies from different parts of the world that compared IVIG with placebo [335] in approximately five thousand preterm or low birth weight newborns. The use of prophylactic IVIG reduced sepsis (RR 0.85; 95\% CI 0.74-0.98), but did not significantly reduce all-cause mortality (RR $0.89 ; 0.75$ 1.05) or mortality due to infectious diseases (RR 0.83 ; 95\% CI 0.56-1.22). The same authors also reviewed nine RCTs restricted to neonates who had a suspected infection during their initial hospital stay [336]. Based on six trials, there was a borderline reduction in overall mortality in the IVIG group (RR 0.63; 95\% CI 0.40-1.00). Seven trials of newborns with confirmed infection showed IVIG did result in a statistically significant reduction in mortality (RR 0.55; 95\% CI 0.31-0.98). However, the authors identified methodological problems, such as lack of allocation concealment, lack of blinding in outcome assessment, high frequency of post-randomization exclusions and lack of long-term follow-up, and suggested further trials be conducted to confirm or refute the effectiveness of IVIG treatment.[336] More recent trials on this subject are not available.

\section{Assessment}

The level of evidence is high, but the intervention has a weak recommendation in favor of adoption. More information on dosing, potential risks[337] and long-term follow-up is needed before IVIG may be widely recommended. The following issues are of particular relevance to LMICs: feasibility (e.g., the need for cold storage and for intravenous administration); cost-benefit analyses; and ensuring formulations include standardization of proper levels of antibodies against prevalent infectious agents. 


\section{Surfactant replacement therapy for respiratory distress syndrome (RDS)}

A single dose of bovine, calf, human or synthetic surfactant to prevent RDS is associated with a decrease in neonatal mortality and chronic lung disease, or bronchopulmonary dysplasia (BPD) [338, 339]. Prophylactic use of surfactant is more effective than administration after RDS symptoms develop, but it is substantially more costly and benefits are limited to very preterm newborns (<30 weeks gestation) [340].

Rescue surfactant treatment provided within two hours of delivery, compared with later administration, is associated with decreases in neonatal mortality, chronic lung disease and chronic lung disease or death at 36 weeks [341]. Three to four doses of surfactant for preterm neonates appear to be more beneficial than single doses for prevention or treatment of RDS with respect to incidence of pneumothorax; however, differences in mortality were not statistically significant in this recent meta-analysis [342]. These findings are of particular relevance to LMICs, as treatment with surfactant within the first two hours of life may reduce mortality while requiring treatment of a substantially smaller number of neonates than the prophylaxis approach. Antenatal steroids are shown to be synergistic with surfactant replacement [343]. Therefore, it is possible that with optimal antenatal steroid coverage fewer neonates would require intubation and those receiving surfactant therapy may further improve their outcomes.

Natural surfactants, compared to synthetics, result in reduced mortality and pneumothorax [344]. Clinically significant differences between porcine and bovine surfactants have not been consistently demonstrated $[345,346]$. However, comparisons of natural surfactants to new synthetic surfactant preparations, which contain surfactant protein analogues, found no differences in mortality at 36 weeks, chronic lung disease, the combined outcome of mortality or chronic lung disease, or mortality at one year [347, 348]. Synthetic forms of surfactant exhibit more temperature stability and have the potential for scaling up production to lower costs. These features are particularly relevant in LMICs.

Surfactant is administered to the newborn lung after endotracheal intubation, which is associated with significant cost and potential morbidity. Alternative surfactant delivery systems have the potential to greatly improve access to and safety of this intervention in both LMICs and HICs. Attempts at nebulizing surfactants have been unsuccessful [345, 349]. More recently, surfactant instilled into the posterior pharynx is shown to be feasible without intubation and to improve lung function, yet further research is needed to assess the efficacy of such an approach [350-352].
Assessment

The quality of evidence for using surfactant replacement therapy to prevent or treat respiratory failure, bronchopulmonary dysplasia and/or death among preterm newborns is high and this modality is used routinely in HICs. Although only three of the 50 studies reviewed are from LMICs, the intervention is strongly recommended. However, multiple challenges remain and should be addressed prior to widespread implementation: identification of optimal dosing and delivery systems, development of low-cost preparations, and refined techniques to identify high-risk newborns who may benefit from surfactant therapy.

\section{Community-based packages of interventions}

So far, this review was centered on standalone biological, behavioral or health care interventions. Communitybased strategies in LMICs, however, often combine several different interventions, making it impossible to disentangle their individual effects. Here we review studies of community-based intervention packages that provide maternal and newborn care.

Nearly half of the world's 124 million births that take place every year occur at home. In South Asia and subSaharan Africa-the two regions with the highest neonatal mortality rates in the world- $64 \%$ of the births take place at home. Most of these births are without skilled attendance. In these areas, the most promising short-term strategy for providing newborn care entails training and outfitting community health workers. Bhutta and colleagues conducted a thorough review of the literature on community-based interventions aimed at reducing perinatal and neonatal morbidity and mortality [353]. All six trials included in this review were from South Asia and had a significant impact on newborn health. Similar studies were not available from other regions of the world.

The classic studies of Bang and associates in Gadchiroli, India, showed an important impact of home-based care by trained village health workers, who provided antenatal care, managed birth asphyxia, hypothermia, neonatal sepsis and secured the care of preterm and low birth weight newborns. This low-cost, sustainable intervention reduced case-fatality of neonatal sepsis, leading to a $71 \%$ reduction in perinatal mortality and a $62 \%$ reduction in neonatal mortality rates [274, 354-356].

In Nepal, a RCT evaluated the impact of a participatory intervention involving women's groups convened by a female facilitator. During these sessions, local problems were identified and possible solutions proposed. Women in the intervention clusters had more antenatal care, institutional deliveries and, skilled birth attendance, and hygienic care than those in the control areas. These changes were accompanied by significant reductions in 
neonatal and maternal mortality in the study areas (adjusted odds ratios 0.70, 95\% C.I. 0.53-0.94 and 0.22, 95\% C.I. 0.05-0.90, respectively) [357].

In Sind, Pakistan, a RCT was conducted in which traditional birth attendants were trained and received disposable delivery kits, and female health workers made the connection of traditional services with health institutions. Women in the intervention communities had more antenatal care and were delivered more often with safe kits. The odds ratio for perinatal mortality in the intervention areas was 0.70 (0.59-0.82) [142].

In a pilot randomized study in Pakistan, female health workers and traditional birth attendants received training in a package of community-based intervention for improving perinatal care. The proportion of deliveries by skilled heath attendants increased in the intervention villages and there were significant reductions in the rates of stillbirth and neonatal death [140].

Another recent RCT conducted in Bangladesh compared three groups: a home-care program (consisting of antenatal and post-natal home visits by community health workers who provided care directly to mothers and newborns), a community-care program (including group sessions on birth and newborn-care preparedness and promotion of careseeking from qualified providers) and a comparison group. In the last 6 months of the 30 month intervention, the neonatal mortality was reduced by $34 \%$ in the home-care program (adjusted relative risk 0.66, 95\% C.I. 0.47-0.93) relative to the comparison group [314]. No impact was observed in the community-care group.

Finally, a RCT conducted in Uttar Pradesh, India, entailed the comparison of three groups. The control group received the usual maternal and newborn services; the first intervention group received a preventive package of essential newborn care interventions, including birth preparedness, clean delivery and cord care, thermal care (with skin-to-skin contact), breastfeeding promotion, and training on recognition of danger signs; the second intervention group received the same basic package described above plus the use of a liquid crystal hypothermia indicator. Both control groups showed improvements in birth preparedness, hygienic delivery, thermal care, umbilical cord care, skin care, and breastfeeding. In comparison with the control group, neonatal mortality was reduced by $54 \%$ in the essential newborn care group (rate ratio 0.46, 95\% C.I. 0.35-0.60) and by $52 \%$ in the essential newborn care plus ThermoSpot group (rate ratio 0.48 , 95\% C.I. 0.35-0.66) [315].

\section{Assessment}

Taken together, these six trials in South Asian countries strongly suggest that community-based programs, particularly those that provide maternal and newborn care by trained village health workers, may have a substantial impact in reducing stillbirth and neonatal mortality. The quality of the evidence is high, and there is a strong recommendation for their implementation in settings where the vast majority of deliveries occur at home.

None of these trials reported impact on preterm deliveries. Also, trials from other regions of the worldparticularly sub-Saharan Africa-are urgently needed.

\section{Research questions: development of interventions for preterm birth and stillbirth}

The review of the literature, summarized above, led to the identification of over 100 research questions. These questions were analyzed and prioritized by workgroups at the International Conference on Prematurity and Stillbirth and will be addressed in a forthcoming Child Health and Nutrition Research Initiative (CHNRI) paper. Workgroup participants are leading international experts in the areas of maternal, fetal newborn and child health.

\section{Conclusion}

After reviewing 2,000 studies on more than 80 interventions, 21 preterm birth and stillbirth interventions are strongly recommended in LMICs. Each of these has high quality evidence it is effective in low-income settings. This extensive review identifies eight proven effective interventions for preventing stillbirth in LMICs and 11 for improving the survival of the preterm neonate. Only two available interventions are strongly recommended for preventing preterm birth.

Additional research must be conducted on many other promising interventions before they can be recommended for scale-up in LMICs. Additional research on the cost-effectiveness of these interventions is also needed, as it was outside the scope of this analysis. It must also be noted that many interventions not strongly recommended for these specific outcomes are indeed recommended for other related maternal and child health outcomes. A summary of these findings, based on the GRADE assessments, is provided in Table 3. The next article discusses scale-up of proven interventions, and addresses delivery in the context of maternal, newborn and child health [3].

\footnotetext{
Acknowledgements

This report was supported by the Global Alliance to Prevent Prematurity and Stillbirth, an initiative of Seattle Children's, through a grant from the Bill \& Melinda Gates Foundation. We thank Catherine Waszak for her superb administrative support

This article has been published as part of BMC Pregnancy and Childbirth Volume 10 Supplement 1, 2010. The full contents of this report are available online at http://www.biomedcentral.com/1471-2393/10?issue=S1. We thank all members of the GAPPS Review Group for their contributions and review of the seven articles in this report, and list them here in alphabetical order: Fernando $C$ Barros, Maneesh Batra, Zulfiqar Ahmed Bhutta, Anne-Véronique Fajon, Michael G Gravett, Thomas N Hansen, Maureen Kelley, Joy E Lawn, Toni M Nunes, Craig E Rubens, Megan Sather, Cynthia Stanton, Cesar G Victora, and Rachel Zaentz.
} 


\section{Author details}

'Post-Graduate Course in Health and Behaviour, Universidade Católica de Pelotas, Brazil

2Division of Women \& Child Health, Aga Khan University, Karachi 74800

Pakistan

${ }^{3}$ Divison of Neonatology, Department of Pediatrics, University of Washington School of Medicine, Seattle, Washington, USA

${ }^{4}$ Seattle Children's, Seattle, Washington, USA

${ }^{5}$ Universidade Federal de Pelotas, Pelotas 96001-970, Brazil

${ }^{6} \mathrm{Global}$ Alliance to Prevent Prematurity and Stillbirth, an initiative of Seattle Children's, Seattle, Washington, USA

'Department of Pediatrics at University of Washington School of Medicine, Seattle, Washington, USA

\section{Authors' contributions}

FB wrote sections relating to prevention of preterm birth, ZB wrote sections on stillbirth, and MB wrote sections on improving survival of preterm newborns. CV contributed to the review and coordination of all sections. TH contributed to the section on preterm newborn interventions. CR helped draft and conceive of this article as part of a global report on preterm birth and stillbirth, and participated in its design, coordination, and review. The article was reviewed by all authors.

\section{Competing interests}

The authors declare that they have no competing interests.

Published: 23 February 2010

\section{References}

1. Lawn JE, Gravett MG, Nunes TM, Rubens CE, Stanton C, and GAPPS Review Group: Global report on preterm birth and stillbirth (1 of 7): Definitions, description of the burden and opportunities to improve data. BMC Pregnancy and Childbirth 2010, 10 (Suppl 1):S1.

2. Gravett MG, Rubens CE, Nunes TM, and GAPPS Review Group: Global report on preterm birth and stillbirth (2 of 7): discovery science. BMC Pregnancy and Childbirth 2010, 10 (Suppl 1):S2

3. Victora CG, Rubens CE, and the GAPPS Review Group: Global report on preterm birth and stillbirth (4 of 7): delivery of interventions. BMC Pregnancy and Childbirth 2010, 10 (Suppl 1):S4

4 Sather M, Fajon AV, Zaentz R, Rubens CE, and the GAPPS Review Group: Global report on preterm birth and stillbirth (5 of 7): advocacy barriers and opportunities. BMC Pregnancy and Childbirth 2010, 10 (Suppl 1):S5.

5. Kelley MK, Rubens CE, and the GAPPS Review Group: Global report on preterm birth and stillbirth (6 of 7): ethical considerations BMC Pregnancy and Childbirth 2010, 10 (Suppl 1):S6.

6. Rubens CE, Gravett MG, Victora CG, Nunes TM, and the GAPPS Review Group: Global report on preterm birth and stillbirth (7 of 7): mobilizing resources to accelerate innovative interventions BMC Pregnancy and Childbirth 2010, 10 (Suppl 1):S7.

7. Atkins D, Best D, Briss PA, Eccles M, Falck-Ytter Y, Flottorp S, Guyatt GH, Harbour RT, Haugh MC, Henry D et al: Grading quality of evidence and strength of recommendations. BMJ (Clinical research ed 2004, 328(7454):1490

8. World Health Organization: WHO Handbook for guideline development. Geneva: WHO; 2008

9. Conde-Agudelo A, Rosas-Bermudez A, Kafury-Goeta AC: Birth spacing and risk of adverse perinatal outcomes: a meta-analysis. Jama 2006, 295(15):1809-1823.

10. Glasier A, Gulmezoglu AM, Schmid GP, Moreno CG, Van Look PF: Sexual and reproductive health: a matter of life and death. Lancet 2006, 368(9547):1595-1607.

11. Cleland J, Bernstein S, Ezeh A, Faundes A, Glasier A, Innis J: Family planning: the unfinished agenda. Lancet 2006, 368(9549):1810-1827.

12. World Health Organization: Report of a WHO Technical Consultation on Birth Spacing. Geneva: WHO; 2005

13. Stephansson O, Dickman PW, Cnattingius S: The influence of interpregnancy interval on the subsequent risk of stillbirth and early neonatal death. Obstet Gynecol 2003, 102(1):101-108.

14. Kallan JE: Effects of interpregnancy intervals on preterm birth, intrauterine growth retardation, and fetal loss. Soc Bio/ 1992, 39(3-4):231-245

15. DaVanzo J, Hale L, Razzaque A, Rahman M: Effects of interpregnancy interval and outcome of the preceding pregnancy on pregnancy outcomes in Matlab, Bangladesh. BJOG 2007, 114(9):1079-1087.

16. Shah PS, Zao J: Induced termination of pregnancy and low birthweight and preterm birth: a systematic review and meta-analyses. BJOG 2009, 116(11):1425-1442.

17. Medical Research Council: Prevention of neural tube defects: results of the Medical Research Council Vitamin Study. MRC Vitamin Study Research Group. Lancet 1991, 338(8760):131-137.

18. Darmstadt GL, Bhutta ZA, Cousens S, Adam T, Walker N, de Bernis L: Evidence-based, cost-effective interventions: how many newborn babies can we save? Lancet 2005, 365(9463):977-988

19. Scholl TO, Hediger ML, Schall Jl, Khoo CS, Fischer RL: Dietary and serum folate: their influence on the outcome of pregnancy. The American journal of clinical nutrition 1996, 63(4):520-525.

20. Shaw GM, Carmichael SL, Nelson V, Selvin S, Schaffer DM: Occurrence of low birthweight and preterm delivery among California infants before and after compulsory food fortification with folic acid. Public Health Rep 2004 119(2):170-173.

21. Bukowski R, Malone FD, Porter F, Nyberg DA, Comstock C, Hankins G, Eddleman K, Gross S, Dugoff L, Craigo S: Preconceptional folate prevents preterm delivery. American Journal of Obstetrics and Gynecology 2007, 197(6S):3-3.

22. Lumley J, Watson L, Watson M, Bower C: Periconceptional supplementation with folate and/or multivitamins for preventing neural tube defects. Cochrane database of systematic reviews (Online) 2001(3):CD001056.

23. Rehfuess E, Mehta S, Pruss-Ustun A: Assessing household solid fuel use: multiple implications for the Millennium Development Goals. Environ Health Perspect 2006, 114(3):373-378

24. Boy E, Bruce N, Delgado H: Birth weight and exposure to kitchen wood smoke during pregnancy in rural Guatemala. Environ Health Perspect 2002, 110(1):109-114.

25. World Health Organization: Indoor air pollution from solid fuels and risk of low birth weight and stillbirth. Geneva: World Health Organization; 2005.

26. Mavalankar DV, Trivedi CR, Gray RH: Levels and risk factors for perinatal mortality in Ahmedabad, India. Bull World Health Organ 1991, 69(4):435-442.

27. Mishra V, Retherford RD, Smith K: Cooking smoke and tobacco smoke as risk factors for stillbirth. Int J Environ Health Res 2005, 15:397-410.

28. Siddiqui A, Gold E, Brown K, Lee K, Bhutta Z: Preliminary analyses of indoor air pollution and low birth weight (LBW) in Southern Pakistan. In Indoor air pollution from solid fuels and risk of low birth weight and stillbirth Report from a symposium held at the Annual Conference of the International Society for Environmental Epidemiology (ISEE): 2005: Johannesburg, South Africa: 2005:11-14.

29. Smith KR, McCracken JP, Thompson L, Edwards R, Shields KN, Canuz E, Bruce $\mathrm{N}$ : Personal child and mother carbon monoxide exposures and kitchen levels: Methods and results from a randomized trial of woodfired chimney cookstoves in Guatemala (RESPIRE). J Expo Sci Environ Epidemio/ 2009.

30. Dherani M, Pope D, Mascarenhas M, Smith KR, Weber M, Bruce N: Indoor air pollution from unprocessed solid fuel use and pneumonia risk in children aged under five years: a systematic review and meta-analysis. Bull World Health Organ 2008, 86(5):321-416.

31. Smith KR, Samet JM, Romieu I, Bruce N: Indoor air pollution in developing countries and acute lower respiratory infections in children. Thorax 2000 55(6):518-532

32. Kirkwood BR, Gove S, Rogers S, Lob-Levyt J, Arthur P, Campbell H: Potential interventions for the prevention of childhood pneumonia in developing countries: a systematic review. Bull World Health Organ 1995, 73(6):793-798

33. Jha P, Ranson MK, Nguyen SN, Yach D: Estimates of global and regional smoking prevalence in 1995, by age and sex. American journal of public health 2002, 92(6):1002-1006.

34. Jha P, Chaloupka FJ, Moore J, Gajalakshmi V, Gupta PC, Peck R, Asma S, Zatonski W: Tobacco addiction. In Disease Control Priorities in Developing Countries (2nd Edition). New York: Oxford University Press; 2007:869-886.

35. Bloch M, Althabe F, Onyamboko M, Kaseba-Sata C, Castilla EE, Freire S, Garces AL, Parida S, Goudar SS, Kadir MM et al: Tobacco use and secondhand smoke exposure during pregnancy: an investigative survey of women in 9 developing nations. American journal of public health 2008, 98(10):1833-1840.

36. Santos IS, Barros AJ, Matijasevich A, Tomasi E, Medeiros RS, Domingues MR Bertoldi AD, Barros FC, Victora CG: Mothers and their pregnancies: a comparison of three population-based cohorts in Southern Brazil. Cadernos de saude publica / Ministerio da Saude, Fundacao Oswaldo Cruz, 
Escola Nacional de Saude Publica 2008, 24 (Suppl 3):S381-389.

37. Fourn L, Ducic S, Seguin L: Smoking and intrauterine growth retardation in Republic of Benin. J Epidemiol Community Health 1999, 53(7):432-433.

38. Gao W, Paterson J, Carter S, Percival T: Risk factors for preterm and small-forgestational-age babies: a cohort from the Pacific Islands Families Study Journal of paediatrics and child health 2006, 42(12):785-792.

39. Goldenberg RL, Culhane JF, lams JD, Romero R: Epidemiology and causes of preterm birth. Lancet 2008, 371(9606):75-84.

40. Kramer MS: Intrauterine growth and gestational duration determinants. Pediatrics 1987, 80(4):502-511.

41. Lumley J, Oliver SS, Chamberlain C, Oakley L: Interventions for promoting smoking cessation during pregnancy. Cochrane database of systematic reviews (Online) 2004(4):CD001055.

42. Crawford JT, Tolosa JE, Goldenberg RL: Smoking cessation in pregnancy: why, how, and what next. Clinical obstetrics and gynecology 2008 51(2):419-435

43. Hogberg $L, C$ nattingius $S$ : The influence of maternal smoking habits on the risk of subsequent stillbirth: is there a causal relation? BJOG 2007, 114(6):699-704

44. Black RE, Allen LH, Bhutta ZA, Caulfield LE, de Onis M, Ezzati M, Mathers C, Rivera J: Maternal and child undernutrition: global and regional exposures and health consequences. Lancet 2008, 371(9608):243-260.

45. Kramer MS, Kakuma R: Energy and protein intake in pregnancy. Cochrane database of systematic reviews (Online) 2003(4):CD000032.

46. Tamura T, Goldenberg RL, Freeberg LE, Cliver SP, Cutter GR, Hoffman HJ: Maternal serum folate and zinc concentrations and their relationships to pregnancy outcome. The American journal of clinical nutrition 1992 56(2):365-370

47. Hendler I, Goldenberg RL, Mercer BM, lams JD, Meis PJ, Moawad AH, MacPherson CA, Caritis SN, Miodovnik M, Menard KM et al: The Preterm Prediction Study: association between maternal body mass index and spontaneous and indicated preterm birth. Am J Obstet Gynecol 2005 , 192(3):882-886

48. Scholl TO: Iron status during pregnancy: setting the stage for mother and infant. The American journal of clinical nutrition 2005, 81(5):12185-1222S.

49. Neggers Y, Goldenberg RL: Some thoughts on body mass index, micronutrient intakes and pregnancy outcome. J Nutr 2003, 133(5 Suppl 2):17375-1740S

50. Haider BA, Bhutta ZA: Multiple-micronutrient supplementation for women during pregnancy. Cochrane database of systematic reviews (Online) 2006(4):CD004905

51. Fawzi MC, Msamanga Gl, Urassa W, Hertzmark E, Petraro P, Willet WC, Spiegelman D: Vitamins and perinatal outcomes among HIV-negative women in Tanzania The New England journal of medicine 2007 356:1423-1431

52. Shankar AH, Jahari AB, Sebayang SK, Aditiawarman, Apriatni M, Harefa $B$ Muadz H, Soesbandoro SD, Tjiong R, Fachry A et al: Effect of maternal multiple micronutrient supplementation on fetal loss and infant death in Indonesia: a double-blind cluster-randomised trial. Lancet 2008 , 371(9608):215-227.

53. Bhutta ZA, Haider BA: Maternal micronutrient deficiencies in developing countries. Lancet 2008, 371(9608):186-187.

54. Yaqoob M, Menezes E, Soomro T, Haws RA, Darmstadt G, Bhutta Z: Reducing stillbirths: behavioural and nutritional interventions before and during pregnancy. BMC Pregnancy \& Childbirth 20099 (Suppl 1): S3.

55. Christian P, Khatry SK, Katz J, Pradhan EK, LeClerq SC, Shrestha SR, Adhikari RK, Sommer A, West KP, Jr.: Effects of alternative maternal micronutrient supplements on low birth weight in rural Nepal: double blind randomised community trial. BMJ 2003, 326(7389):571.

56. Osrin D, Vaidya A, Shrestha Y, Baniya RB, Manandhar DS, Adhikari RK, Filteau S, Tomkins A, Costello AM: Effects of antenatal multiple micronutrient supplementation on birthweight and gestational duration in Nepal: double-blind, randomised controlled trial. Lancet 2005, 365(9463):955-962.

57. Christian PS, Darmstadt GL, Wu L, Khatry SK, Leclerg SC, Katz J. West KP, Jr. Adhikari RK: The impact of maternal micronutrient supplementation on early neonatal morbidity in rural Nepal: a randomized, controlled, community trial. Arch Dis Child Fetal Neonatal Ed 2007.

58. Haider ea: In press. Int J Epidemiol 2010.

59. World Health Organization: The prevalence of anemia in women: a tabluation of available information. Geneva: WHO; 1992.

60. Pena-Rosas JP. Viteri FE: Effects of routine oral iron supplementation with or without folic acid for women during pregnancy. Cochrane database of systematic reviews (Online) 2006, 3:CD004736.

61. Menendez C, Todd J, Alonso PL, Francis N, Lulat S, Ceesay S, M'Boge B, Greenwood BM: The effects of iron supplementation during pregnancy, given by traditional birth attendants, on the prevalence of anaemia and malaria. Trans R Soc Trop Med Hyg 1994, 88(5):590-593.

62. Valee JB, Flachuk KH: The biochemical basis of zinc physiology. Physiology Review 1993, 73:79-118

63. Sandstead HH, Smith JC, Jr.: Deliberations and evaluations of approaches, endpoints and paradigms for determining zinc dietary recommendations. J Nutr 1996, 126(9 Suppl):2410S-2418S.

64. Mahomed K, Bhutta Z, Middleton P: Zinc supplementation for improving pregnancy and infant outcome. Cochrane database of systematic reviews (Online) 2007(3).

65. Hess SY, King JC: Effects of maternal zinc supplementation on pregnancy and lactation outcomes. Food Nutr Bull 2009, 30(1 Suppl):S60-78.

66. Kumar D, Zourlas PA, Barnes AC: In Vitro and in Vivo Effects of Magnesium Sulfate on Human Uterine Contractility. Am J Obstet Gynecol 1963, 86:1036-1040

67. Makrides M, Crowther CA: Magnesium supplementation in pregnancy Cochrane database of systematic reviews (Online) 2001 (4):CD000937.

68. Doyle LW, Crowther CA, Middleton P, Marret S: Magnesium sulphate for women at risk of preterm birth for neuroprotection of the fetus. Cochrane Database Syst Rev 2007(3):CD004661.

69. Villar J, Say L, Shennan A, Lindheimer M, Duley L, Conde-Agudelo A, Merialdi M: Methodological and technical issues related to the diagnosis, screening, prevention, and treatment of pre-eclampsia and eclampsia. International journal of gynaecology and obstetrics: the official organ of the International Federation of Gynaecology and Obstetrics 2004, 85 Suppl 1:S28-41.

70. Villar J, Belizan JM, Fischer PJ: Epidemiologic observations on the relationship between calcium intake and eclampsia. International journal of gynaecology and obstetrics: the official organ of the International Federation of Gynaecology and Obstetrics 1983, 21(4):271-278.

71. Hofmeyr GJ, Atallah AN, Duley L: Calcium supplementation during pregnancy for preventing hypertensive disorders and related problems (Review). Cochrane database of systematic reviews (Online) 2006(3).

72. Kumar A, Devi SG, Batra S, Singh C, Shukla DK: Calcium supplementation for the prevention of pre-eclampsia. International journal of gynaecology and obstetrics: the official organ of the International Federation of Gynaecology and Obstetrics 2009, 104(1):32-36.

73. Simopoulos AP: Omega-3 fatty acids in health and disease and in growth and development. The American journal of clinical nutrition 1991, 54(3):438-463.

74. Makrides M, Duley L, Olsen SF: Marine oil, and other prostaglandin precursor, supplementation for pregnancy uncomplicated by preeclampsia or intrauterine growth restriction. Cochrane database of systematic reviews (Online) 2006, 3:CD003402.

75. Horvath A, Koletzko B, Szajewska H: Effect of supplementation of women in high-risk pregnancies with long-chain polyunsaturated fatty acids on pregnancy outcomes and growth measures at birth: a meta-analysis of randomized controlled trials. Br J Nutr 2007, 98(2):253-259.

76. Pattison N, McCowan L: Cardiotocography for antepartum fetal assessment. Cochrane Database of Systematic Reviews; 1999(1):CD001068.

77. Flynn A, Kelly J, Mansfield H, Needham P, O'Conor M, Viegas O: A Randomized Controlled Trial of Non-stress Antepartum Cardiotocography Br J Obstet Gynaecol 1982, 89(6):427-433.

78. Freeman RK, Anderson G, Dorchester W: A prospective multi-institutional study of antepartum fetal heart rate monitoring. II. Contraction stress test versus nonstress test for primary surveillance. Am J Obstet Gynecol 1982. 143(7):778-781.

79. Hofmeyr GJ, Lawrie T, de Jager M: Primary care fetal assessment--low-cost fetal arousal testing. S Afr Med J 1997, 87(2):171-172.

80. Neilson JP, Z Alfirevic: Doppler ultrasound for fetal assessment in high risk pregnancies. Cochrane Database of Systematic Reviews; 1996(4):CD000073.

81. Bricker L, Neilson JP, Dowswell T: Routine ultrasound in late pregnancy (after 24 weeks' gestation). Cochrane database of systematic reviews (Online) 2008(4):CD001451.

82. World Health Organization: Global prevalence and incidence of selected curable sexually transmitted infections. Geneva: WHO; 2001

83. Gray RH, Wabwire-Mangen F, Kigozi G, Sewankambo NK, Serwadda D, 
Moulton LH, Quinn TC, O'Brien KL, Meehan M, Abramowsky C et al: Randomized trial of presumptive sexually transmitted disease therapy during pregnancy in Rakai, Uganda. Am J Obstet Gynecol 2001, 185(5):1209-1217

84. Watson-Jones D, Gumodoka B, Weiss H, Changalucha J, Todd J, Mugeye K, Buve A, Kanga Z, Ndeki L, Rusizoka M et al: Syphilis in pregnancy in Tanzania. II. The effectiveness of antenatal syphilis screening and single-dose benzathine penicillin treatment for the prevention of adverse pregnancy outcomes. J Infect Dis 2002, 186(7):948-957.

85. Taha TE, Dallabetta GA, Hoover DR, Chiphangwi JD, Mtimavalye LA, Liomba GN, Kumwenda NI, Miotti PG: Trends of HIV-1 and sexually transmitted diseases among pregnant and postpartum women in urban Malawi. AIDS 1998, 12(2):197-203

86. World Health Organization: Global prevalence and incidence of selected curable sexually transmitted infections. Geneva: WHO; 2001.

87. Genc M, Ledger WJ: Syphilis in pregnancy. Sexually transmitted infections 2000, 76(2):73-79.

88. Watson-Jones D, Changalucha J, Gumodoka B, Weiss H, Rusizoka M, Ndeki L, Whitehouse A, Balira R, Todd J, Ngeleja D et al: Syphilis in pregnancy in Tanzania. I. Impact of maternal syphilis on outcome of pregnancy. J Infect Dis 2002, 186(7):940-947.

89. Steketee RW, Wirima JJ, Slutsker WL, Khoromana CO, Breman JG, Heymann $\mathrm{DL}:$ Objectives and methodology in a study of malaria treatment and prevention in pregnancy in rural Malawi: The Mangochi Malaria Research Project. Am J Trop Med Hyg 1996, 55(1 Suppl):8-16

90. Walker GJ: Antibiotics for syphilis diagnosed during pregnancy. Cochrane Database Syst Rev 2001(3):CD001143.

91. Guinness LF, Sibandze S, McGrath E, Cornelis AL: Influence of antenatal screening on perinatal mortality caused by syphilis in Swaziland Genitourin Med 1988, 64(5):294-297.

92. Temmerman M, Gichangi P, Fonck K, Apers L, Claeys P, Van Renterghem L, Kiragu D, Karanja G, Ndinya-Achola J, Bwayo J: Effect of a syphilis control programme on pregnancy outcome in Nairobi, Kenya. Sex Transm Infect 2000, 76(2):117-121.

93. Menendez C, Ordi J, Ismail MR, Ventura PJ, Aponte JJ, Kahigwa E, Font F, Alonso PL: The impact of placental malaria on gestational age and birth weight. J Infect Dis 2000, 181:1740-1745.

94. Garner P, Gulmezoglu AM: Drugs for preventing malaria in pregnant women. Cochrane database of systematic reviews (Online) 2006(4):CD000169.

95. Jones G, Steketee RW, Black RE, Bhutta ZA, Morris SS: How many child deaths can we prevent this year? Lancet 2003, 362(9377):65-71

96. Bryce J, Terreri N Victora CG, Mason E, Daelmans B, Bhutta ZA, Bustreo F Songane F, Salama P, Wardlaw T: Countdown to 2015: tracking intervention coverage for child survival. Lancet 2006, 368(9541):1067-1076.

97. Gamble C, Ekwaru PJ, Garner P, ter Kuile FO: Insecticide-Treated Nets for the Prevention of Malaria in Pregnancy: A Systematic Review of Randomised Controlled Trials. PLoS Med 2007, 4(3):e107.

98. ter Kuile FO, Terlouw DJ, Phillips-Howard PA, Hawley WA, Friedman JF, Kariuki SK, Shi YP, Kolczak MS, Lal AA, Vulule JM et al: Reduction of malaria during pregnancy by permethrin-treated bed nets in an area of intense perennial malaria transmission in western Kenya. Am J Trop Med Hyg 2003, 68(4 Suppl):50-60.

99. Gamble C, Ekwaru JP, ter Kuile FO: Insecticide-treated nets for preventing malaria in pregnancy. Cochrane Database Syst Rev 2006(2):CD003755.

100. Romero R, Oyarzun E, Mazor M, Sirtori M, Hobbins JC, Bracken M: Metaanalysis of the relationship between asymptomatic bacteriuria and preterm delivery/low birth weight. Obstet Gyneco/ 1989, 73(4):576-582.

101. Smaill F, Vazquez JC: Antibiotics for asymptomatic bacteriuria in pregnancy. Cochrane database of systematic reviews (Online) 2007(2):CD000490.

102. Romero R, Espinoza J, Kusanovic JP, Gotsch F, Hassan S, Erez O, Chaiworapongsa T, Mazor M: The preterm parturition syndrome. BJOG 2006, 113 Suppl 3:17-42

103. Guise JM, Mahon SM, Aickin M, Helfand M, Peipert JF, Westhoff C: Screening for bacterial vaginosis in pregnancy. American journal of preventive medicine 2001, 20(3 Suppl):62-72.

104. Leitich H, Bodner-Adler B, Brunbauer M, Kaider A, Egarter C, Husslein P: Bacterial vaginosis as a risk factor for preterm delivery: a meta-analysis Am J Obstet Gynecol 2003, 189(1):139-147.

105. Riggs MA, Klebanoff MA: Treatment of vaginal infections to prevent preterm birth: a meta-analysis. Clinical obstetrics and gynecology 2004, 47(4):796-807.
106. Okun N, Gronau KA, Hannah ME: Antibiotics for bacterial vaginosis or Trichomonas vaginalis in pregnancy: a systematic review. Obstet Gynecol 2005, 105(4):857-868

107. McDonald H, Brocklehurst P, Parsons J: Antibiotics for treating bacterial vaginosis in pregnancy. Cochrane database of systematic reviews (Online) 2007(1).

108. National Collaborating Centre for Women's and Children's Health: Antenatal care: routine care for the healthy pregnant woman. London: RCOG Press; 2003.

109. Iams JD, Romero R, Culhane JF, Goldenberg RL: Primary, secondary, and tertiary interventions to reduce the morbidity and mortality of preterm birth. Lancet 2008, 371(9607):164-175.

110. Nygren P, Fu R, Freeman M, Bougatsos C, Klebanoff M, Guise JM: Evidence on the benefits and harms of screening and treating pregnant women who are asymptomatic for bacterial vaginosis: an update review for the U.S. Preventive Services Task Force. Ann Intern Med 2008, 148(3):220-233.

111. Yudin MH, Money DM: Screening and management of bacterial vaginosis in pregnancy. J Obstet Gynaecol Can 2008, 30(8):702-716.

112. European Collaborative Sudy. Swiss Mother and Child HIV Cohort Study: Combination antiretroviral therapy and duration of pregnancy. AIDS 2000 14(18):2913-2920

113. Cotter AM, Garcia AG, Duthely ML, Luke B, O'Sullivan MJ: Is antiretroviral therapy during pregnancy associated with an increased risk of preterm delivery, low birth weight, or stillbirth? J Infect Dis 2006, 193(9):1 195-1201.

114. Kourtis AP, Schmid CH, Jamieson DJ, Lau J: Use of antiretroviral therapy in pregnant HIV-infected women and the risk of premature delivery: a metaanalysis. AIDS 2007, 21(5):607-615.

115. Boer K, Nellen JF, Patel D, Timmermans S, Tempelman C, Wibaut M, Sluman $M A$, van der Ende ME, Godfried MH: The AmRo study: pregnancy outcome in HIV-1-infected women under effective highly active antiretroviral therapy and a policy of vaginal delivery. BJOG 2007, 114(2):148-155.

116. Martin F, Taylor GP: Increased rates of preterm delivery are associated with the initiation of highly active antiretrovial therapy during pregnancy: a single-center cohort study. J Infect Dis 2007, 196(4):558-561.

117. Schulte J, Dominguez K, Sukalac T, Bohannon B, Fowler MG: Declines in low birth weight and preterm birth among infants who were born to HIVinfected women during an era of increased use of maternal antiretroviral drugs: Pediatric Spectrum of HIV Disease, 1989-2004. Pediatrics 2007, 119(4):e900-906.

118. Machado ES, Hofer CB, Costa TT, Nogueira SA, Oliveira RH, Abreu TF, Evangelista LA, Farias IF, Mercadante RT, Garcia MD et al: Pregnancy outcome in HIV-1 infected women receiving combination antiretroviral therapy prior versus after conception. Sex Transm Infect 2008.

119. Tuomala RE, Shapiro DE, Mofenson LM, Bryson Y, Culnane M, Hughes MD, O'Sullivan MJ, Scott G, Stek AM, Wara D et al: Antiretroviral therapy during pregnancy and the risk of an adverse outcome. N Eng/J Med 2002, 346(24):1863-1870.

120. Tuomala RE, Watts DH, Li D, Vajaranant M, Pitt J, Hammill H, Landesman S, Zorrilla C, Thompson B: Improved obstetric outcomes and few maternal toxicities are associated with antiretroviral therapy, including highly active antiretroviral therapy during pregnancy. J Acquir Immune Defic Syndr 2005, 38(4):449-473.

121. Townsend CL, Cortina-Borja M, Peckham CS, Tookey PA: Antiretroviral therapy and premature delivery in diagnosed HIV-infected women in the United Kingdom and Ireland. AIDS 2007, 21(8):1019-1026.

122. Ekouevi DK, Coffie PA, Becquet R, Tonwe-Gold B, Horo A, Thiebaut R, Leroy V, Blanche S, Dabis F, Abrams EJ: Antiretroviral therapy in pregnant women with advanced HIV disease and pregnancy outcomes in Abidjan, Cote d'Ivoire. AIDS 2008, 22(14):1815-1820.

123. Tonwe-Gold B, Ekouevi DK, Viho I, Amani-Bosse C, Toure S, Coffie PA, Rouet F, Becquet R, Leroy V, El-Sadr WM et al: Antiretroviral treatment and prevention of peripartum and postnatal HIV transmission in West Africa: evaluation of a two-tiered approach. PLoS Med 2007, 4(8):e257.

124. Larocque R, Casapia M, Gotuzzo E, MacLean JD, Soto JC, Rahme E, Gyorkos TW: A double-blind randomized controlled trial of antenatal mebendazole to reduce low birthweight in a hookworm-endemic area of Peru. Trop Med Int Health 2006, 11(10):1485-1495.

125. Haider BA, Bhutta Z: Effects of Interventions for Soil Transmitted Helminthic Infections in Pregnancy. Cochrane Library 2009

126. de Silva NR, Sirisena UL, Gunasekera DP, Ismail MM, de Silva HJ: Effect of mebendazole therapy during pregnancy on birth outcome. Lancet 1999, 353(9159):1145-1149. 
127. Gyorkos TW, Larocque R, Casapia M, Gotuzzo E: Lack of risk of adverse birth outcomes after deworming in pregnant women. Pediatr Infect Dis J 2006, 25(9):791-794

128. Vergnes JN, Sixou M: Preterm low birth weight and maternal periodontal status: a meta-analysis. Am J Obstet Gynecol 2007, 196(2):135 e131-137.

129. Agueda A, Echeverria A, Manau C: Association between periodontitis in pregnancy and preterm or low birth weight: Review of the literature. Medicina oral, patologia oral y cirugia bucal 2008, 13(9):E609-615.

130. Michalowicz BS, Hodges JS, DiAngelis AJ, Lupo VR, Novak MJ, Ferguson JE, Buchanan W, Bofill J, Papapanou PN, Mitchell DA et al: Treatment of periodontal disease and the risk of preterm birth. The New England journal of medicine 2006, 355(18):1885-1894.

131. Lopez NJ, Smith PC, Gutierrez J: Periodontal therapy may reduce the risk of preterm low birth weight in women with periodontal disease: a randomized controlled trial. J Periodontol 2002, 73(8):911-924.

132. Offenbacher S, Lin D, Strauss R, McKaig R, Irving J, Barros SP, Moss K, Barrow $D A$, Hefti A, Beck JD: Effects of periodontal therapy during pregnancy on periodontal status, biologic parameters, and pregnancy outcomes: a pilot study. J Periodontol 2006, 77(12):2011-2024

133. Dodd JM, Flenady VJ, Cincotta R, Crowther CA: Progesterone for the prevention of preterm birth: a systematic review. Obstet Gynecol 2008, 112(1):127-134

134. Berghella V, Odibo AO, To MS, Rust OA, Althuisius SM: Cerclage for Short Cervix on Ultrasonography Meta-Analysis of Trials Using Individual Patient-Level Data. Obstet Gynecol 2005, 106(1):181-189.

135. Drakeley AJ, Roberts D, Alfirevic Z: Cervical stitch (cerclage) for preventing pregnancy loss in women. Cochrane database of systematic reviews (Online) 2003(1):CD003253

136. Jorgensen AL, Alfirevic Z, Tudur Smith C, Williamson PR: Cervical stitch (cerclage) for preventing pregnancy loss: individual patient data metaanalysis. Bjog 2007, 114(12):1460-1476.

137. Fawzi WW, Msamanga GI, Spiegelman D, Urassa EJ, McGrath N, Mwakagile D, Antelman G, Mbise R, Herrera G, Kapiga S: Randomised trial of effects of vitamin supplements on pregnancy outcomes and T cell counts in HIV-1infected women in Tanzania. Lancet 1998, 351(9114):1477-1482.

138. Kongnyuy EJ, Wiysonge CS, Shey MS: A systematic review of randomized controlled trials of prenatal and postnatal vitamin A supplementation of HIV-infected women. International journal of gynaecology and obstetrics: the official organ of the International Federation of Gynaecology and Obstetrics 2009, 104:5-8

139. $\mathrm{MOH}$ (Senegal), BASICS II for the United States Agency for International Development: Newborn Health Interventions nin Senegal. The early implementation phase. Senegal and Arlington, VA, USA: MOH (Senegal) and BASICS II for the United States Agency for International Development; 2004.

140. Bhutta ZA, Memon ZA, Soofi S, Salat MS, Cousens S, Martines J: Implementing community-based perinatal care: results from a pilot study in rural Pakistan. Bull World Health Organ 2008, 86(6):452-459.

141. Darmstadt $\mathrm{G}$ ea: Impact of community-based behaviour change management on neonatal mortality: a cluster-randomised, controlled trial in Shivgarh, Uttar Pradesh, India. In Countdown to 2015: 2005; London; 2005.

142. Jokhio AH, Winter HR, Cheng KK: An intervention involving traditional birth attendants and perinatal and maternal mortality in Pakistan. The New England journal of medicine 2005, 352(20):2091-2099.

143. Manandhar DS, Osrin D, Shrestha BP, Mesko N, Morrison J, Tumbahangphe KM, Tamang S, Thapa S, Shrestha D, Thapa B et al: Effect of a participatory intervention with women's groups on birth outcomes in Nepal: clusterrandomised controlled trial. Lancet 2004, 364(9438):970-979.

144. Lavender T, Hart A, Smyth RM: Effect of partogram use on outcomes for women in spontaneous labour at term. Cochrane Database Syst Rev 2008(4):CD005461.

145. Lavender T, Alfirevic Z, Walkinshaw S: Partogram action line study: a randomised trial. Br J Obstet Gynaecol 1998, 105(9):976-980.

146. Lavender T, Alfirevic Z, Walkinshaw S: Effect of different partogram action lines on birth outcomes: a randomized controlled trial. Obstet Gynecol 2006, 108(2):295-302.

147. World Health Organization partograph in management of labour. World Health Organization Maternal Health and Safe Motherhood Programme. Lancet 1994, 343(8910):1399-1404

148. Froen JF, Tveit JV, Saastad E, Bordahl PE, Stray-Pedersen B, Heazell AE, Flenady $V$, Fretts RC: Management of decreased fetal movements. Semin Perinatol 2008, 32(4):307-311.
149. Grant A, Elbourne D, Valentin L, Alexander S: Routine formal fetal movement counting and risks of antepartum late deaths in nomally formed singletons. Lancet 1989, 2:345-347.

150. Thomsen SG, Legarth J, Weber T, Kristensen J: Monitoring of normal pregnancies by daily fetal movement registration or hormone assessment. A random allocation study. Journal of Obstetrics and Gynaecology 1990, 10:189-193.

151. UNICEF/WHO/UNFPA: Guidelines for monitoring the availability and use of obstetric services. New York: UNICEF; 1997.

152. Dumont A, Bernis L, Bouvier-Colle MH, Breart G: Caesarean section rate for maternal indication in sub-Saharan Africa: a systematic review. Lancet 2001, 358(9290):1328-1333.

153. Goldenberg RL, McClure EM, Bann CM: The relationship of intrapartum and antepartum stillbirth rates to measures of obstetric care in developed and developing countries. Acta Obstet Gynecol Scand 2007, 86(11):1303-1309.

154. Majoko F, Gardener G: Trial of instrumental delivery in theatre versus immediate caesarean section for anticipated difficult assisted births. Cochrane Database Syst Rev 2008(4):CD005545.

155. Johanson RB, Menon V: Vacuum extraction versus forceps for assisted vaginal delivery. Cochrane Database of Systematic Reviews; 1999(2):CD000224.

156. Weerasekera DS, Premaratne S: A randomised prospective trial of the obstetric forceps versus vacuum extraction using defined criteria. J Obstet Gynaecol 2002, 22(4):344-345.

157. Mustafa R, Mustafa R: Perinatal and maternal outcome in ventouse versus forceps delivery. Journal of the College of Physicians \& Surgeons Pakistan; 2002, 12(6):345-347.

158. Villar J, Valladares E, Wojdyla D, Zavaleta N, Carroli G, Velazco A, Shah A, Campodonico L, Bataglia V, Faundes A et al: Caesarean delivery rates and pregnancy outcomes: the 2005 WHO global survey on maternal and perinatal health in Latin America. Lancet 2006, 367(9525):1819-1829.

159. Hofmeyr GJ, Hannah ME: Planned caesarean section for term breech delivery. Cochrane Database Syst Rev 2003(3):CD000166.

160. Gulmezoglu AM, Crowther CA, Middleton P: Induction of labour for improving birth outcomes for women at or beyond term. Cochrane database of systematic reviews (Online) 2006(4):CD004945.

161. Dare MR, Middleton P, Crowther CA, Flenady VJ, Varatharaju B: Planned early birth versus expectant management (waiting) for prelabour rupture of membranes at term (37 weeks or more). Cochrane database of systematic reviews (Online) 2006(1):CD005302

162. Hodnett ED, Downe S, Edwards N, Walsh D: Home-like versus conventional institutional settings for birth. Cochrane Database Syst Rev 2005(1):CD000012

163. Tracy SK, Dahlen H, Caplice S, Laws P, Wang YA, Tracy MB, Sullivan E: Birth centers in Australia: a national population-based study of perinatal mortality associated with giving birth in a birth center. Birth 2007, 34(3):194-201

164. NIH (National Institutes of Health): Effect of corticosteroids for fetal maturation on perinatal outcomes. Am J Obstet Gynecol 1994, 173:246-252.

165. Lee BH, Stoll BJ, McDonald SA, Higgins RD: Adverse neonatal outcomes associated with antenatal dexamethasone versus antenatal betamethasone. Pediatrics 2006, 117(5):1503-1510.

166. Brownfoot FC, Crowther CA, Middleton P: Different corticosteroids and regimens for accelerating fetal lung maturation for women at risk of preterm birth. Cochrane database of systematic reviews (Online) 2008(4):CD006764

167. Crowley P: Prophylactic corticosteroids for preterm birth. Cochrane database of systematic reviews (Online) 2000(2):CD000065.

168. Goldenberg RL, Hauth JC, Andrews WW: Intrauterine infection and preterm delivery. The New England journal of medicine 2000, 342(20):1500-1507.

169. Dammann O, Leviton A, Gappa M, Dammann CEL: Lung and brain damage in preterm newborns, and their association with gestational age, prematurity subgroup, infection/inflammation and long term outcome. BJOG 2005, 112(s 1):4-9.

170. Kenyon S, Boulvain M, Neilson J: Antibiotics for preterm rupture of membranes. Cochrane database of systematic reviews (Online) 2003(2):CD001058

171. Kenyon S, Pike K, Jones D, Brocklehurst P, Marlow N, Salt A, Taylor D: Childhood outcomes after prescription of antibiotics to pregnant women with preterm rupture of the membranes: 7-year follow-up of the ORACLE I trial. Lancet 2008

172. King J, Flenady V: Prophylactic antibiotics for inhibiting preterm labour 
with intact membranes. Cochrane database of systematic reviews (Online) 2002(4):CD000246

173. Simcox R, Sin WT, Seed PT, Briley A, Shennan AH: Prophylactic antibiotics for the prevention of preterm birth in women at risk: a meta-analysis. The Australian \& New Zealand journal of obstetrics \& gynaecology 2007, 47(5):368-377.

174. Kenyon S, Pike K, Jones D, Brocklehurst P, Marlow N, Salt A, Taylor D: Childhood outcomes after prescription of antibiotics to pregnant women with spontaneous preterm labour: 7-year follow-up of the ORACLE II trial. Lancet 2008

175. Oh W, Lind J, Gessner IH: The circulatory and respiratory adaptation to early and late cord clamping in newborn infants. Acta Paediatr Scand 1966, 55(1):17-25.

176. Oh W, Wallgren G, Hanson JS, Lind J: The effects of placental transfusion on respiratory mechanics of normal term newborn infants. Pediatrics 1967 40(1):6-12.

177. Saigal S, Usher RH: Symptomatic neonatal plethora. Biol Neonate 1977 32(1-2):62-72

178. Yao AC, Lind J, Vuorenkoski V: Expiratory grunting in the late clamped normal neonate. Pediatrics 1971, 48(6):865-870

179. Saigal S, O'Neill A, Surainder Y, Chua LB, Usher R: Placental transfusion and hyperbilirubinemia in the premature. Pediatrics 1972, 49(3):406-419.

180. Yao AC, Lind J: Placental transfusion. Am J Dis Child 1974, 127(1):128-141.

181. Cernadas JMC: Early versus delayed umbilical cord clamping in preterm infants: RHL commentary GENEVA: WHO REPRODUCTIVE HEALTH LIBRARY; 2006.

182. Rabe H, Reynolds G, Diaz-Rossello J: A systematic review and meta-analysis of a brief delay in clamping the umbilical cord of preterm infants. Neonatology 2008, 93(2):138-144.

183. Rabe H, Reynolds G, Diaz-Rossello J: Early versus delayed umbilical cord clamping in preterm infants. Cochrane database of systematic reviews (Online) 2004(4):CD003248

184. Strauss RG, Mock DM, Johnson KJ, Cress GA, Burmeister LF, Zimmerman MB, Bell EF, Rijhsinghani A: A randomized clinical trial comparing immediate versus delayed clamping of the umbilical cord in preterm infants: shortterm clinical and laboratory endpoints. Transfusion 2008, 48(4):658-665.

185. Ultee CA, van der Deure J, Swart J, Lasham C, van Baar AL: Delayed cord clamping in preterm infants delivered at 3436 weeks' gestation: a randomised controlled trial. Arch Dis Child Fetal Neonatal Ed 2008, 93(1):F20-23.

186. Kugelman A, Borenstein-Levin L, Riskin A, Chistyakov I, Ohel G, Gonen R, Bader D: Immediate versus delayed umbilical cord clamping in premature neonates born $<35$ weeks: a prospective, randomized, controlled study. Am J Perinatol 2007, 24(5):307-315.

187. Baenziger O, Stolkin F, Keel M, von Siebenthal K, Fauchere JC, Das Kundu S, Dietz V, Bucher HU, Wolf M: The influence of the timing of cord clamping on postnatal cerebral oxygenation in preterm neonates: a randomized, controlled trial. Pediatrics 2007, 119(3):455-459.

188. Saugstad OD: Resuscitation with room-air or oxygen supplementation. Clin Perinatol 1998, 25(3):741-756, xi.

189. te Pas AB, Walther FJ: A randomized, controlled trial of delivery-room respiratory management in very preterm infants. Pediatrics 2007 120(2):322-329.

190. Capasso L, Capasso A, Raimondi F, Vendemmia M, Araimo G, Paludetto R: A randomized trial comparing oxygen delivery on intermittent positive pressure with nasal cannulae versus facial mask in neonatal primary resuscitation. Acta Paediatr 2005, 94(2):197-200.

191. Palme C, Nystrom B, Tunell R: An evaluation of the efficiency of face masks in the resuscitation of newborn infants. Lancet 1985, 1(8422):207-210.

192. Massawe A, Kilewo C, Irani S, Verma RJ, Chakrapam AB, Ribbe T, Tunell R, Fischler B: Assessment of mouth-to-mask ventilation in resuscitation of asphyxic newborn babies. A pilot study. Trop Med Int Health 1996, 1(6):865-873.

193. Bhutta ZA, Darmstadt GL, Hasan BS, Haws RA: Community-based interventions for improving perinatal and neonatal health outcomes in developing countries: a review of the evidence. Pediatrics 2005, 115(2 Suppl):519-617.

194. Sanchez-Torres AM, Garcia-Alix A, Cabanas F, Elorza MD, Madero R, Perez J, Quero J: [Impact of cardiopulmonary resuscitation on extremely low birth weight infants]. An Pediatr (Barc) 2007, 66(1):38-44.

195. Viggedal G, Carlsson G: Visual attention in young adulthood after cardiopulmonary resuscitation at birth or being born small for gestational age. Percept Mot Skills 2004, 99(2):555-564

196. Viggedal G, Carlsson G, Hugdahl K: Language asymmetry and auditory attention in young adulthood after being born small-for-gestational age or with cardio-pulmonary resuscitation at birth. Child Neuropsychol 2004, 10(3):195-200.

197. Vakrilova L, Kalaidzhieva M, Sluncheva B, Popivanova A, Metodieva V, Garnizov T: [Resuscitation in very low birth weight and extremely low birth weight newborns in the delivery room]. Akush Ginekol (Sofia) 2002, $41(2): 18-23$.

198. Kjellmer I, Beijer E, Carlsson G, Hrbek A, Viggedal G: Follow-up into young adulthood after cardiopulmonary resuscitation in term and near-term newborn infants. I. Educational achievements and social adjustment. Acta Paediatr 2002, 91(11):1212-1217.

199. Viggedal G, Lundalv E, Carlsson G, Kjellmer I: Follow-up into young adulthood after cardiopulmonary resuscitation in term and near-term newborn infants. II. Neuropsychological consequences. Acta Paediatr 2002 91(11):1218-1226

200. Dorfsman ML, Menegazzi JJ, Wadas RJ, Auble TE: Two-thumb vs. two-finger chest compression in an infant model of prolonged cardiopulmonary resuscitation. Acad Emerg Med 2000, 7(10):1077-1082.

201. Deulofeut R, Sola A, Lee B, Rogido M: [Delivery room cardiopulmonary resucitation of very preterm infant is associated with adverse short- and long-term outcomes]. An Pediatr (Barc) 2007, 66(1):31-37.

202. Saugstad OD, Ramji S, Soll RF, Vento M: Resuscitation of newborn infants with $21 \%$ or $100 \%$ oxygen: an updated systematic review and metaanalysis. Neonatology 2008, 94(3):176-182.

203. Rabi Y, Rabi D, Yee W: Room air resuscitation of the depressed newborn: a systematic review and meta-analysis. Resuscitation 2007, 72(3):353-363.

204. Vento M, Asensi M, Sastre J, Lloret A, Garcia-Sala F, Minana JB, Vina J: Hyperoxemia caused by resuscitation with pure oxygen may alter intracellular redox status by increasing oxidized glutathione in asphyxiated newly born infants. Semin Perinato/ 2002, 26(6):406-410.

205. Naumburg E, Bellocco R, Cnattingius S, Jonzon A, Ekbom A: Supplementary oxygen and risk of childhood lymphatic leukaemia. Acta Paediatr 2002, 91(12):1328-1333.

206. Tan A, Schulze A, O'Donnell CP, Davis PG: Air versus oxygen for resuscitation of infants at birth. Cochrane Database Syst Rev 2005(2):CD002273.

207. Saugstad OD, Ramji S, Vento M: Resuscitation of depressed newborn infants with ambient air or pure oxygen: a meta-analysis. Biol Neonate 2005, $87(1): 27-34$.

208. Tan A, Schulze A, O'Donnell CP, Davis PG: Air versus oxygen for resuscitation of infants at birth. Cochrane Database Syst Rev 2004(3):CD002273.

209. Zhu JJ, Wu MY: [Which is better to resuscitate asphyxiated newborn infants: room air or pure oxygen?]. Zhonghua Er Ke Za Zhi 2007, 45(9):644-649.

210. Ramji S, Ahuja S, Thirupuram S, Rootwelt T, Rooth G, Saugstad OD: Resuscitation of asphyxic newborn infants with room air or $100 \%$ oxygen Pediatr Res 1993, 34(6):809-812.

211. Wang CL, Anderson C, Leone TA, Rich W, Govindaswami B, Finer NN: Resuscitation of preterm neonates by using room air or $100 \%$ oxygen Pediatrics 2008, 121(6):1083-1089.

212. Escrig R, Arruza L, Izquierdo I, Villar G, Saenz P, Gimeno A, Moro M, Vento M: Achievement of targeted saturation values in extremely low gestational age neonates resuscitated with low or high oxygen concentrations: a prospective, randomized trial. Pediatrics 2008, 121(5):875-881.

213. Harling AE, Beresford MW, Vince GS, Bates M, Yoxall CW: Does the use of $50 \%$ oxygen at birth in preterm infants reduce lung injury? Arch Dis Child Fetal Neonatal Ed 2005, 90(5):F401-405.

214. Saugstad OD, Ramii S, Irani SF, El-Meneza S, Hernandez EA, Vento M, TalvikT, Solberg R, Rootwelt T, Aalen OO: Resuscitation of newborn infants with $21 \%$ or $100 \%$ oxygen: follow-up at 18 to 24 months. Pediatrics 2003 , 112(2):296-300.

215. Hellstrom-Westas L, Forsblad K, Sjors G, Saugstad OD, Bjorklund $\sqcup$, Marsal K Kallen K: Earlier Apgar score increase in severely depressed term infants cared for in Swedish level III units with 40\% oxygen versus 100\% oxygen resuscitation strategies: a population-based register study. Pediatrics 2006 118(6):e1798-1804

216. Bryce J, Boschi-Pinto C, Shibuya K, Black RE: WHO estimates of the causes of death in children. Lancet 2005, 365(9465):1147-1152.

217. Sen A, Mahalanabis D, Singh AK, Som TK, Bandyopadhyay S: Impact of a 
district level sick newborn care unit on neonatal mortality rate: 2-year follow-up. J Perinatol 2009, 29(2):150-155.

218. Payne NR, LaCorte M, Karna P, Chen S, Finkelstein M, Goldsmith JP, Carpenter $J \mathrm{H}$ : Reduction of bronchopulmonary dysplasia after participation in the Breathsavers Group of the Vermont Oxford Network Neonatal Intensive Care Quality Improvement Collaborative. Pediatrics 2006, 118 Suppl 2:S73-77.

219. Mufti P, Setna F, Nazir K: Early neonatal mortality: effects of interventions on survival of low birth babies weighing 1000-2000g. J Pak Med Assoc 2006, 56(4):174-176

220. Symington A, Pinelli J: Developmental care for promoting development and preventing morbidity in preterm infants. Cochrane Database Syst Rev 2006(2):CD001814

221. McNamara PJ, Mak W, Whyte HE: Dedicated neonatal retrieval teams improve delivery room resuscitation of outborn premature infants. $J$ Perinato/ 2005, 25(5):309-314.

222. Kabbur PM, Herson VC, Zaremba S, Lerer T: Have the year 2000 neonatal resuscitation program guidelines changed the delivery room management or outcome of meconium-stained infants? J Perinatol 2005, 25(11):694-697.

223. Patel D, Piotrowski ZH: Positive changes among very low birth weight infant Apgar scores that are associated with the Neonatal Resuscitation Program in Illinois. J Perinatol 2002, 22(5):386-390.

224. Chomba E, McClure EM, Wright LL, Carlo WA, Chakraborty H, Harris H: Effect of WHO newborn care training on neonatal mortality by education. Ambul Pediatr 2008, 8(5):300-304.

225. Zhu XY, Fang HQ, Zeng SP, Li YM, Lin HL, Shi SZ: The impact of the neonatal resuscitation program guidelines (NRPG) on the neonatal mortality in a hospital in Zhuhai, China. Singapore Med J 1997, 38(11):485-487.

226. Deorari AK, Paul VK, Singh M, Vidyasagar D: The National Movement of Neonatal Resuscitation in India. J Trop Pediatr 2000, 46(5):315-317.

227. Vakrilova L, Elleau C, Sluncheva B: [French-Bulgarian program “Resuscitation of the newborn in a delivery room"--results and perspectives]. Akush Ginekol (Sofia) 2005, 44(3):35-40.

228. Opiyo N, Were F, Govedi F, Fegan G, Wasunna A, English M: Effect of newborn resuscitation training on health worker practices in Pumwani Hospital, Kenya. PLOS ONE 2008, 3(2):e1599.

229. Duran R, Aladag N, Vatansever U, Sut N, Acunas B: The impact of Neonatal Resuscitation Program courses on mortality and morbidity of newborn infants with perinatal asphyxia. Brain Dev 2008, 30(1):43-46.

230. Senarath U, Fernando DN, Rodrigo I: Effect of training for care providers on practice of essential newborn care in hospitals in Sri Lanka. J Obstet Gynecol Neonatal Nurs 2007, 36(6):531-541.

231. Ryan CA, Clark LM, Malone A, Ahmed S: The effect of a structured neonatal resuscitation program on delivery room practices. Neonatal Netw 1999, 18(1):25-30.

232. Singh J, Santosh S, Wyllie JP, Mellon A: Effects of a course in neonatal resuscitation--evaluation of an educational intervention on the standard of neonatal resuscitation. Resuscitation 2006, 68(3):385-389.

233. Bang AT, Baitule SB, Reddy HM, Deshmukh MD, Bang RA: Low birth weight and preterm neonates: can they be managed at home by mother and a trained village health worker? J Perinatol 2005, 25 Suppl 1:S72-81.

234. Dunn S, Niday P, Watters NE, McGrath P, Alcock D: The provision and evaluation of a neonatal resuscitation program. J Contin Educ Nurs 1992, 23(3):118-126

235. Daga AS, Daga SR, Dighole RV, Patil RP, Patil MR: Evaluation of training programme for traditional birth attendants in newborn care. Indian Pediatr 1997, 34(11):1021-1024.

236. Kumar R, Thakur JS, Aggarwal AK: Effect of continuing training on knowledge and practices of traditional birth attendants about maternal and newborn care. Indian J Public Health 2000, 44(4):118-123.

237. Xiayu Z: Neonatal resuscitation. World Health Forum 1993, 14:289-290.

238. Sibley L ST: Traditional Birth Attendant Training Effectiveness: A Metaanalysis. Cochrane Database of Systematic Reviews 2002(Issue 3).

239. Rowley MJ, Hensley MJ, Brinsmead MW, Wlodarczyk JH: Continuity of care by a midwife team versus routine care during pregnancy and birth: a randomised trial. Med J Aust 1995, 163(6):289-293.

240. Aziz K, Chadwick M, Downton G, Baker M, Andrews W: The development and implementation of a multidisciplinary neonatal resuscitation team in a Canadian perinatal centre. Resuscitation 2005, 66(1):45-51.

241. O'Hare BA, Nakakeeto M, Southall DP: A pilot study to determine if nurses trained in basic neonatal resuscitation would impact the outcome of neonates delivered in Kampala, Uganda. J Trop Pediatr 2006, 52(5):376-379.

242. Enweronu-Laryea CC, Nkyekyer K, Rodrigues OP: The impact of improved neonatal intensive care facilities on referral pattern and outcome at a teaching hospital in Ghana. J Perinatol 2008, 28(8):561-565.

243. Darlow BA, Graham PJ: Vitamin A supplementation to prevent mortality and short and long-term morbidity in very low birthweight infants. Cochrane Database Syst Rev 2007(4):CD000501.

244. Mactier H, Weaver LT: Vitamin A and preterm infants: what we know, what we don't know, and what we need to know. Arch Dis Child Fetal Neonatal Ed 2005, 90(2):F103-108.

245. Bhutta ZA, Ali S, Cousens S, Ali TM, Haider BA, Rizvi A, Okong P, Bhutta SZ, Black RE: Alma-Ata: Rebirth and Revision 6 Interventions to address maternal, newborn, and child survival: what difference can integrated primary health care strategies make? Lancet 2008, 372(9642):972-989.

246. Humphrey JH, Agoestina T, Juliana A, Septiana S, Widjaja H, Cerreto MC, Wu LS, Ichord RN, Katz J, West KP, Jr.: Neonatal vitamin A supplementation: effect on development and growth at 3 y of age. Am J Clin Nutr 1998, 68(1):109-117.

247. Klemm RD, Labrique AB, Christian P, Rashid M, Shamim AA, Katz J, Sommer A, West KP, Jr: Newborn vitamin A supplementation reduced infant mortality in rural Bangladesh. Pediatrics 2008, 122(1):e242-250.

248. Rahmathullah L, Tielsch JM, Thulasiraj RD, Katz J, Coles C, Devi S, John R, Prakash K, Sadanand AV, Edwin N et al: Impact of supplementing newborn infants with vitamin A on early infant mortality: community based randomised trial in southern India. BMJ 2003, 327(7409):254.

249. Clarke P, Mitchell S: Vitamin K Prophylaxis in Preterm Infants: Current Practices. J Thromb Haemost 2003, 1:384-386.

250. Crowther C, Henderson-Smart DJ: Vitamin K Prior to Preterm Birth for Preventing Neonatal Periventricular Haemorrhage. Cochrane Database of Systematic Reviews 2001, 1(CD000229).

251. Liu J, Wang Q, Gao F, He J, Zhao, JH: Maternal Antenatal Administration of Vitamin K1 Results in Increasing the activities of Vitamin K-dependent coagulation factors in umbilical blood and in decreasing the incidence rate of periventricular-intraventricular hemorrhage in premature infants. $J$ Perinat Med 2006, 34:173-176.

252. Victora CG, Van Haecke P: Vitamin K prophylaxis in less developed countries: policy issues and relevance to breastfeeding promotion. Am J Public Health 1998, 88(2):203-209.

253. Kumar D, Greer F, Super D, Suttie J, Moore J: Vitamin K status of premature infants: implications for current recommendations. Pediatrics 2001, 108:1117-1122.

254. Clarke P, Mitchell SJ, Wynn R, Sundaram S, Speed V, Gardener E, Roeves D, Shearer MJ: Vitamin K prophylaxis for preterm infants: a randomized, controlled trial of 3 regimens. Pediatrics 2006, 118(6):e1657-1666.

255. Prasad AS: Zinc in human health: effect of zinc on immune cells. Mol Med 2008, 14(5-6):353-357.

256. Loui A, Raab A, Obladen M, Bratter P: Nutritional zinc balance in extremely low-birth-weight infants. J Pediatr Gastroenterol Nutr 2001, 32(4):438-442.

257. Castillo-Duran C, Weisstaub G: Zinc supplementation and growth of the fetus and low birth weight infant. J Nutr 2003, 133 (5 Suppl 1):1494S-1497S

258. Bueno O, Bueno G, Moreno LA, Nuviala RJ, Perez-Gonzalez JM, Bueno M: Zinc supplementation in infants with asymmetric intra uterine growth retardation; effect on growth, nutritional status and leptin secretion. Nutr Hosp 2008, 23(3):212-219.

259. Castillo-Duran C, Perales CG, Hertrampf ED, Marin VB, Rivera FA, Icaza G: Effect of zinc supplementation on development and growth of Chilean infants. J Pediatr 2001, 138(2):229-235

260. Lira PI, Ashworth A, Morris SS: Effect of zinc supplementation on the morbidity, immune function, and growth of low-birth-weight, full-term infants in northeast Brazil. Am J Clin Nutr 1998, 68(2 Suppl):418S-424S.

261. Sazawal S, Black RE, Menon VP, Dinghra P, Caulfield LE, Dhingra U, Bagati A: Zinc supplementation in infants born small for gestational age reduces mortality: a prospective, randomized, controlled trial. Pediatrics 2001, 108(6):1280-1286.

262. Friel JK, Andrews WL, Matthew JD, Long DR, Cornel AM, Cox M, McKim E, Zerbe GO: Zinc supplementation in very-low-birth-weight infants. J Pediatr Gastroenterol Nutr 1993, 17(1):97-104

263. Sur D, Gupta DN, Mondal SK, Ghosh S, Manna B, Rajendran K, Bhattacharya SK: Impact of zinc supplementation on diarrheal morbidity and growth pattern of low birth weight infants in kolkata, India: a randomized, 
double-blind, placebo-controlled, community-based study. Pediatrics 2003, 112(6 Pt 1):1327-1332.

264. Rayman MP: The importance of selenium to human health. Lancet 2000 356(9225):233-241.

265. Arthur JR, McKenzie RC, Beckett GJ: Selenium in the immune system. J Nutr 2003, 133(5 Suppl 1):1457S-1459S

266. Darlow BA, Austin NC: Selenium supplementation to prevent short-term morbidity in preterm neonates. Cochrane Database Syst Rev 2003(4):CD003312

267. Lawn JE, Cousens S, Zupan J: 4 million neonatal deaths: when? Where? Why? Lancet 2005, 365(9462):891-900,

268. Mullany LC, Darmstadt GL, Tielsch JM: Role of antimicrobial applications to the umbilical cord in neonates to prevent bacterial colonization and infection: a review of the evidence. Pediatr Infect Dis J 2003, 22(11):996-1002.

269. Wilson CM, Gray G, Read JS, Mwatha A, Lala S, Johnson S, Violari A, Sibiya PM, Fleming TR, Koonce A et al: Tolerance and safety of different concentrations of chlorhexidine for peripartum vaginal and infant washes: HIVNET 025. $J$ Acquir Immune Defic Syndr 2004, 35(2):138-143.

270. Pezzati M, Rossi S, Tronchin M, Dani C, Filippi L, Rubaltelli FF: Umbilical cord care in premature infants: the effect of two different cord-care regimens (salicylic sugar powder vs chlorhexidine) on cord separation time and other outcomes. Pediatrics 2003, 112(4):e275.

271. Mullany LC, Darmstadt GL, Tielsch JM: Safety and impact of chlorhexidine antisepsis interventions for improving neonatal health in developing countries. Pediatr Infect Dis J 2006, 25(8):665-675.

272. Tielsch JM, Darmstadt GL, Mullany LC, Khatry SK, Katz J, LeClerq SC, Shrestha S, Adhikari R: Impact of newborn skin-cleansing with chlorhexidine on neonatal mortality in southern Nepal: a community-based, clusterrandomized trial. Pediatrics 2007, 119(2):e330-340.

273. World Health Organization.: Programme of Acute Respiratory Infections. Report of the fourth meeting of technical advisory group 6-10 March 1989. Geneva, Switzerland: World Health Organization; 1989

274. Bang AT, Bang RA, Baitule SB, Reddy MH, Deshmukh MD: Effect of homebased neonatal care and management of sepsis on neonatal mortality: field trial in rural India. Lancet 1999, 354(9194):1955-1961.

275. Bartlett AV, Paz de Bocaletti ME, MA. B: Neonatal and early postneonatal morbidity and mortality in a rural Guatemalan community: the importance of infectious diseases and their management. Pediatr Infect Dis J 1991, 10:752-757.

276. Datta N, Kumar V, Kumar L, Singhi S: Application of case management to the control of acute respiratory infections in low-birth-weight infants: a feasibility study. Bull World Health Organ 1987, 65(1):77-82.

277. Rey ES, Martinez HG: Manejo racional del nino prematuro. In Curso de Medicina Fetal. Edited by Universidad Nacional de Colombia. Bogota; 1983.

278. Conde-Agudelo A, Diaz-Rossello JL, Belizan JM: Kangaroo mother care to reduce morbidity and mortality in low birthweight infants. Cochrane database of systematic reviews (Online) 2003(2):CD002771.

279. Sloan NL, Ahmed S, Mitra SN, Choudhury N, Chowdhury M, Rob U, Winikoff B: Community-based kangaroo mother care to prevent neonatal and infant mortality: a randomized, controlled cluster trial. Pediatrics 2008 121(5):e1047-1059.

280. Suman RP, Udani R, Nanavati R: Kangaroo mother care for low birth weight infants: a randomized controlled trial Indian Pediatr 2008, 45(1):17-23.

281. Worku B, Kassie A: Kangaroo mother care: a randomized controlled trial on effectiveness of early kangaroo mother care for the low birthweight infants in Addis Ababa, Ethiopia. Journal of tropical pediatrics 2005, 51(2):93-97.

282. Victora CG: Effect of breastfeeding on infant and child mortality due to infectious diseases in less developed coutries: a pooled analysis. Lancet 2000, 355:451-455.

283. McGuire W, Anthony MY: Donor human milk versus formula for preventing necrotising enterocolitis in preterm infants: systematic review. Arch Dis Child Fetal Neonatal Ed 2003, 88(1):F11-14.

284. Edmond K, Bahl R: Optimal feeding of low birth weight infants: technical review. Geneva: World Health Organization; 2006.

285. Lucas A, Morley R, Cole TJ, Lister G, Leeson-Payne C: Breast milk and subsequent intelligence quotient in children born preterm. Lancet 1992, 339(8788):261-264.

286. Anderson JW, Johnstone BM, Remley DT: Breast-feeding and cognitive development: a meta-analysis. The American journal of clinical nutrition 1999, 70(4):525-535
287. Huffman SL, Zehner ER, Victora C: Can improvements in breast-feeding practices reduce neonatal mortality in developing countries? Midwifery 2001, 17(2):80-92.

288. World Health Organization: Indicators for assessing infant and young child feeding practices. Geneva: WHO; 2007.

289. Dodrill P, Donovan T, Cleghorn G, McMahon S, Davies PS: Attainment of early feeding milestones in preterm neonates. J Perinato/ 2008, 28(8):549-555.

290. Nyqvist KH: Early attainment of breastfeeding competence in very preterm infants. Acta Paediatr 2008, 97(6):776-781.

291. Moore ER, Anderson GC, Bergman N: Early skin-to-skin contact for mothers and their healthy newborn infants. Cochrane database of systematic reviews (Online) 2007(3):CD003519.

292. Hake-Brooks SJ, Anderson GC: Kangaroo care and breastfeeding of motherpreterm infant dyads 0-18 months: a randomized, controlled trial. Neonatal Netw 2008, 27(3):151-159.

293. Edmond KM, Kirkwood BR, Tawiah CA, Agyei SO: Impact of early infant feeding practices on mortality in low birth weight infants from rural Ghana. J Perinato/ 2008, 28(6):438-444.

294. Mullany LC, Katz J, Li YM, Khatry SK, LeClerq SC, Darmstadt GL, Tielsch JM: Breast-feeding patterns, time to initiation, and mortality risk among newborns in southern Nepal. J Nutr 2008, 138(3):599-603.

295. Clemens J, Elyazeed RA, Rao M, Savarino S, Morsy BZ, Kim Y, Wierzba T, Naficy A, Lee YJ: Early initiation of breastfeeding and the risk of infant diarrhea in rural Egypt. Pediatrics 1999, 104(1):e3.

296. Schanler RJ, Lau C, Hurst NM, Smith EO: Randomized trial of donor human milk versus preterm formula as substitutes for mothers' own milk in the feeding of extremely premature infants. Pediatrics 2005, 116(2):400-406.

297. World Health Organization: Thermal protection of the newborn: a practical guide. Geneva: WHO; 1997.

298. Richardson DK, Gray JE, McCormick MC, Workman K, Goldmann DA: Score for Neonatal Acute Physiology: a physiologic severity index for neonatal intensive care. Pediatrics 1993, 91(3):617-623.

299. Silverman WA, Fertig JW, Berger AP: The influence of the thermal environment upon the survival of newly born premature infants. Pediatrics 1958, 22(5):876-886.

300. Christensson K, Bhat GJ, Eriksson B, Shilalukey-Ngoma MP, Sterky G: The Effect of Routine Hospital Care on the Health of Hypothermic Newborn Infants in Zambia. Journal of tropical pediatrics 1995, 41(4):210-214.

301. Ogunlesi TA, Ogunfowora OB, Adekanmbi FA, Fetuga BM, Olanrewaju DM: Point-of-admission hypothermia among high-risk Nigerian newborns. BMC pediatrics 2008, 8:40

302. Ellis M, Manandhar N, Shakya U, Manandhar DS, Fawdry A: Postnatal hypothermia and cold stress among newborn infants in Nepal monitored by continuous ambulatory recording. Archives of Disease in Childhood Fetal \& Neonatal Edition 1996, 75(1):42F.

303. Bhutta ZA, Darmstadt GL, Hasan BS: Community-Based Interventions for Improving Perinatal and Neonatal Health Outcomes in Developing Countries: A Review of the Evidence. Pediatrics 2005, 115(2):519.

304. Lyon A: Applied psysiology: temperature control in the newborn infant. Current Paediatrics 2004, 14:137-144.

305. McCall EM, Alderdice FA, Halliday HL, Jenkins JG, Vohra S: Interventions to prevent hypothermia at birth in preterm and/or low birthweight babies Cochrane database of systematic reviews (Online) 2005(1):CD004210.

306. Flenady VJ, Woodgate PG: Radiant warmers versus incubators for regulating body temperature in newborn infants. Cochrane database of systematic reviews (Online) 2002(2):CD000435.

307. Bergman NJ, Linley LL, Fawcus SR: Randomized controlled trial of skin-toskin contact from birth versus conventional incubator for physiological stabilization in 1200- to 2199-gram newborns. Acta Paediatr 2004, 93(6):779-785.

308. Ibe OE, Austin T, Sullivan K, Fabanwo O, Disu E, Costello AM: A comparison of kangaroo mother care and conventional incubator care for thermal regulation of infants $<2000 \mathrm{~g}$ in Nigeria using continuous ambulatory temperature monitoring. Annals of tropical paediatrics 2004, 24(3):245-251.

309. Vohra S, Frent G, Campbell V, Abbott M, Whyte R: Effect of polyethylene occlusive skin wrapping on heat loss in very low birth weight infants at delivery: a randomized trial. The Journal of pediatrics 1999, 134(5):547-551.

310. Vohra S, Roberts RS, Zhang B, Janes M, Schmidt B: Heat Loss Prevention (HeLP) in the delivery room: A randomized controlled trial of polyethylene occlusive skin wrapping in very preterm infants. The Journal of pediatrics 2004, 145(6):750-753. 
311. Knobel RB, Wimmer JE, Jr., Holbert D: Heat loss prevention for preterm infants in the delivery room. J Perinato/ 2005, 25(5):304-308.

312. Kent AL, Williams J: Increasing ambient operating theatre temperature and wrapping in polyethylene improves admission temperature in premature infants. Journal of paediatrics and child health 2008, 44(6):325-331.

313. Kaushal M, Agarwal R, Aggarwal R, Singal A, Upadhyay M, Srinivas V, Paul VK, Deorari AK: Cling wrap, an innovative intervention for temperature maintenance and reduction of insensible water loss in very lowbirthweight babies nursed under radiant warmers: a randomized, controlled trial. Annals of tropical paediatrics 2005, 25(2):111-118.

314. Baqui AH, El-Arifeen S, Darmstadt GL, Ahmed S, Williams EK, Seraji HR, Mannan I, Rahman SM, Shah R, Saha SK et al: Effect of community-based newborn-care intervention package implemented through two servicedelivery strategies in Sylhet district, Bangladesh: a cluster-randomised controlled trial. Lancet 2008, 371(9628):1936-1944.

315. Kumar V, Mohanty S, Kumar A, Misra RP, Santosham M, Awasthi S, Baqui AH, Singh P, Singh V, Ahuja RC et al: Effect of community-based behaviour change management on neonatal mortality in Shivgarh, Uttar Pradesh, India: a cluster-randomised controlled trial. Lancet 2008, 372(9644):1151-1162.

316. Ho JJ, Subramaniam P, Henderson-Smart DJ, Davis PG: Continuous distending pressure for respiratory distress syndrome in preterm infants. Cochrane Database Syst Rev 2002(2):CD002271.

317. Ho JJ, Henderson-Smart DJ, Davis PG: Early versus delayed initiation of continuous distending pressure for respiratory distress syndrome in preterm infants. Cochrane Database Syst Rev 2002(2):CD002975.

318. Avery ME, Tooley WH, Keller JB, Hurd SS, Bryan MH, Cotton RB, Epstein MF, Fitzhardinge PM, Hansen CB, Hansen TN et al: Is chronic lung disease in low birth weight infants preventable? A survey of eight centers. Pediatrics 1987, 79(1):26-30

319. Van Marter $\sqcup$, Allred EN, Pagano M, Sanocka U, Parad R, Moore M, Susser M, Paneth N, Leviton A: Do clinical markers of barotrauma and oxygen toxicity explain interhospital variation in rates of chronic lung disease? The Neonatology Committee for the Developmental Network. Pediatrics 2000, 105(6):1194-1201.

320. Vanpee M, Walfridsson-Schultz U, Katz-Salamon M, Zupancic JA, Pursley D, Jonsson B: Resuscitation and ventilation strategies for extremely preterm infants: a comparison study between two neonatal centers in Boston and Stockholm. Acta Paediatr 2007, 96(1):10-16; discussion 18-19.

321. Lindner W, Vossbeck S, Hummler H, Pohlandt F: Delivery room management of extremely low birth weight infants: spontaneous breathing or intubation? Pediatrics 1999, 103(5 Pt 1):961-967.

322. De Klerk AM, De Klerk RK: Nasal continuous positive airway pressure and outcomes of preterm infants. J Paediatr Child Health 2001, 37(2):161-167.

323. Geary C, Caskey M, Fonseca R, Malloy M: Decreased incidence of bronchopulmonary dysplasia after early management changes, including surfactant and nasal continuous positive airway pressure treatment at delivery, lowered oxygen saturation goals, and early amino acid administration: a historical cohort study. Pediatrics 2008, 121(1):89-96.

324. Meyer M, Mildenhall L, Wong M: Outcomes for infants weighing less than 1000 grams cared for with a nasal continuous positive airway pressurebased strategy. J Paediatr Child Health 2004, 40(1-2):38-41.

325. Subramaniam P. Henderson-Smart DJ, Davis PG: Prophylactic nasal continuous positive airways pressure for preventing morbidity and mortality in very preterm infants. Cochrane Database Syst Rev 2005(3):CD001243.

326. Koyamaibole L, Kado J, Qovu JD, Colquhoun S, Duke T: An evaluation of bubble-CPAP in a neonatal unit in a developing country: effective respiratory support that can be applied by nurses. J Trop Pediatr 2006 52(4):249-253.

327. Pieper CH, Smith J, Maree D, Pohl FC: Is nCPAP of value in extreme preterms with no access to neonatal intensive care? J Trop Pediatr 2003, 49(3):148-152

328. Morley CJ, Davis PG, Doyle LW, Brion LP, Hascoet JM, Carlin JB: Nasal CPAP or intubation at birth for very preterm infants. N Engl J Med 2008, 358(7):700-708

329. De Paoli AG, Davis PG, Faber B, Morley CJ: Devices and pressure sources for administration of nasal continuous positive airway pressure (NCPAP) in preterm neonates. Cochrane Database Syst Rev 2008(1):CD002977.

330. Morley CJ, Lau R, De Paoli A, Davis PG: Nasal continuous positive airway pressure: does bubbling improve gas exchange? Arch Dis Child Fetal
Neonatal Ed 2005, 90(4):F343-344.

331. Lee KS, Dunn MS, Fenwick M, Shennan AT: A comparison of underwater bubble continuous positive airway pressure with ventilator-derived continuous positive airway pressure in premature neonates ready for extubation. Biol Neonate 1998, 73(2):69-75.

332. Courtney SE, Pyon KH, Saslow JG, Arnold GK, Pandit PB, Habib RH: Lung recruitment and breathing pattern during variable versus continuous flow nasal continuous positive airway pressure in premature infants: an evaluation of three devices. Pediatrics 2001, 107(2):304-308.

333. Courtney SE, Aghai ZH, Saslow JG, Pyon KH, Habib RH: Changes in lung volume and work of breathing: A comparison of two variable-flow nasal continuous positive airway pressure devices in very low birth weight infants. Pediatr Pulmonol 2003, 36(3):248-252.

334. Christensen RD, Brown MS, Hall DC, Lassiter HA, Hill HR: Effect on neutrophil kinetics and serum opsonic capacity of intravenous administration of immune globulin to neonates with clinical signs of early-onset sepsis. The Journal of pediatrics 1991, 118(4 ( Pt 1)):606-614

335. Ohlsson A, Lacy JB: Intravenous immunoglobulin for preventing infection in preterm and/or low-birth-weight infants. Cochrane database of systematic reviews (Online) 2004(1):CD000361.

336. Ohlsson A, Lacy JB: Intravenous immunoglobulin for suspected or subsequently proven infection in neonates. Cochrane database of systematic reviews (Online) 2004(1):CD001239.

337. Stiehm ER, Keller MA, Vyas GN: Preparation and use of therapeutic antibodies primarily of human origin. Biologicals 2008, 36(6):363-374

338. Soll RF: Prophylactic natural surfactant extract for preventing morbidity and mortality in preterm infants. Cochrane Database Syst Rev 2000(2):CD000511

339. Soll RF: Prophylactic synthetic surfactant for preventing morbidity and mortality in preterm infants. Cochrane Database Syst Rev 2000(2):CD001079

340. Soll RF, Morley CJ: Prophylactic versus selective use of surfactant in preventing morbidity and mortality in preterm infants. Cochrane Database Syst Rev 2001(2):CD000510.

341. Yost CC, Soll RF: Early versus delayed selective surfactant treatment for neonatal respiratory distress syndrome. Cochrane Database Syst Rev 2000(2):CD001456

342. Soll R, Ozek E: Multiple versus single doses of exogenous surfactant for the prevention or treatment of neonatal respiratory distress syndrome. Cochrane Database Syst Rev 2009(1):CD000141.

343. Jobe AH, Mitchell BR, Gunkel JH: Beneficial effects of the combined use of prenatal corticosteroids and postnatal surfactant on preterm infants. Am J Obstet Gynecol 1993, 168(2):508-513.

344. Soll RF, Blanco F: Natural surfactant extract versus synthetic surfactant for neonatal respiratory distress syndrome. Cochrane Database Syst Rev 2001(2):CD000144.

345. Taeusch HW, Ramierez-Schrempp D, Laing IA: Surfactant Therapy of Respiratory Disorders. In Avery's Diseases of the Newborn. 8 edition. Edited by Taeusch HW, Ballard RA, Gleason CA. Philadelphia: Elsevier Saunders; 2005:670-685.

346. Sanchez-Mendiola M, Martinez-Natera OC, Herrera-Maldonado N, OrtegaArroyo J: [Treatment of hyaline membrane disease in the preterm newborn with exogenous lung surfactant: a controlled study]. Gac Med Mex 2005, 141(4):267-271.

347. Pfister RH, Soll RF, Wiswell T: Protein containing synthetic surfactant versus animal derived surfactant extract for the prevention and treatment of respiratory distress syndrome. Cochrane Database Syst Rev 2007(3):CD006069.

348. Moya F, Sinha S, Gadzinowski J, D’Agostino R, Segal R, Guardia C, Mazela J, Liu $\mathrm{G}$ : One-year follow-up of very preterm infants who received lucinactant for prevention of respiratory distress syndrome: results from 2 multicenter randomized, controlled trials. Pediatrics 2007, 119(6):e1361-1370.

349. Mazela J, Merritt TA, Finer NN: Aerosolized surfactants. Curr Opin Pediatr 2007, 19(2):155-162.

350. Kattwinkel J, Robinson M, Bloom BT, Delmore P, Ferguson JE: Technique for intrapartum administration of surfactant without requirement for an endotracheal tube. J Perinatol 2004, 24(6):360-365.

351. Stewart C, Attridge J, Kattwinkel J: Randomized Controlled Trial of Surfactant Administration by Laryngeal Mask Airway (LMA). In Pediatric Academic Societies. Honolulu, Hawaii; 2008.

352. Trevisanuto D, Grazzina N, Ferrarese P, Micaglio M, Verghese C, Zanardo V: Laryngeal mask airway used as a delivery conduit for the administration 
of surfactant to preterm infants with respiratory distress syndrome. Bio Neonate 2005, 87(4):217-220.

353. Bhutta ZA, Ali S, Cousens S, Ali TM, Haider BA, Rizvi A, Okong P, Bhutta SZ, Black RE: Alma-Ata: Rebirth and Revision 6. Interventions to address maternal, newborn, and child survival: what difference can integrated primary health care strategies make? Lancet 2008, 372(9642):972-989.

354. Bang AT, Paul VK, Reddy HM, Baitule SB: Why do neonates die in rural Gadchiroli, India? (Part I): primary causes of death assigned by neonatologist based on prospectively observed records. J Perinatol 2005, 25 (Suppl 1):S29-S34.

355. Bang AT, Reddy HM, Bang RA, Deshmukh MD: Why do neonates die in rura Gadchiroli, India? (Part II): estimating population attributable risks and contribution of multiple morbidities for identifying a strategy to prevent deaths. J Perinatol 2005, 25 (Suppl 1):S35-S43.
356. Bang AT, Reddy HM, Deshmukh MD, Baitule SB, Bang RA: Neonatal and infant mortality in the ten years (1993 to 2003) of the Gadchiroli field trial: effect of home-based neonatal care. J Perinatol 2005, 25 (Suppl 1):S92-S107. 357. Manandhar DS, Osrin D, Shrestha BP, Mesko N, Morrison J, Tumbahangphe KM, Tamang S, Thapa S, Shrestha D, Thapa B: Effect of a participatory intervention with women's groups on birth outcomes in Nepal: clusterrandomised controlled trial. Lancet 2004, 364(9438):970-979.

doi:10.1186/1471-2393-S1-S3

Cite this article as: Barros FC, et al:: Global report on preterm birth and stillbirth (3 of 7): evidence for effectiveness of interventions. BMC Pregnancy and Childbirth 2010, 10(Suppl 1):S3. 